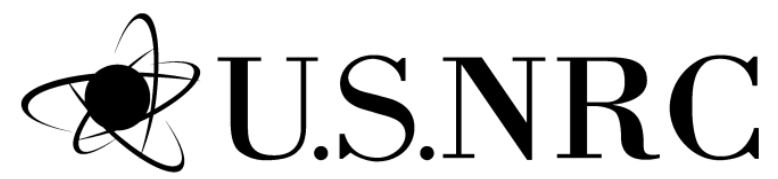

United States Nuclear Regulatory Commission

\title{
Hydrated Phases in Blended Cement Systems and Synthetic Saltstone Grouts
}

Prepared by:

Kenneth A. Snyder

Paul E. Stutzman

National Institute of Standards and Technology

Engineering Laboratory

100 Bureau Drive

Gaithersburg, MD 20899-8615

Manuscript Completed:

Date Published:

Jacob Philip, NRC Program Manager

NRC Job Code: XX-\#\#\#\#\#

Office of Nuclear Regulatory Research

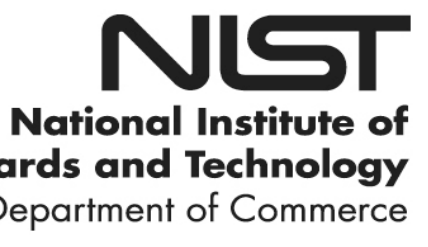


NISTIR 7947

\title{
Hydrated Phases in Blended Cement Systems and Synthetic Saltstone Grouts
}

\author{
Kenneth A. Snyder
}

Paul E. Stutzman

Materials and Structural Systems Division

Engineering Laboratory

http://dx.doi.org/10.6028/NIST.IR.7947

June 2013

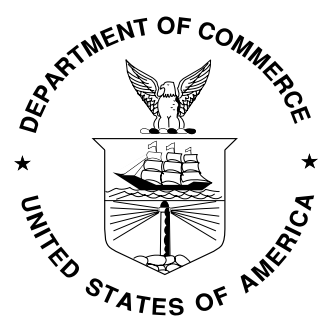

U.S. Department of Commerce Cameron F. Kerry, Acting Secretary

National Institute of Standards and Technology Patrick D. Gallagher, Under Secretary of Commerce for Standards and Technology and Director 


\section{ABSTRACT}

A blended binder system (10\% portland cement, $45 \%$ fly ash, and $45 \%$ slag) is characterized as part of a broader study of its long-term effectiveness in stabilizing treated salt waste at the Savannah River Site. The binder system is reproduced in the laboratory using a simulated salt solution, and the hydrated phases are identified and quantified out through one year of hydration. The phases are identified through the use of thermogravimetric analysis and X-ray diffraction. Supporting information is obtained from scanning electron microscopy and pore solution analysis by inductively coupled plasma optical spectroscopy. The evidence suggests that the phases being formed are the types one would expect, given the starting materials. Moreover, even though the salt solution adds considerable sulfate to the system, there is no evidence of excess sulfate bearing phases indicative of expansive sulfate attack. Furthermore, the data out to one year of hydration suggests that the phases observed are stable. 


\section{TABLE OF CONTENTS}

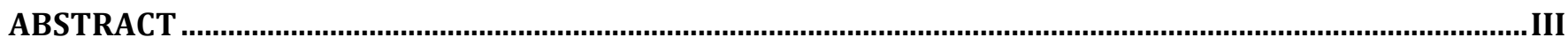

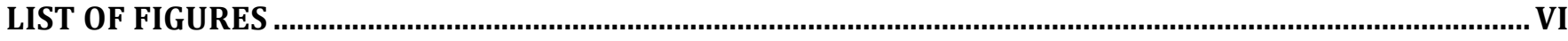

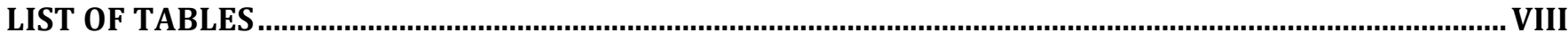

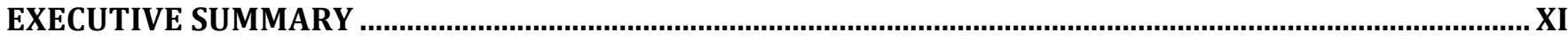

ABBREVIATIONS

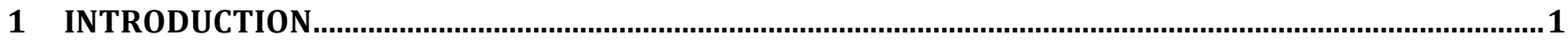

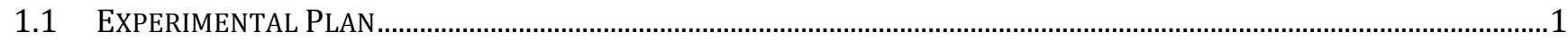

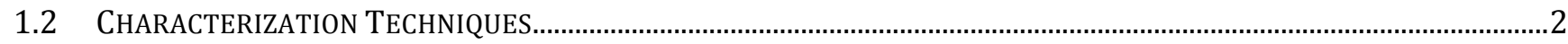

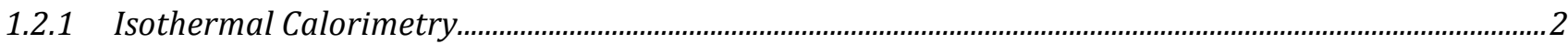

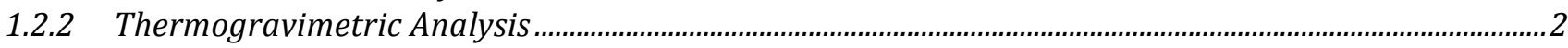

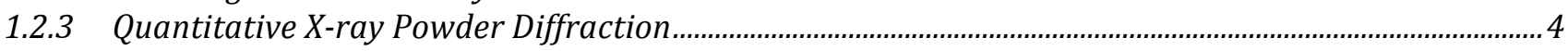

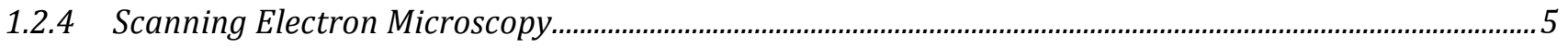

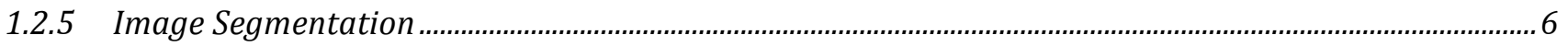

1.2.6 Inductively-Coupled Plasma Spectroscopy ................................................................................................ 14

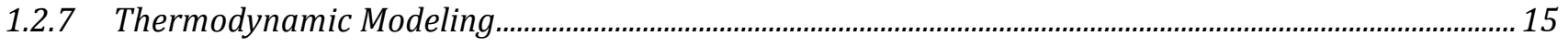

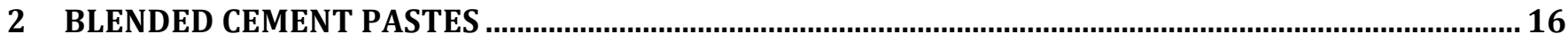

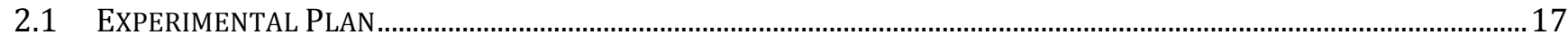

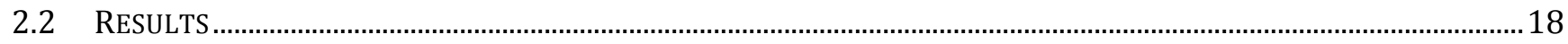

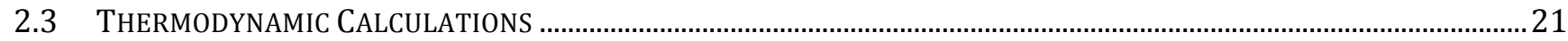

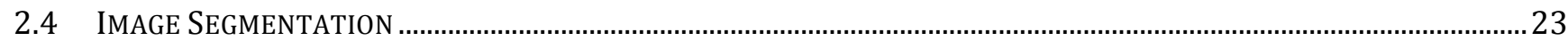

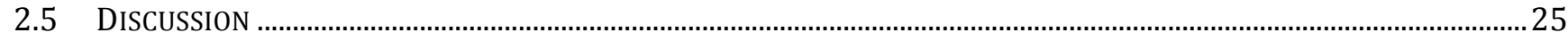

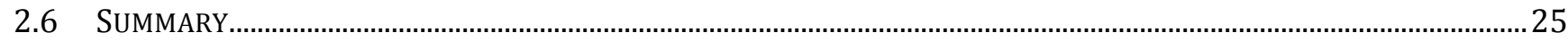

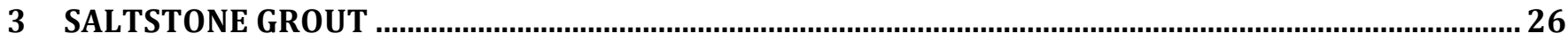

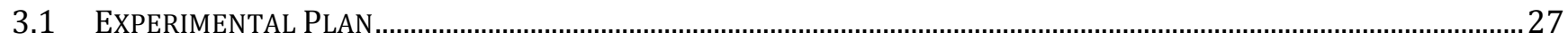

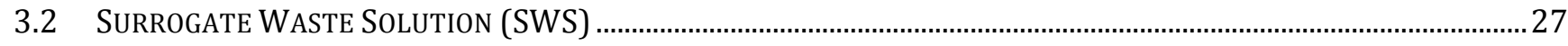

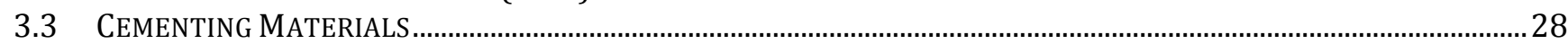

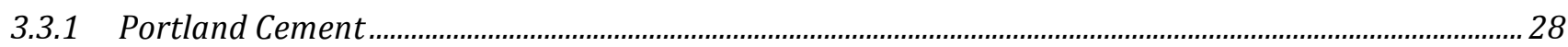

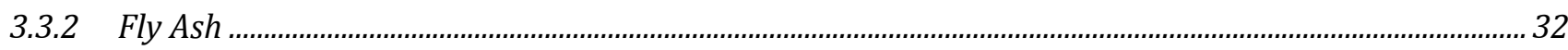

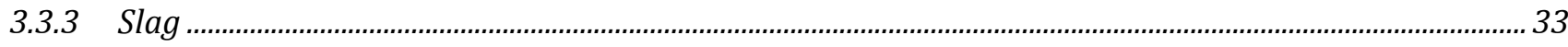

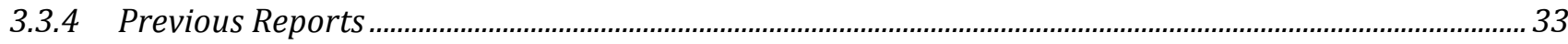

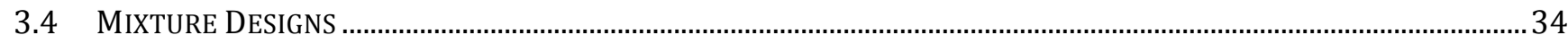

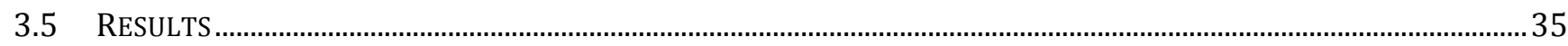

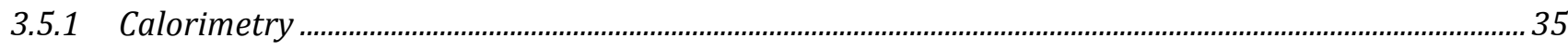

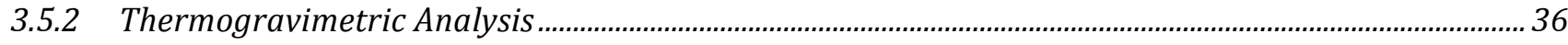

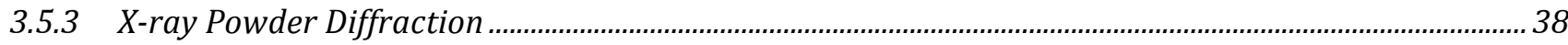

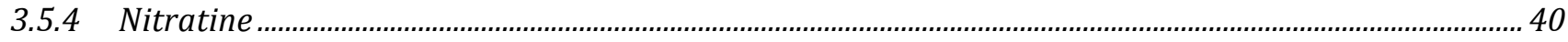

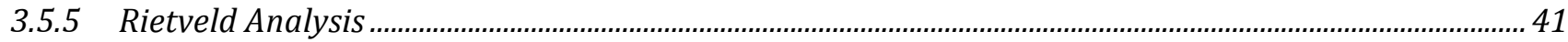

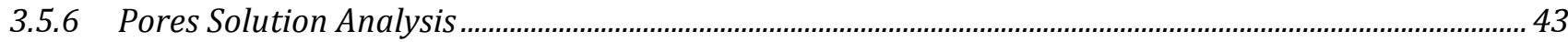

3.5.7 Total Sulfur

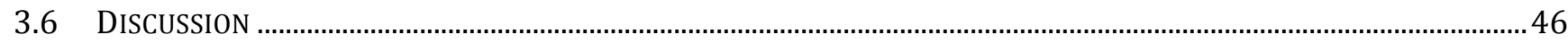

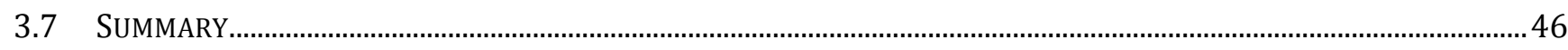

4 CONCLUSION

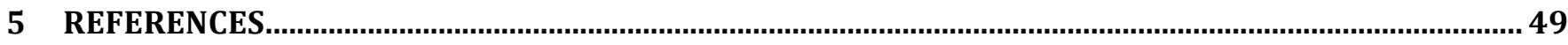




\section{LIST OF FIGURES}

Figure 1. The backscattered electron image and a segmented, color-composite image derived from a set of X-ray and the BEI illustrate the chemical and compositional complexity of cement, and use of the image set to assign phase classes (lower-right) to a segmented image.

Figure 2. Backscattered electron image (BEI) of hydrated cement paste after 3 months of hydration. ..... 7

Figure 3. Original elemental maps of the major components for Mix 1 at 3 months hydration............... 8

Figure 4. A summary of image processing techniques used in the segmentation. The bottom row demonstrates before (left) and after (right) images of the despeckle and median filter algorithms......9

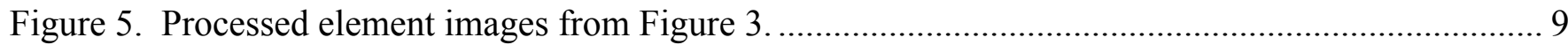

Figure 6. Phase identification color maps; only a portion of the entire image is shown to enhance detail. The three element labels that appear over each image represent (from left to right) the red, green, and

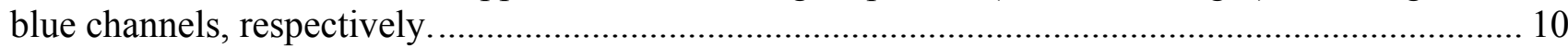

Figure 7. Phase training sets for the cement paste shown in Figure 2 .......................................... 11

Figure 8. Statistics reported by MultiSpec software after a segmentation analysis............................. 11

Figure 9. The segmented image when using processed starting images........................................ 12

Figure 10. Segmentation statistics using the same training set locations, and the original (unprocessed) images.

Figure 11. Comparison of the segmented image using unprocessed starting images and the original BEI

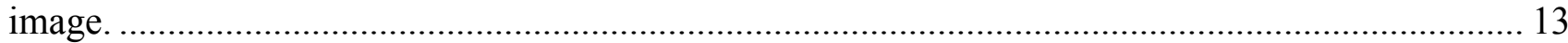

Figure 12. Calorimetry data for Mixes 1-4 (1) and for Mixes 5-8 (r). Inset shows data from Mix 8 until 800 hours of hydration. 18

Figure 13: Thermogravimetric data for Mix 1-4 (1) and Mix 5-8 (r) after 12 weeks of hydration. 19

Figure 14: XRD scans for all 8 mixes. The consecutive upper curves are displaced from the immediately lower curve by a value of 5 .

Figure 15. Backscattered electron image (BEI) and segmented image of the fly ash cement paste in Mix 1

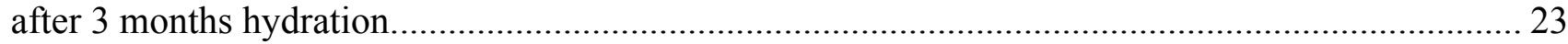

Figure 16. Backscattered electron image (BEI) and segmented image of the fly ash cement paste in Mix 2

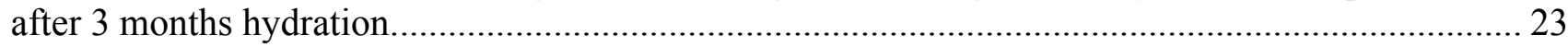

Figure 17. Backscattered electron image (BEI) and segmented image of the slag cement paste in Mix 3

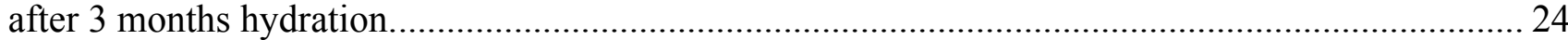

Figure 18. Relative remaining mass $\mu$ as a function of temperature for the portland cement. Individual peaks are labeled; the mass loss near $100{ }^{\circ} \mathrm{C}$ is due to water loss from C-S-H and other hydrated phases.

Figure 19. Analysis of the portlandite peak in the cement: (left) regression to the TGA data, showing the background function $b(T)$ and the peak function $p(T)$; (right) the measured data minus the background function, compared with the peak function (the two lie nearly on top of one another). 30

Figure 20. Analysis of the syngenite peak in the cement: (left) regression to the TGA data, showing the background function $b(T)$ and the peak function $p(T)$; (right) the measured data minus the background function, compared with the peak function (the two lie nearly on top of one another).... 
Figure 21. Analysis of the limestone peak in the cement: (left) regression to the TGA data, showing the background function $b(T)$ and the two peak functions $p_{1}(T)$ and $p_{2}(T)$; (right) the measured data minus the background function, compared with the sum of the two peak functions (the two lie nearly on top of one another)

Figure 22. Heat generation rates $(\mathrm{W} / \mathrm{g}$ ) as a function of time (hours) for the $0.40 \mathrm{w} / \mathrm{cm}$ pastes (left) and

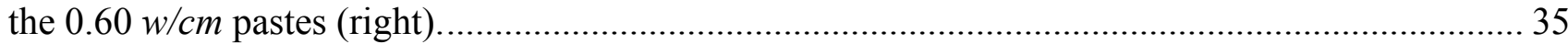

Figure 23. Differential relative mass loss $(\mathrm{d} \mu / \mathrm{d} T)$ as a function of temperature $\left({ }^{\circ} \mathrm{C}\right)$ for pastes made with portland cement and water: $w / \mathrm{cm}=0.4$ (left); $w / \mathrm{cm}=0.60$ (right). Each line corresponds to a different age: $7 \mathrm{~d}, 14 \mathrm{~d}, 28 \mathrm{~d}$, and $56 \mathrm{~d}$. 36

Figure 24. Differential relative mass loss $(\mathrm{d} \mu / \mathrm{d} T)$ as a function of temperature $\left({ }^{\circ} \mathrm{C}\right)$ for pastes made with portland cement and surrogate waste solution: $w / \mathrm{cm}=0.4$ (left); $w / \mathrm{cm}=0.60$ (right). Each line corresponds to a different age: $7 \mathrm{~d}, 14 \mathrm{~d}$, and $28 \mathrm{~d}$. 36

Figure 25. Differential relative mass loss $(-\mathrm{d} \mu / \mathrm{d} T)$ as a function of temperature $\left({ }^{\circ} \mathrm{C}\right)$ for pastes made with portland cement paste, fly ash, slag, and surrogate waste solution: $w / \mathrm{cm}=0.4$ (left); $w / \mathrm{cm}=0.60$ (right). Each line corresponds to a different age: $7 \mathrm{~d}, 14 \mathrm{~d}$, and $28 \mathrm{~d}$. 37

Figure 26. X-ray powder diffraction data showing counts as a function of angle $2 \theta$ for pastes made with portland cement and water: $w / \mathrm{cm}=0.4$ (left); $w / \mathrm{cm}=0.60$ (right). Data after $7 \mathrm{~d}$ are offset for comparison purposes.

Figure 27. X-ray powder diffraction data showing counts as a function of angle $2 \theta$ for pastes made with portland cement and surrogate waste solution: $w / \mathrm{cm}=0.4$ (left); $w / \mathrm{cm}=0.60$ (right). Data after $7 \mathrm{~d}$ are offset for comparison purposes. 39

Figure 28. X-ray powder diffraction data showing counts as a function of angle $2 \theta$ for pastes made with portland cement, fly ash, slag, and surrogate waste solution: $w / \mathrm{cm}=0.4$ (left); $w / \mathrm{cm}=0.60$ (right). Data after $7 \mathrm{~d}$ are offset for comparison purposes.

Figure 29. Six successive X-ray powder diffraction scans of the 60-1-055 mixture after 16 weeks of hydration. Successive scans are 20 minutes apart. The nitratine peaks are near $29^{\circ} 2 \theta, 32^{\circ} 2 \theta$, and $39^{\circ} 2 \theta$ 


\section{LIST OF TABLES}

Table 1. The volume fraction (VF) and mass fraction (MF) of the phases identified in the segmented images for the processed and unprocessed starting images.

Table 2. The composition of the three different standard solutions used to analyze the extracted pore solutions from the OPC pastes (Standard A) and the saltstone waste forms (Standard B1 and Standard B2).

Table 3. Mixture mass fractions of the cementitious binders in each mixture.

Table 4. Oxide mass fractions for the binders. The cement calcite content and the slag sulfide content are also given.

Table 5: Estimated portlandite mass fraction as calculated from TGA data. The parameter coefficient of variation reported by the regression software was typically less than $0.3 \%$, and other comparisons to XRD data were generally within $2 \%$.

Table 6: Hydrated phase mass fractions after 3 months hydration at $25^{\circ} \mathrm{C}$, as determined by Rietveld analysis. Mix 1 through Mix 7 use the portlandite content (see Table 5) as the internal standard. Mix 8 uses corundum as an internal standard.

Table 7: Estimated phase mass fractions after 3 months hydration as calculated using the Lothenbach et al. [15] thermodynamic hydration model. 21

Table 8. Estimated mass fractions from quantitative XRD (QXRD) and imaging.

Table 9. Binder proportions for mixtures at two water:cementitious material mass ratios $(w / \mathrm{cm})$, neglecting the dissolved salts in the surrogate waste solution. The quantity of cement, fly ash, and slag are designated by the corresponding mass fraction.

Table 10. Composition of the surrogate waste solution; there are $0.8866 \mathrm{~kg}$ of water in each liter of solution.

Table 11. The component composition of the surrogate waste solution. The numbers between parentheses represent the oxidation state; this is the notation used in a number of thermodynamic databases.

Table 12. Oxide composition of the ASTM Type I/II cement from the mill certificate report based on a single measurement.

Table 13. Portland cement mineral phase composition as determined by X-ray diffraction with Rietveld analysis (ASTM C1365); uncertainty expresses one standard deviation.

Table 14. Fly ash oxide composition reported in the mill certificate, based on a single measurement.... 32

Table 15. Fly ash mineral phase composition as determined by X-ray powder diffraction and Rietveld analysis.

Table 16. Oxide percentages reported by Harbour et al. [24 (Table 3-5)] for the portland cement, the fly ash, and the slag

Table 17. Mixture designs for $w / \mathrm{cm}=0.40$ pastes.

Table 18. Mixture designs for $w / c m=0.60$ pastes

Table 19. Portlandite mass fraction, as determined by TGA analysis, for the four portland cement mixtures. The uncertainty represents the measurement uncertainty having a coverage factor of one standard deviation. 
Table 20. Results of Rietveld analysis for the six mixtures. The values reported are the mass fractions, and the numbers in parentheses represent the uncertainty (one standard deviation) in the last two digits.

Table 21. Pore solution composition of the $0.40 \mathrm{w} / \mathrm{cm}$ paste made with only portland cement; numbers in parentheses indicate one standard deviation of uncertainty.

Table 22. Pore solution composition of the $0.60 \mathrm{w} / \mathrm{cm}$ paste made with only portland cement; numbers in parentheses indicate one standard deviation of uncertainty.

Table 23. Pore solution composition of the $0.40 \mathrm{w} / \mathrm{cm}$ paste made with fly ash, slag, and surrogate waste solution; numbers in parentheses indicate one standard deviation of uncertainty.

Table 24. Pore solution composition of the $0.60 \mathrm{w} / \mathrm{cm}$ paste made with fly ash, slag, and surrogate waste solution; numbers in parentheses indicate one standard deviation of uncertainty. 


\section{EXECUTIVE SUMMARY}

A novel cementitious blend of portland cement, fly ash, and slag (mass ratio - 10:45:45) has been developed for stabilizing a salt waste for disposal at Savannah River Site (SRS), and the mixture of binder and treated salt solution is referred to as a saltstone grout. The blend exploits the reduced state of sulfur (sulfide) in the slag to help immobilize radionuclides, the high alkalinity of the treated salt solution to help activate the hydration reaction, and the lower heat of hydration of fly ash to achieve construction requirements. Because the formulation and the application are novel, studies are needed to forecast the long-term performance of these engineered materials. A key parameter in the assessment of the longterm performance of these materials is the identification and quantification of the hydrated phases. This information serves as the initial conditions to computer models that can simulate the effects of different environments on the long-term performance of cementitious materials.

Understanding the long-term performance of cementitious engineered barriers is an important challenge because these materials account for much of the components within disposal facilities. To help meet this challenge, the Department of Energy (DOE), the National Institute of Standards and Technology (NIST), and the U.S. Nuclear Regulatory Commission (NRC) formed the Cementitious Barriers Partnership (CBP) to develop tools that facilitate performance assessment of cementitious engineered structures. A requirement of these tools is to predict the chemical and physical state of the hydrated binder over time; the chemical state can change due to both the hydration processes (the chemical reaction between the liquid and powder) and the chemical degradation processes that arise from interactions with the environment. An important challenge for these tools is predicting the initial chemical state of the material: i.e., the type and quantity of mineral phases present and the chemical composition of the pore solution that remains behind in the microscopic pores after the hydration reaction.

Although the cement and concrete industries have considerable experience working with blended binders, the proposed saltstone mixture is considerably different than those used in the concrete construction industry. In construction, binary mixtures of portland cement and either fly ash or slag are common practice, and ternary mixtures (that may alternately contain silica fume or limestone) are also used, but to a lesser extent. As a rule, however, the portland cement component of the cementitious binder in these commercial applications is almost always $50 \%$ or more, by mass. Moreover, the mixtures used in the concrete construction industry are almost always made with potable water. By comparison, the treated salt solution is a highly concentrated (more than $5 \mathrm{~mol} / \mathrm{L}$ ) alkaline solution containing, among other species, sulfate ions, which are associated with a concrete degradation mechanism known as sulfate attack that leads to expansion and the loss of material.

To aid in the development of these tools to accurately predict the properties and performance of saltstone grouts, the NIST used a number of techniques for characterizing the hydrated phases in the saltstone. The characterization techniques included quantitative X-ray powder diffraction, thermogravimetric analysis, scanning electron microscope imaging coupled with scanning electron micro-probe elemental analysis imaging, and inductively-coupled plasma elemental analysis of the pore solution.

After one year of hydration the mineral phases present and the composition of the pore solution are generally consistent with the expectations based on thermodynamic modeling. The phases that are formed appear to be stable after one year. Also, even though the salt solution includes sulfates, there do not appear to be sufficient expansive sulfate phases present to cause degradation. The reason for this is because the high alkalinity of the salt solution appears to suppress the formation of these sulfate phases. Based on this assumption, as long as the alkalinity is maintained in these systems, one would not expect expansion over the long-term. 


\section{ABBREVIATIONS}

BEI Backscattered Electron Image

CBP Cementitious Barriers Partnership (http://www.cementbarriers.org)

C-S-H Calcium Silicate Hydrate (gel)

DOE Department of Energy

GGBFS Ground Granulated Blast Furnace Slag

HDPE High-Density Polyethylene

ICP-OES Inductively-Coupled Plasma Optical Emission Spectroscopy

NIST National Institute of Standards and Technology

NRC U.S. Nuclear Regulatory Commission

OPC Ordinary Portland Cement

QXRD Quantitative X-ray Powder Diffraction

PA Performance Assessment

SEM Scanning Electron Microscope

SRM (NIST) Standard Reference Material®

SRNL Savannah River National Laboratory

SWS Surrogate Waste Solution

TGA Thermogravimetric Analysis

$w / \mathrm{cm} \quad$ water:cementitious material (mass ratio)

XR X-ray Microanalysis

XRD X-ray Diffraction 


\section{INTRODUCTION}

The various infrastructure elements of future nuclear facilities may be composed of the broad range of cementitious binder proportions: structural elements may be composed entirely of portland cement concrete; massive concrete elements may contain large quantities of fly ash and/or ground granulated blast furnace slag (GGBFS); and saltstone grouts [1] may contain less than 10 percent portland cement, with fly ash and slag making up the remainder. Improved performance assessment (PA) tools are needed for predicting the performance of all these systems because existing tools were developed for systems composed mostly of portland cement. An important aspect of these tools is the ability to estimate the type and quantity of hydrated phases present, and the pore solution composition, as these factors impact overall performance because they control, among other things, the buffering capacity of the material, the mobility of certain radionuclides, and the chemical composition of any effluent.

Sophisticated computer tools for predicting transport and reaction in cementitious systems incorporate thermodynamic data for the mineral phases present. Transport of ions from the external ground water changes the chemical equilibrium, and the thermodynamic model adjusts the quantity of phases to maintain equilibrium. Therefore, an accurate assessment/prediction of the initial hydrated phases and pore solution composition is vital component to an accurate PA tool.

Standard test methods exist for characterizing the raw materials used to make mortars and concretes (e.g., ASTM C1365 - X-ray diffraction analysis of portland cement paste). By comparison, there are few standardized techniques for quantifying the hydrated phases. There are, however, a number of characterization techniques that could be applicable to these blended cement systems. The principle objective when considering these techniques is the ability to identify and quantify the hydration phases or the composition of the pore solution. Although these techniques have been used to identify and quantify phases and solutions for other applications, they have not been evaluated for use with these unique blended cement systems.

\subsection{Experimental Plan}

The experimental plan was composed of two parts. The first part investigated blended cements mixed with water, and the second part replicated the saltstone mixture using binder materials obtained from Savannah River Site (SRS), and approximated the treated salt solution using previously published formulations. The objective of the first part of the plan was to use familiar materials to develop characterization techniques for hydrated systems composed of large quantities of glassy binders. Because no single characterization technique could provide a complete description, a combination of techniques was needed.

The specific techniques that were used differed between the two parts of the plan. The first part, which characterized blended cements mixed with water, used calorimetry, quantitative X-ray powder diffraction, thermogravimetric analysis, and electron micro-probe X-ray image analysis. The second part, which characterized the saltstone binder mixed with surrogate waste solution (SWS), used calorimetry, quantitative X-ray powder diffraction, thermogravimetric analysis, and inductively-coupled plasma - optical emission spectroscopy to characterize the hydrated paste and the pore solution. 


\subsection{Characterization Techniques}

The initial conditions of a comprehensive PA tool for engineered cementitious barriers are the type and quantity of mineral phases present, and the chemical composition of the pore solution, both of which are the result of the hydration reactions. For cementitious materials composed largely of portland cement, existing tools can reliably predict the composition of the hydrated system. The novel mixtures used to make saltstone, however, use very low portland cement content and a concentrated "mix water" solution, and there are few, if any, data with which to validate these prediction models.

A number of experimental techniques were used to characterize the saltstone mixture. Each technique had advantages and disadvantages, and it was only when looking at combinations of techniques that one could make sound inferences from the results.

\subsubsection{Isothermal Calorimetry}

Isothermal calorimetry is a measure of the heat generated by a chemical reaction. For these systems, the binders react with water to form a hardened paste, and this reaction is exothermic. The technique requires that the sample be maintained at a constant temperature and the amount of energy required to maintain a constant temperature is a measure of the heat, either given off or consumed by the chemical reaction. This characterization method has been standardized in ASTM C1679 [2], but only for the first few weeks of reaction. Although calorimetry does not give specific information about the type and quantity of phases created by the hydration reaction, it is a qualitative measure of the overall hydration reaction process.

The isothermal calorimetry was performed on paste (water and binder) specimens (approximately $10 \mathrm{~g}$ ). Immediately after mixing in the laboratory, the samples were transferred to the calorimeter maintained at $25^{\circ} \mathrm{C}$. The system was brought to equilibrium over a period of 45 minutes prior to data collection. The rate of heat output was reported per gram of cementitious binder.

\subsubsection{Thermogravimetric Analysis}

Thermogravimetric analysis (TGA) consists of monitoring the mass of a sample during heating in an inert atmosphere. A number of the phases present in a hydrated cementitious system contain chemically bound water, which is released at a temperature that is specific to that phase; alternatively, some phases may contain carbonate (bound carbon dioxide) that is also released at a specific temperature. If the temperature range over which the chemically bound water or carbon dioxide is released is isolated from the mass loss from other phases, one can use TGA to identify and quantify certain phases that may be present.

The thermogravimetric data reported here were scaled so that mass losses would be a direct measure of the relative mass. The data collection process consisted of recording the mass $m$ of the sample at a temperature $T$. The relative mass $\mu$ expresses the ratio of the mass $m(T)$ to the initial mass $m_{0}$ :

$$
\mu(T)=\frac{m(T)}{m_{0}}
$$


The initial value of the relative mass $\mu$ is one, and it decreases monotonically as water and (sometimes) carbon dioxide (from limestone) are liberated from the sample. The differential relative mass $(-d \mu / d T)$ gives an indication of how much mass is lost at a particular temperature, which is usually represented by a peak. Although the temperature at which a relatively large mass is lost can be indicative of a particular phase that is decomposing, and the precise temperature at which the mass loss occurs can also depend upon experimental parameters such as the heating rate and the size of the sample.

The TGA measurements were performed on samples that were cut from small cylindrical specimen that were approximately $25 \mathrm{~mm}$ in diameter and $25 \mathrm{~mm}$ long. A diamond saw was used to cut $1.5 \mathrm{~mm}$ (approx.) thick circular wafer, using ethanol as the cutting fluid. The wafer was broken into small pieces, two of which were placed into the TGA sample cup. The typical total sample mass was between $50 \mathrm{mg}$ and $75 \mathrm{mg}$. The sample was equilibrated at $30^{\circ} \mathrm{C}$, and then the temperature increased at $5{ }^{\circ} \mathrm{C} / \mathrm{min}$ up to $950^{\circ} \mathrm{C}$. During testing, the sample chamber was purged with high purity $(99.995 \%)$ nitrogen.

An advantage of TGA is that it can be used to quantify the portlandite (calcium hydroxide) present in the system because its decomposition occurs at a temperature that few other phases are decomposing. This information can be coupled with X-ray powder diffraction analysis, and can eliminate the need for adding an internal standard. Although portlandite decomposition occurs at temperatures that are isolated from the decomposition of other phases, there is a background mass loss that occurs (but at a much slower rate), so the analysis of the portlandite peak must account for this background mass loss.

At a mineral decomposition temperature $T_{0}$ for each identifiable phase (e.g., portlandite, limestone) there is an increase in the rate of mass loss, resulting in a peak in the differential relative mass curve. The quantity of mass loss associated with this peak is estimated by fitting the measured mass data (near the peak) to an equation $f(T)$ that is a sum of a background function $b(T)$ and a peak function $p(T)$ : $f(T)=b(T)+p(T)$.

The functional forms of the background and peak functions were chosen to allow sufficient flexibility. For these analyses, the background was assumed to be quadratic:

$$
b(T)=A_{0}+A_{1}\left(T-T_{b}\right)+A_{2}\left(T-T_{b}\right)^{2}
$$

The parameter $T_{b}$ is a fitting parameter and has no physical meaning in the estimation of the mass loss. There are two peak functions used, one for symmetrical peaks, and the other for asymmetric peaks. For symmetrical peaks that are centered on the decomposition temperature $T_{0}$, the relative mass data are modeled by the complementary error function [3]:

$$
p(T)=\frac{B_{0}}{2} \operatorname{erfc}\left[B_{1}\left(T-T_{0}\right)\right]
$$

The parameter $B_{1}$ is related to the Gaussian standard deviation $s:\left(B_{1}=1 / s \sqrt{2}\right)$. For asymmetrical peaks, the data are modeled by the asymmetric sigmoidal logistic function:

$$
p(T)=\frac{B_{0} \mathrm{e}^{B_{1} B_{2}\left(T-T_{0}\right)}}{\left(1+\mathrm{e}^{-B_{1}\left(T-T_{0}\right)}\right)^{B_{2}}}
$$

For both peak functions, the parameter $B_{0}$ is an estimate for the mass loss due to decomposition. The uncertainty in the mass loss is estimated from the uncertainty of the fitted parameter $B_{0}$. 


\subsubsection{Quantitative X-ray Powder Diffraction}

X-ray powder diffraction (XRD) measures the angular-dependent X-ray reflection from crystalline phases within a powder sample. If there are crystallographic structural models for the crystalline materials being analyzed, one can identify the component mass ratios that would best agree with the measured reflections. This process of estimating mass fractions using the crystallographic structural models is part of the Rietveld analysis that is the basis of quantitative X-ray powder diffraction (QXRD). If there are only crystalline phases present in the sample, and there are structural models for each phase, the mass ratios obtained by the Rietveld analysis can be used to determine the mass fractions of each phase.

If there are amorphous phases present, an internal standard must be used to determine the mass fractions. Amorphous components do not exhibit distinguishable peaks in the XRD data. Rather, they typically contribute a broad background "hump" to the data. Although a quantitative Rietveld analysis can still be used to estimate the mass ratios of the remaining crystalline phases, the total mass fraction of the amorphous phase is still unknown. To overcome this challenge, one can add an internal standard, which is a unique crystalline phase that is added to the sample at a known mass fraction. Using the known mass fraction of the internal standard, QXRD can be used to determine the total mass fraction of the crystalline phases, and to determine the mass fraction of total amorphous content by subtraction.

For analysis of the portland cement, a 5 g powder sample of material was wet-ground in $20 \mathrm{~mL}$ of ethanol to a mean particle size of about $7 \mu \mathrm{m}$. Vacuum filtration removes the ethanol, then the powder is dried at $60{ }^{\circ} \mathrm{C}$. Analysis by XRD was performed on three sub-samples run in triplicate: a potassium hydroxide-sucrose extraction residue composed essentially of the silicates and periclase; a salicylic acidmethanol extraction residue containing the interstitial phases periclase and alkali sulfates; and a bulk (untreated) sample. Selective extractions aid the phase identification: 1) there are fewer phases due to the selective dissolution, making identification of the remaining phases simpler, 2) concentrating the remaining phases makes low-abundance phases easier to identify and include in the subsequent quantitative analysis, and 3) quantitative chemical extraction provides additional data for the final quantitative analysis estimates. This XRD characterization technique has been standardized in the ASTM 1365 [4] standard test method for quantitative phase abundance analysis of portland cement.

By contrast, identifying and quantifying the hydrated phases using X-ray diffraction techniques requires special considerations. Portland cement contains virtually no amorphous material, obviating the need for an internal crystalline standard. Hydrated cementitious systems, by contrast, can contain a majority mass fraction of amorphous material. The approach of adding an inert crystalline material at the time of mixing may have an unanticipated effect on the rate of hydration. Alternatively, adding a known amount of an internal standard to a sample of hydrated paste requires moisture stabilization to reach equilibrium with the laboratory atmosphere, and this can affect the structure of those phases that are sensitive to changes in temperature and humidity (e.g., ettringite, monosulfate, etc.).

In these studies, these challenges were overcome in two ways. For mixtures that would create portlandite from the hydration reaction, TGA was used to determine the mass fraction of portlandite. For the other mixtures in which the portlandite was consumed by the fly ash or slag hydration, an internal standard (corundum) was added at the time of mixing. To avoid moisture loss due to grinding a sample to a powder, the XRD specimen was prepared by cutting a thin $(2 \mathrm{~mm})$ specimen and polishing the cut 
surface. The solid specimen was loaded into the XRD sample holder such that the polished surface was flush with the top of the sample holder, and the sample was rotated to increase the sampling volume.

The quantitative X-ray powder diffraction analysis was performed with a commercial diffractometer in reflection mode with a step size of $0.016^{\circ} 2 \theta$. For the starting powder binder materials, the scans were preformed from approximately $10^{\circ} 2 \theta$ to $77^{\circ} 2 \theta(\mathrm{Cu} \mathrm{K \alpha})$ with a total scan time of approximately 70 minutes. For the hydrated systems, the scans were performed from approximately $5^{\circ} 2 \theta$ to $80^{\circ} 2 \theta(\mathrm{Cu}$ $\mathrm{K} \alpha$ ) with a total scan time of approximately 80 minutes. The Rietveld analysis was performed using the commercial software supplied with the X-ray diffractometer. Preferred orientation corrections were limited to the portlandite and the ettringite phases.

Attenuation contrast between phases and the matrix introduces a potential for bias through a complex combination of chemistry and particle size, resulting in a systematic underestimation of materials that are high absorbers, and an overestimation of those that are low absorbers [5]. Given that the estimates of the internal standard are crucial in assessing the glassy (amorphous) fraction of the specimens, matching the absorption characteristics and particle size are important as well as knowledge of the crystalline fraction of the internal standard. NIST produces a set of powder diffraction standards for quantitative analysis that span the range of absorption characteristics and with a known crystalline content, providing flexibility in selection of an appropriate material $[6,7]$. The most suitable match for the cement is rutile, with zincite for the fly ash, and corundum for the slag.

\subsubsection{Scanning Electron Microscopy}

Specimens for scanning electron microscopy were impregnated in epoxy, cut on a diamond saw using ethanol as a lubricant, polished to a mirror finish, and then coated with carbon to avoid charging. The scanning electron microscope (SEM) used an electron accelerating voltage $10 \mathrm{kV}$ accelerating voltage, approximately $3 \mathrm{nA}$ probe current (adjusted to keep an X-ray dead time below $40 \%$ ), 5 min. per frame scan rate to minimize backscattered electron (BE) noise, and a working distance of approximately $12 \mathrm{~mm}$. The magnification was adjusted to retain a spatial resolution of $0.50 \mu \mathrm{m}$ to $0.75 \mu \mathrm{m}$ per pixel. The SEM was equipped with an energy-dispersive detector to collect secondary electrons for microprobe analysis. The sample was imaged using backscattered electrons (grey scale is proportional to density) and the electron micro-probe elemental analysis (grey scale is proportional to elemental content), with one image for each element analyzed.

The backscattered electron image (BEI) and the X-ray microanalysis (XR) images of polished crosssections are used for image processing (feature extraction) and image analysis (measurements) [8, 9, 10]. Once the images are segmented, a variety of measurements, such as phase abundance and surface area, may be determined. In the BEI, local brightness is proportional to the backscattered electron coefficient, $\eta[11]$. The reported coefficients are approximate as substitution affects the average atomic number. Xray imaging captures the element spatial distribution over the same field of view as the BEI. Phase identifications are made upon the basis of relative BEI brightness, bulk chemistry from X-ray imaging, and morphology. A partial SEM image set for the cement is presented in Figure 1. The contrast between alite $(\eta \approx 0.176)$ and belite $(\eta \approx 0.171)$ is relatively strong and their distinction is clear, while that between belite and cubic aluminate $(\eta \approx 0.168)$ is generally too weak to distinguish these constituents. However, aluminate and belite have distinct chemical compositions, so use of the aluminum X-ray image serves to distinguish these phases. Similarly, the mullite phase in the fly ash has a $\eta$ similar to that of quartz, but the aluminum will also serve to distinguish between the phases. This may be visualized 
through a process whereby the images are merged into a red-green-blue composite image. This process will be useful in reconciling the QXRD data with fly ash and slag image sets.

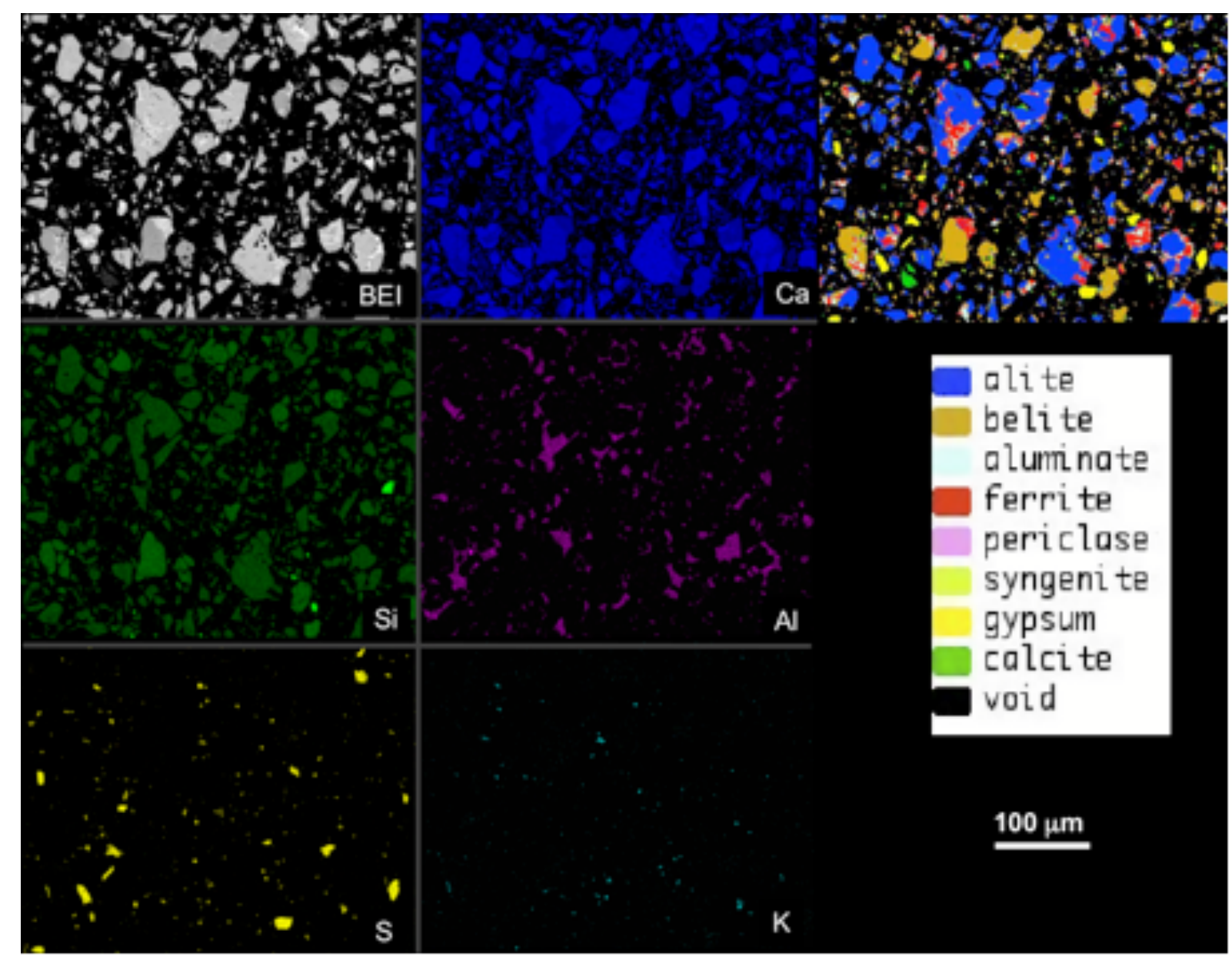

Figure 1. The backscattered electron image and a segmented, color-composite image derived from a set of X-ray and the BEI illustrate the chemical and compositional complexity of cement, and use of the image set to assign phase classes (lower-right) to a segmented image.

\subsubsection{Image Segmentation}

Image segmentation is a process by which common elements within an image can be identified, and the area fractions quantified. A common use for image segmentation is the study of satellite images of farmland whereby different crop types (corn, wheat, oats, etc.) are identified and the relative areas quantified. In general, information is gathered using multiple "filters," and the combined information is sufficient to ensure identification. For example, the satellite images can be taken with red, green, blue, and infrared filters, from which the composite data are used to identify the different crops in an image.

The most straightforward way of segmenting the image is to use a training set of data from which to classify the remaining portion of the image. For example, a few of the crop types in a satellite image that can be identified with near certainty are "outlined" and classified. The relative contributions from each filter (red, green, blue, and infrared) are characterized statistically, and all the pixels in the image are classified depending upon the degree to which its filter components agree with the classification from the 
training set; it is possible that pixels from a training set will be re-classified, and the degree to which this occurs is an indication of the robustness of the training set.

For cementitious systems, image segmentation is performed on images created on an SEM. The "filters" include the BEI, where the brightness is proportional to electron density, and the different elemental maps that are created using electron microprobe analysis. The combination of the BEI and the chemical information gleaned from the elemental maps provide very effective means of identifying certain phases with a high degree of confidence.

The entire image segmentation process is performed with the assistance of publicly available software. Because the elemental maps have relatively few counts, phase identification for developing a training set is facilitated by enhancing the starting images through eliminating noise and increasing the contrast. This was accomplished using the ImageJ software [12] from the National Institutes of Health. The segmentation was performed using the MultiSpec software [13] from Purdue University.

Figure 2 is a BEI of a polished section taken from cement paste that had hydrated for 3 months. In the image, one can see the features of individual phases, identifiable (primarily) from the greyscale. Segmenting by greyscale alone, however, is not reliable, and additional information is helpful.

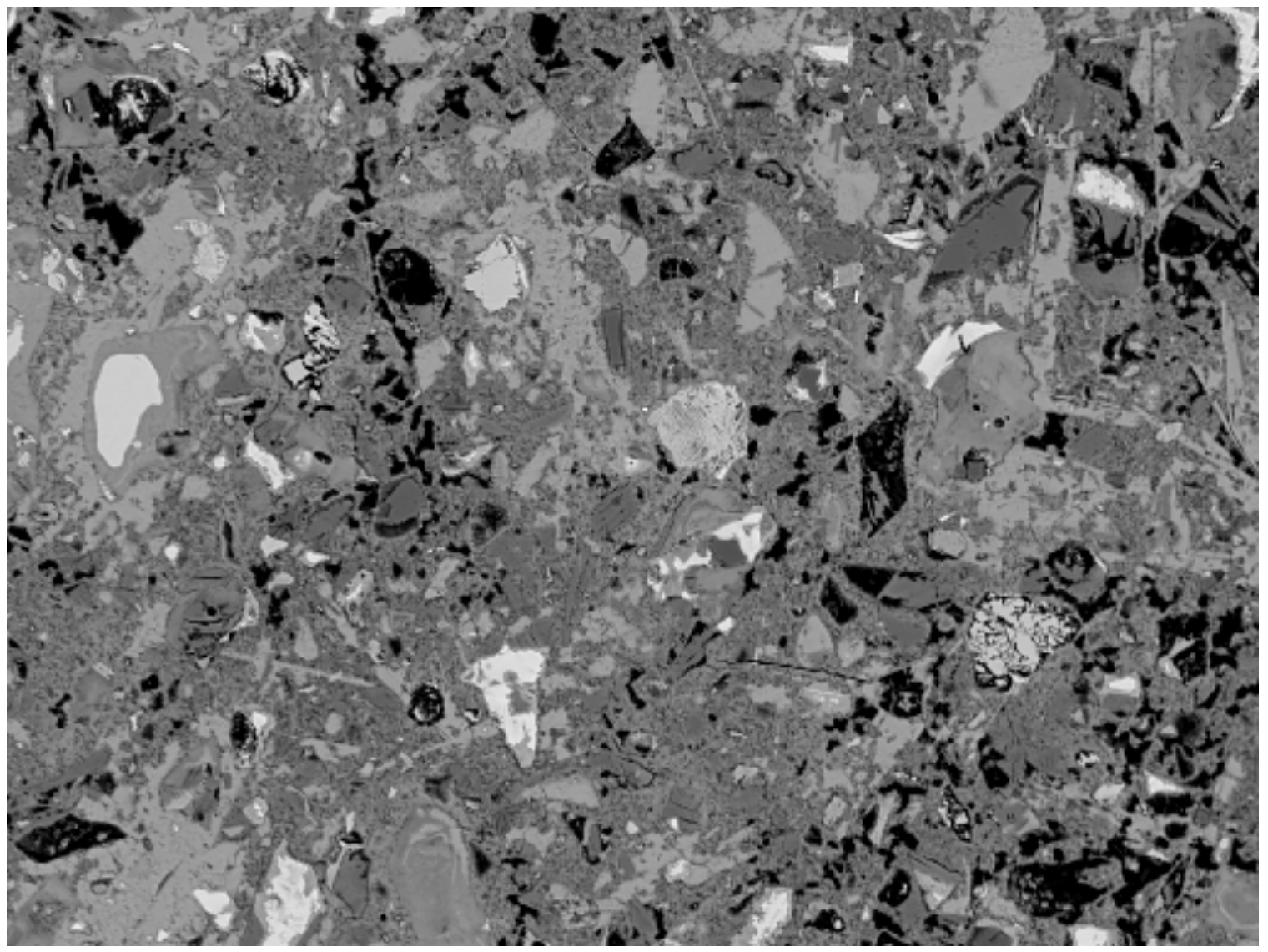

Figure 2. Backscattered electron image (BEI) of hydrated cement paste after 3 months of hydration.

The polished section in Figure 2 is also analyzed with electron microprobe analysis. For identifying phases commonly found in hydrated pastes, there are six primary elements of interest: calcium $(\mathrm{Ca})$, silicon $(\mathrm{Si})$, aluminum $(\mathrm{Al})$, iron $(\mathrm{Fe})$, magnesium $(\mathrm{Mg})$, and sulfur $(\mathrm{S})$. These "elemental maps" are 
given in Figure 3, and correspond to the entire field of view in Figure 2. From these elemental maps, one can observe that some elements are distributed throughout the paste ( $\mathrm{Ca}, \mathrm{Si}$, and $\mathrm{S})$, and a number of elements appear to be localized in certain phases ( $\mathrm{Al}, \mathrm{Fe}$, and $\mathrm{Mg}$ ).

Ca

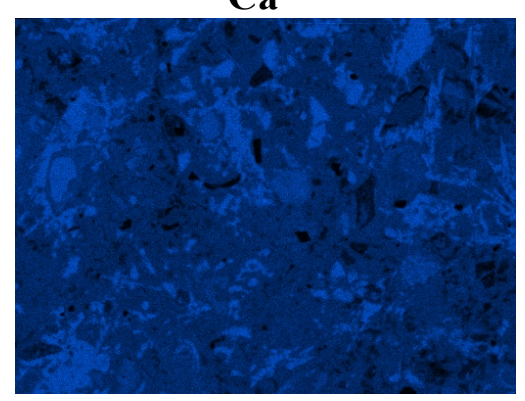

Fe

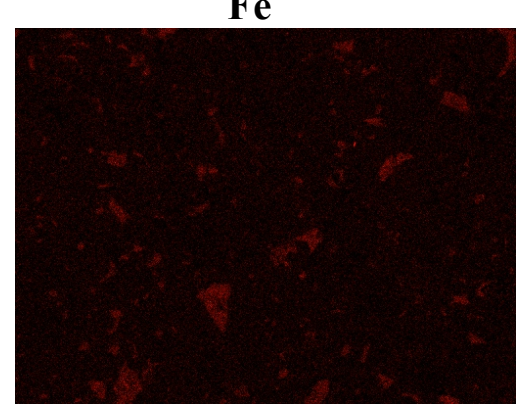

Si

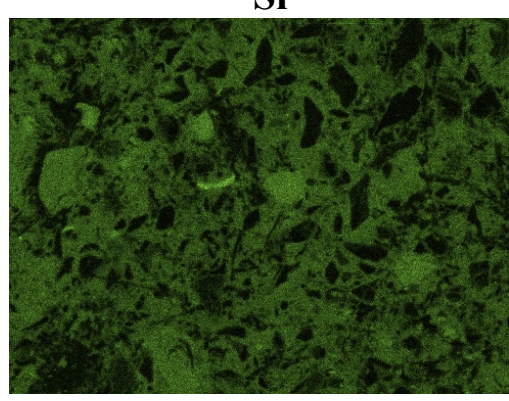

Mg

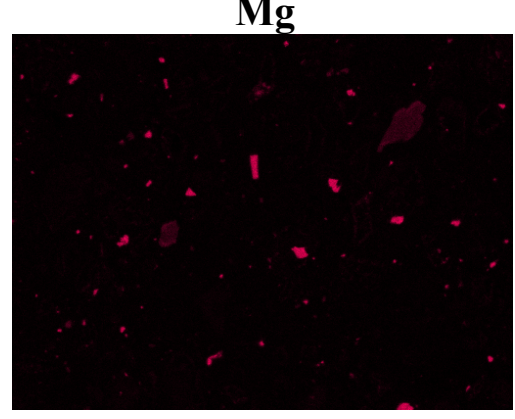

Al

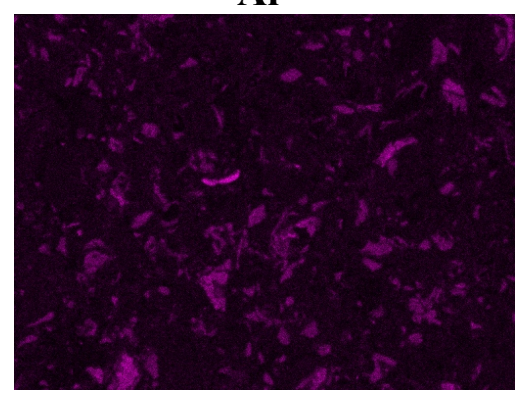

$\mathbf{S}$

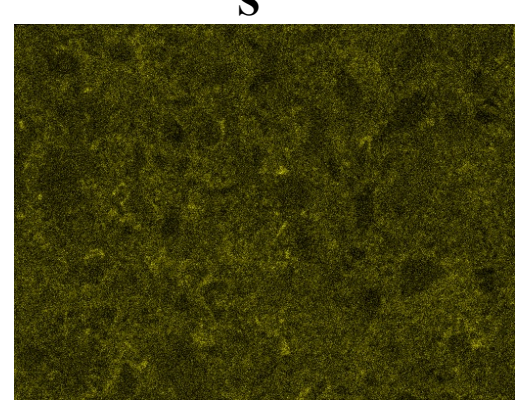

Figure 3. Original elemental maps of the major components for Mix 1 at 3 months hydration.

The original elemental map images in Figure 3 have relative low intensity counts, making phase identification difficult. To reduce noise and improve contrast, the following procedure, summarized in Figure 4, was used to enhance each elemental map. First, the contrast was enhanced by expanding the recorded counts to extend throughout the 0 to 255 dynamic range, and then by eliminating the pixels having an intensity less than the modal value. Then, noise was removed using the ImageJ despeckle filter to eliminate isolated pixels. Finally, to enhance the perception of uniform phases, a $3 \times 3$ median filter was used to smooth out neighboring pixels. 

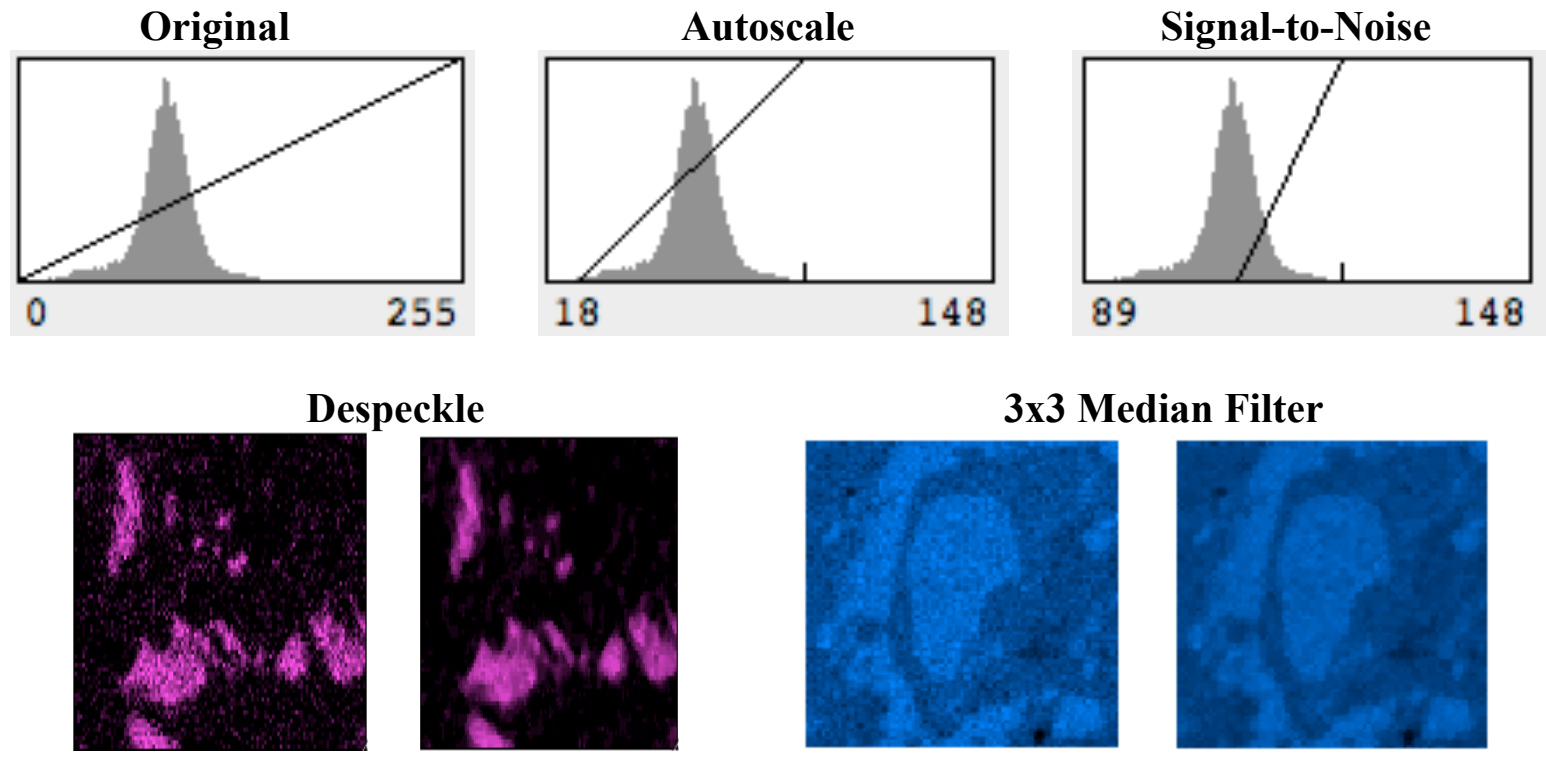

Figure 4. A summary of image processing techniques used in the segmentation. The bottom row demonstrates before (left) and after (right) images of the despeckle and median filter algorithms

The resulting enhanced elemental images are shown below in Figure 5. The enhanced images exhibit more distinct regions, which facilitates individual phase identification. These resulting images are then combined with the BEI image in Figure 2 to identify individual phases.

$\mathbf{C a}$

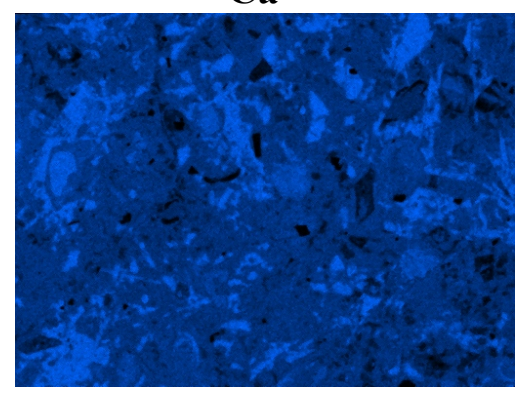

Fe

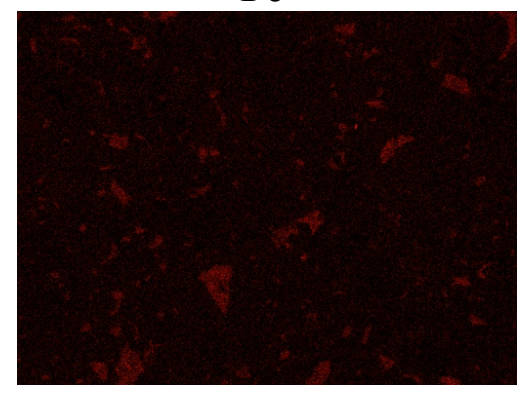

Si

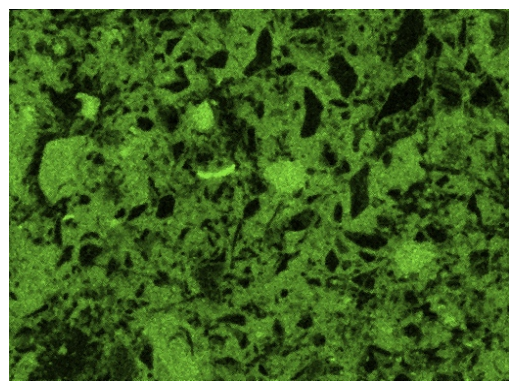

Mg

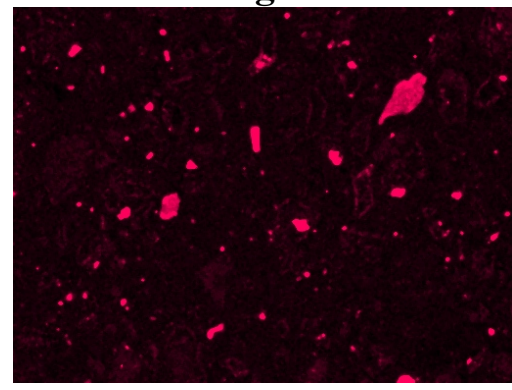

Al

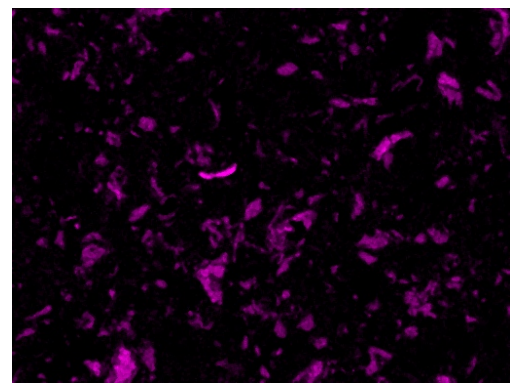

$\mathbf{S}$

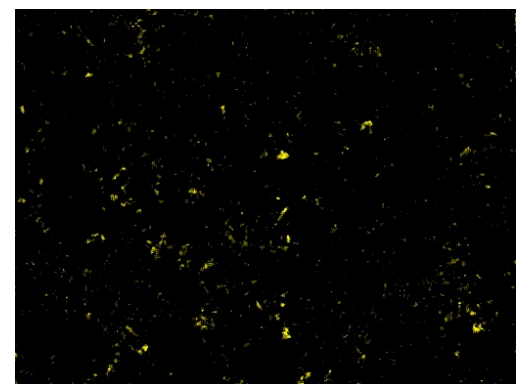

Figure 5. Processed element images from Figure 3. 
BEI

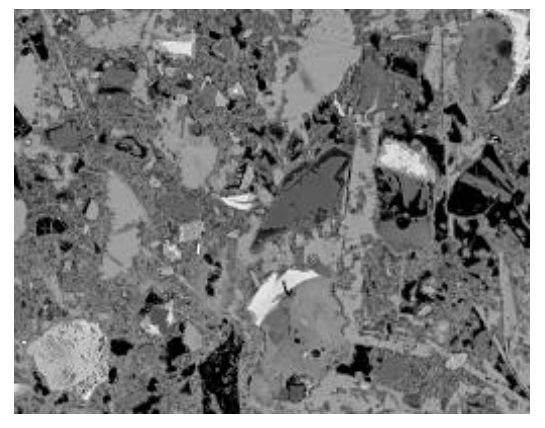

$\mathrm{Ca} \mathrm{Ca} \mathrm{Mg}$

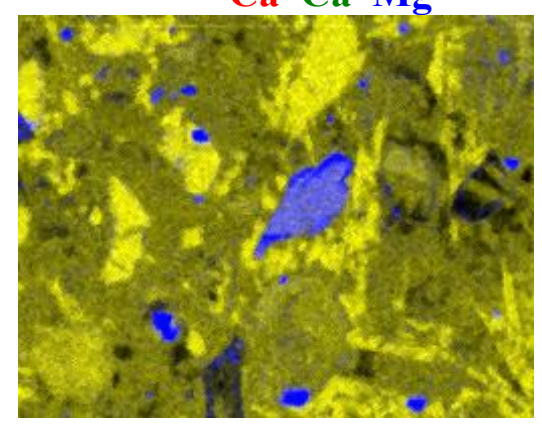

Ca Si Al

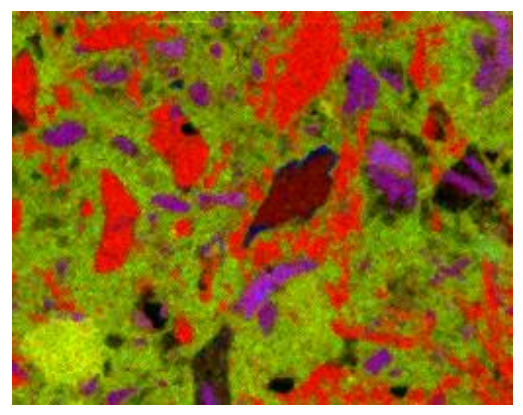

Ca Al Fe

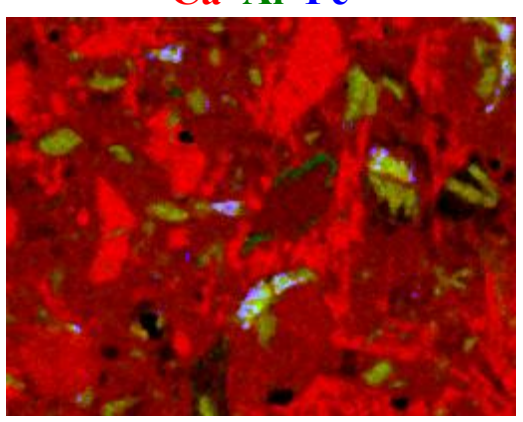

Al Ca Si

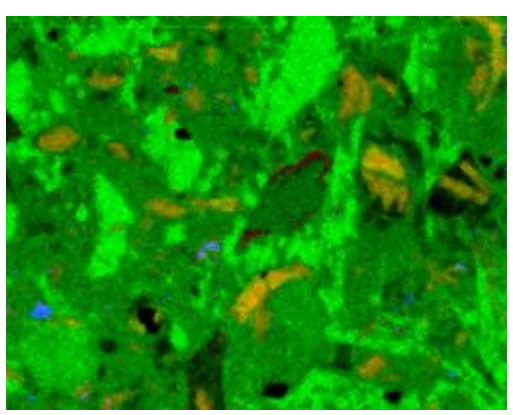

Al Ca S

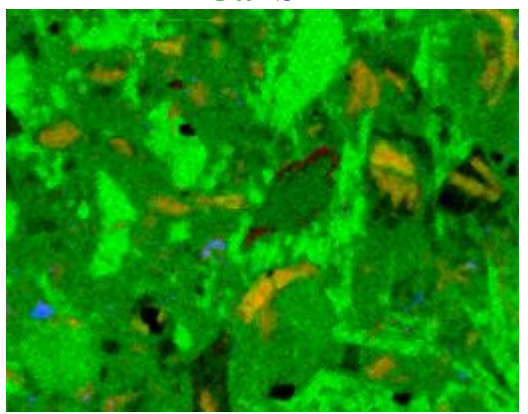

Figure 6. Phase identification color maps; only a portion of the entire image is shown to enhance detail. The three element labels that appear over each image represent (from left to right) the red, green, and blue channels, respectively.

Using the enhanced elemental maps and the BEI, MultiSpec is used to identify distinct phases and create training sets. MultiSpec allows the user to overlay different combinations of three images, using the red, green, and blue channels to represent three different images. Useful combinations of elements are used, like those shown in Figure 6, to ensure accurate phase identification; the BEI can also be used as one of the color channels.

For each three-color combination, different phases are identified to create a training set for segmentation. The best examples found for each phase are outlined and labeled in the image, and multiple regions can be used as part of the training set for a particular phase. The training set for the paste is shown in Figure 7. 


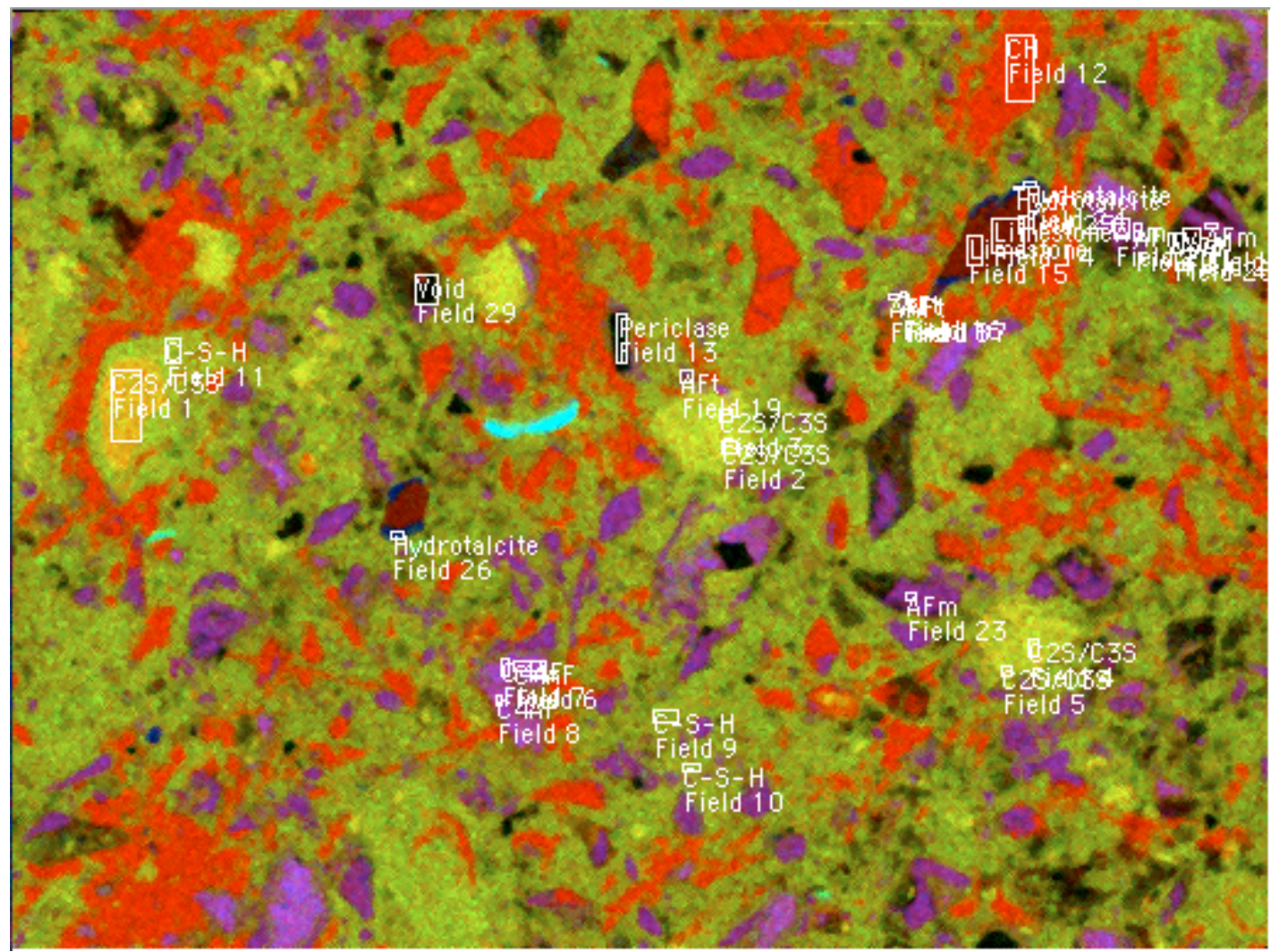

Figure 7. Phase training sets for the cement paste shown in Figure 2.

Once the training set has been established, the software classifies all the pixels based on the training set. Each pixel is characterized by the contributions from all seven input images: the BEI and the six elemental maps. At each pixel, the relative contribution from each image forms a type of "fingerprint." A global "fingerprint" is created from all the pixels in a phase training set. The segmentation software then classifies all the pixels in the image, including the pixels in training sets, based on how "close" a pixels resembles the global fingerprint of the a training set. All pixels are assigned to a phase, and some pixels from a training set may be "reassigned" to a different phase. The degree to which this occurs is a measure of the accuracy of the training set.

\begin{tabular}{|c|c|c|c|c|c|c|c|c|c|c|c|c|}
\hline Phase & Assignment & Sample & 1 & 2 & 3 & 4 & 5 & 6 & 7 & 8 & 9 & 10 \\
\hline $1 \mathrm{C} 2 \mathrm{~S} / \mathrm{C} 3 \mathrm{~S}$ & 0.996 & 447 & 445 & 0 & 0 & 2 & 0 & 0 & 0 & 0 & 0 & 0 \\
\hline 2 C4AF & 1.000 & 81 & 0 & 81 & 0 & 0 & 0 & 0 & 0 & 0 & 0 & 0 \\
\hline $3 \mathrm{C}-\mathrm{S}-\mathrm{H}$ & 1.000 & 131 & 0 & 0 & 131 & 0 & 0 & 0 & 0 & 0 & 0 & 0 \\
\hline $4 \mathrm{CH}$ & 1.000 & 297 & 0 & 0 & 0 & 297 & 0 & 0 & 0 & 0 & 0 & 0 \\
\hline 5 Periclase & 1.000 & 80 & 0 & 0 & 0 & 0 & 80 & 0 & 0 & 0 & 0 & 0 \\
\hline 6 Limestone & 1.000 & 254 & 0 & 0 & 0 & 0 & 0 & 254 & 0 & 0 & 0 & 0 \\
\hline $7 \mathrm{AFt}$ & 1.000 & 40 & 0 & 0 & 0 & 0 & 0 & 0 & 40 & 0 & 0 & 0 \\
\hline $8 \mathrm{AFm}$ & 1.000 & 88 & 0 & 0 & 0 & 0 & 0 & 0 & 0 & 88 & 0 & 0 \\
\hline 9 Hydrotalcite & 1.000 & 29 & 0 & 0 & 0 & 0 & 0 & 0 & 0 & 0 & 29 & 0 \\
\hline \multirow[t]{3}{*}{10 Void } & 1.000 & 203 & 0 & 0 & 0 & 0 & 0 & 0 & 0 & 0 & 0 & 203 \\
\hline & Totals: & 1650 & 445 & 81 & 131 & 299 & 80 & 254 & 40 & 88 & 29 & 203 \\
\hline & Accuracy: & & 1.000 & 1.000 & 1.000 & 0.993 & 1.000 & 1.000 & 1.000 & 1.000 & 1.000 & 1.000 \\
\hline
\end{tabular}

Figure 8. Statistics reported by MultiSpec software after a segmentation analysis. 
The segmentation analysis results based on the training set in Figure 7 are reported in Figure 8. The numbers ("1" through "10") along the top row correspond to the numbered phases in the leftmost column. The second column from the left is an indication of what fraction of the training set for that phase was ultimately classified in that phase (i.e., the "purity" of the training set). The "Accuracy" along the bottom row is an indication of the certainty to which phases are being classified. In general, enhanced images result in relatively high purity and accuracy.

The resulting segmented image is shown below in Figure 9. The image shows well-defined component phases. By comparison to the original BEI, the segmentation appears to be consistent with what one would arrive at if using only a BEI.

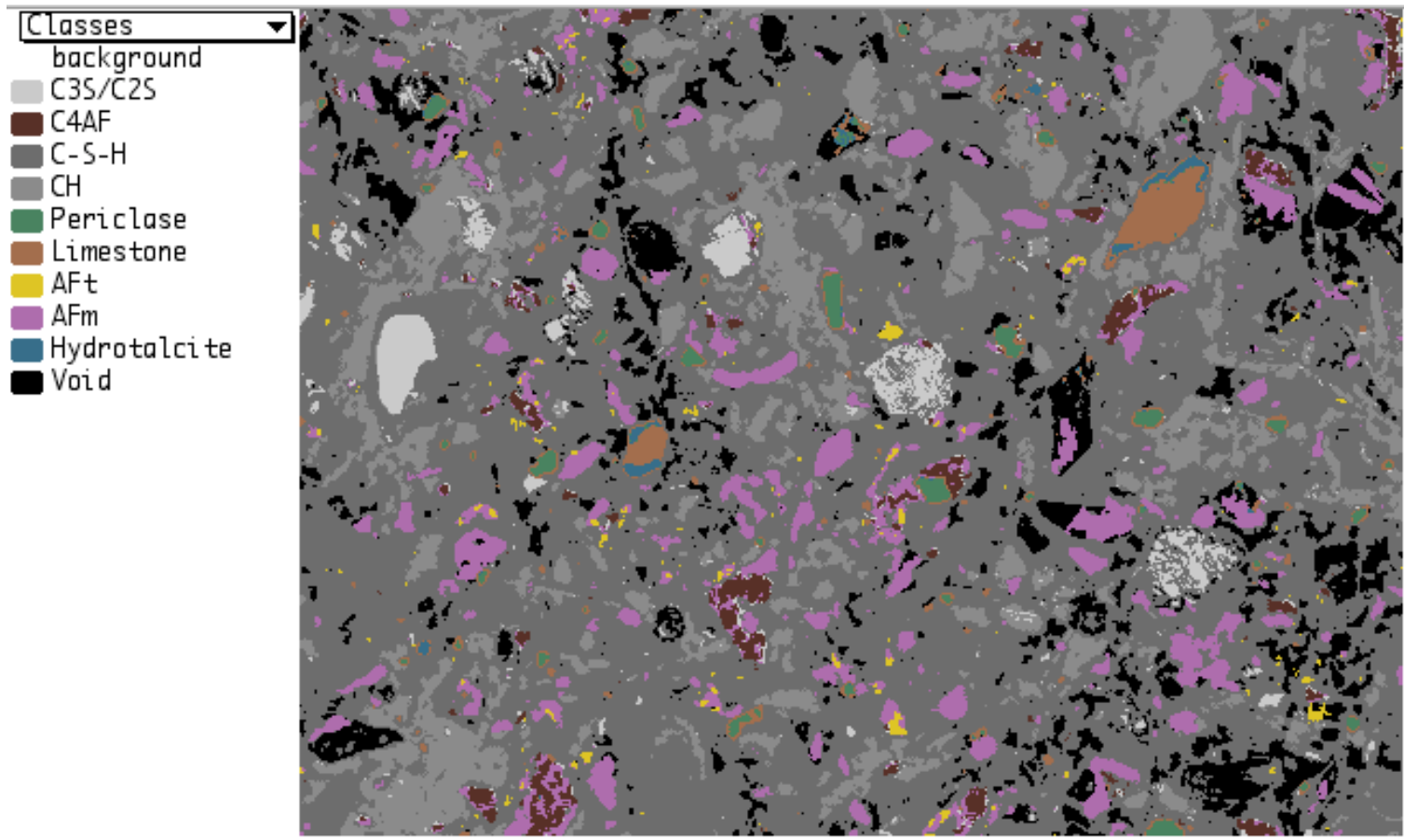

Figure 9. The segmented image when using processed starting images.

Upon closer inspection, one realizes that the image processing has eliminated a lot of fine detail associated with the sulfur-bearing phases such as monosulfate (AFm) and ettringite (AFt). These phases tend to be finely divided, and uniformly distributed throughout the cement paste, which is consistent with being formed through precipitation of diffusing sulfur and aluminum species.

To remedy this, the segmentation was repeated using the same locations of the training set of pixels, but using the original (unprocessed) images. The segmentation statistics given below in Figure 10 indicate a lower purity of the training set, and a lower overall accuracy in the segmentation. 


\begin{tabular}{|c|c|c|c|c|c|c|c|c|c|c|c|c|c|}
\hline \multicolumn{2}{|c|}{ Phase } & Assignment & Sample & 1 & 2 & 3 & 4 & 5 & 6 & 7 & 8 & 9 & 10 \\
\hline \multicolumn{2}{|c|}{$1 \mathrm{c} 2 \mathrm{~S} / \mathrm{C} 3 \mathrm{~S}$} & 99.6 & 447 & 445 & 0 & 0 & 2 & 0 & 0 & 0 & 0 & 0 & 0 \\
\hline 2 & C4AF & 97.5 & 81 & 2 & 79 & 0 & 0 & 0 & 0 & 0 & 0 & 0 & 0 \\
\hline 3 & C-S-H & 88.5 & 131 & 0 & 0 & 116 & 3 & 0 & 7 & 4 & 1 & 0 & 0 \\
\hline 4 & $\mathrm{CH}$ & 99.7 & 297 & 0 & 0 & 1 & 296 & 0 & 0 & 0 & 0 & 0 & 0 \\
\hline 5 & Periclase & 100 & 80 & 0 & 0 & 0 & 0 & 80 & 0 & 0 & 0 & 0 & \\
\hline 6 & Limestone & 100 & 254 & 0 & 0 & 0 & 0 & 0 & 254 & 0 & 0 & 0 & \\
\hline 7 & AFt & 82.5 & 40 & 0 & 0 & 4 & 0 & 0 & 0 & 33 & 3 & 0 & \\
\hline 8 & AFm & 92 & 88 & 0 & 0 & 3 & 0 & 0 & 0 & 4 & 81 & 0 & 0 \\
\hline 9 & Hydrotalcite & 100 & 29 & 0 & 0 & 0 & 0 & 0 & 0 & 0 & 0 & 29 & \\
\hline \multirow[t]{3}{*}{10} & Void & 100 & 203 & 0 & 0 & 0 & 0 & 0 & 0 & 0 & 0 & 0 & 203 \\
\hline & & Totals: & 1650 & 447 & 79 & 124 & 301 & 80 & 261 & 41 & 85 & 29 & 203 \\
\hline & & Accuracy: & & 0.996 & 1.000 & 0.935 & 0.983 & 1.000 & 0.973 & 0.805 & 0.953 & 1.000 & 1.000 \\
\hline
\end{tabular}

Figure 10. Segmentation statistics using the same training set locations, and the original (unprocessed) images.

The resulting segmented image shown in Figure 11, however, has identified far more AFm and AFt, and these are more finely distributed throughout the paste.
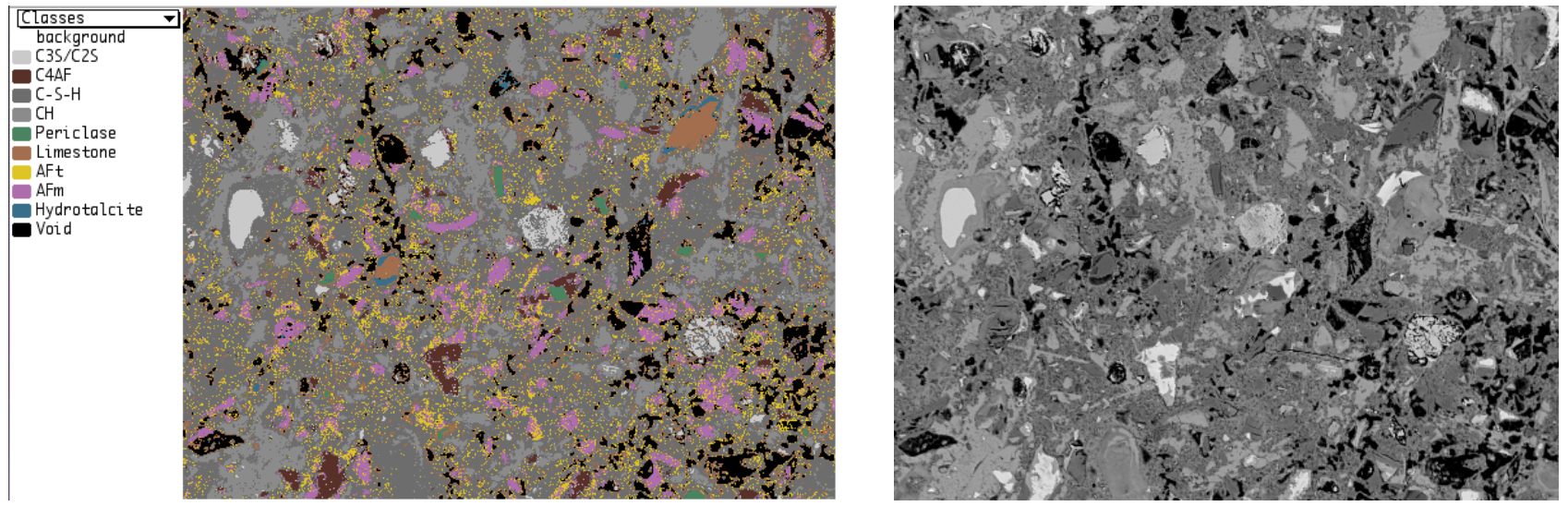

Figure 11. Comparison of the segmented image using unprocessed starting images and the original BEI image.

The area fractions of the segmented phases are an estimate for the phase volume fraction. For comparison to XRD analysis, the volume fractions are converted to mass fractions using the density of the phase. The volume and mass fractions for both segmented images, using either the processed or the unprocessed starting images, are shown in Table 1. The data in the table suggest that using the unprocessed images (based on training sets created from processed images) increases the detection limit of the more finely distributed, lower volume fraction phases. For the combined mass fraction of AFt and AFm, the segmentation performed using the original images doubled the quantity detected. 
Table 1. The volume fraction (VF) and mass fraction (MF) of the phases identified in the segmented images for the processed and unprocessed starting images.

\begin{tabular}{lcccc} 
& \multicolumn{2}{c}{ PROCESSED } & \multicolumn{2}{c}{ UNPROCESSED } \\
& VF & MF & VF & MF \\
C2S/C3S & 0.022 & 0.028 & 0.020 & 0.027 \\
C4AF & 0.015 & 0.023 & 0.021 & 0.033 \\
C-S-H & 0.648 & 0.705 & 0.520 & 0.572 \\
CH & 0.137 & 0.130 & 0.138 & 0.133 \\
Periclase & 0.007 & 0.006 & 0.006 & 0.005 \\
Limestone & 0.014 & 0.016 & 0.079 & 0.091 \\
AFt & 0.004 & 0.003 & 0.075 & 0.052 \\
AFm & 0.066 & 0.086 & 0.063 & 0.084 \\
Hydrotalcite & 0.002 & 0.002 & 0.004 & 0.004
\end{tabular}

Therefore, it appears that using processed starting images to identify a training set, and then obtaining segmentation statistics using the original image is a viable means of identifying hydrated phases, especially those that are finely distributed throughout the cement paste, like AFm and AFt.

\subsubsection{Inductively-Coupled Plasma Spectroscopy}

Inductively-coupled plasma optical emission spectroscopy (ICP-OES) was used to characterize the elemental composition of the saltstone grout pore solution. This method is coupled with pore expression [14], whereby the material is cast into a $50 \mathrm{~mm}$ (dia) x $100 \mathrm{~mm}$ (long) sealable plastic cylindrical molds that were stored in re-sealable plastic bags that were kept in a walk-in chamber maintained at $25^{\circ} \mathrm{C}$. At the desired age, the specimen was removed from the plastic mold and pressed in a die, using a compressive testing machine, to expel the liquid remaining in the pore space; the press is flushed with nitrogen to prevent carbonation during the process. The captured liquid was filtered (less than $0.5 \mu \mathrm{m}$ ) to remove suspended particles, and then diluted with water and $5 \%$ (by mass) nitric acid $\left(\mathrm{HNO}_{3}\right)$.

The solutions used to standardize the ICP analysis were made with the same atomic elements that were expected in the extracted samples. In addition to the elements supplied by the SWS, the hydrating cementitious materials will contribute potassium, calcium, and silicon. The Standard A solution was developed for analyzing mixtures that were made with water. A separate standard was developed for systems made with the SWS. Initially, the expectation was that the high $\mathrm{pH}$ would reduce the silicon concentration to very low values. Subsequent thermodynamic modeling indicated the opposite. As a result, there were two standard solutions developed for systems made with the SWS: the initial Standard B1 (without silicon), and the subsequent Standard B2 (with silicon). In addition, assuming that a significant fraction of the nitrate and nitrite concentrations of the "mix water" would remain in the pore solution, nitrates were added to Standard B. The composition of both of these standard solutions appears below in Table 2.

Table 2. The composition of the three different standard solutions used to analyze the extracted pore solutions from the OPC pastes (Standard A) and the saltstone waste forms (Standard B1 and Standard B2). 


\begin{tabular}{|c|l|l|l|}
\hline Element & $\begin{array}{c}\text { Standard A } \\
(\mathbf{m o l} / \mathbf{k g w})\end{array}$ & $\begin{array}{c}\text { Standard B1 } \\
(\mathbf{m o l} / \mathbf{k g w})\end{array}$ & $\begin{array}{c}\text { Standard B2 } \\
(\mathbf{m o l} / \mathbf{k g w})\end{array}$ \\
\hline $\mathrm{Na}$ & 0.04360 & 0.7329 & 0.7482 \\
\hline $\mathrm{K}$ & 0.02597 & 0.09304 & 0.1871 \\
\hline $\mathrm{S}$ & 0.03119 & 0.1054 & 0.08563 \\
\hline $\mathrm{Ca}$ & 0.02451 & 0.00018 & 0.00018 \\
\hline $\mathrm{Al}$ & 0.03719 & 0.00008 & \\
\hline $\mathrm{Mg}$ & 0.04115 & & \\
\hline $\mathrm{Si}$ & & & 0.00408 \\
\hline $\mathrm{N}$ & & & 0.3195 \\
\hline
\end{tabular}

The solutions used to standardize the ICP were made using de-ionized water $(18 \mathrm{M} \Omega-\mathrm{cm})$ and by diluting the standard solution by factors of 10,20 , and 40 using a $5 \%$ (by mass) nitric acid $\left(\mathrm{HNO}_{3}\right)$ solution. The unknown sample measurements were repeated 3,4 , or 5 times, depending on the volume of sample obtained.

\subsubsection{Thermodynamic Modeling}

Thermodynamic modeling has been developing as a tool for analyzing both hydration reactions and degradation reactions. One of the most advanced thermodynamic models is a combination of thermodynamic data for the phases that may occur during hydration [15] and a Gibbs free energy minimization solver (GEMS) [16]. The analyst provides these models with a type and quantity of components present (each element, and if appropriate, the various oxidation states of these elements), and the model determines the equilibrium distribution of species (in solution) and precipitated mineral phases. Because thermodynamic models are equilibrium calculations, they cannot model hydration without additional information regarding the rate that mineral phases react. For a hydrating system like portland cement, the analyst would supplement the thermodynamic model with a kinetic model for rate of hydration for each of the phases in a cement (i.e., alite, belite, aluminate, ferrite). In addition, cementitious systems typically incorporate dissolved species into the hydration products, so the thermodynamic model must also have a model (e.g., partitioning coefficients, surface complexation models) to account for these species.

The thermodynamic hydration model of Lothenbach et al. [17] was used to estimate the type and quantity of phases present after 3 months hydration of cementitious pastes made with water. The model has equations characterizing the rate of portland cement hydration. By contrast, there are no established rate equations for fly ash or slag, and a complementary experimental program would be required to identify the relevant material properties for establishing a model. 


\section{BLENDED CEMENT PASTES}

The various infrastructure elements of future nuclear facilities may be composed of the broad range of cementitious binder proportions: structural elements may be composed entirely of portland cement concrete; massive concrete elements may contain large quantities of fly ash and/or ground granulated blast furnace slag (GGBFS); and saltstone grouts [1] may contain less than 10 percent portland cement, with fly ash and slag making up the remainder. Improved performance assessment (PA) tools are needed for predicting the performance of all these systems because existing tools were developed for systems composed mostly of portland cement. An important component of these tools is the ability to estimate the type and quantity of hydrated phases present, and the pore solution composition, as these factors impact overall performance because they control, among other things, the buffering capacity of the material, the mobility of certain radionuclides, and the chemical composition of the effluent.

Sophisticated computer tools for predicting transport and reaction in cementitious systems incorporate thermodynamic data for the mineral phases present. Transport of ions from the external ground water changes the chemical equilibrium, and the thermodynamic model adjusts the quantity of phases to maintain equilibrium. Therefore, an accurate assessment/prediction of the initial hydrated phases and pore solution composition is vital component to an accurate PA tool.

To validate the hydrated phases prediction component of PA tools, standardized materials characterization techniques are needed to identify the phases in existing materials. In addition, system characterization data are required for model validation. Two very useful characterization tools are X-ray powder diffraction (XRD) and thermogravimetric analysis (TGA).

X-ray diffraction characterization techniques for quantifying hydrated cementitious phases differ from that for quantifying portland cement. Portland cement contains virtually no amorphous material, obviating the need for an internal crystalline standard. Also, a standardized method for portland cement characterization has been documented [4]. Hydrated cementitious systems, by contrast, contain a considerable mass fraction of amorphous material. The approach of adding an inert crystalline powder at the time of mixing may have an undesirable effect on the rate of hydration. Alternatively, adding a known amount of an internal standard to a sample of hydrated paste requires moisture stabilization to reach equilibrium with the laboratory atmosphere, and this can affect the structure of those phases that are sensitive to changes in temperature and humidity (e.g., ettringite, monosulfate, etc.).

As an alternative to adding an internal standard, TGA is used to quantify the calcium hydroxide (portlandite) present in the system. The water loss during conversion of portlandite to calcium oxide (lime) happens at a distinct and identifiable temperature. Because other hydrated phases are losing water over the same temperature range (but at a much slower rate), the analysis of the portlandite peak must account for the background mass loss.

The type and quantity of hydrated phases in paste samples are estimated by combining XRD and TGA data for systems made with blended cementitious powders for which the portland cement mass fraction varied from $100 \%$ to $10 \%$. The XRD data are used to identify the mineral phases present, and the relative mass fractions of each phase. TGA is used to estimate the portlandite content, from which the absolute mass fraction of each phase is estimated. The results are compared to estimates from a thermodynamic hydration model.

Image segmentation is also considered as an alternative approach to estimating the type and quantity of hydrated phases present. Backscattered electron imaging is used to indicate the phase density, and 
electron probe microanalysis images represent the relative concentration of elements. The various images are used to identify individual phases within the field of view, and a training set is used to classify all the pixels within the image. The results are compared to phase estimates from QXRD.

\subsection{Experimental Plan}

Eight cement paste mixtures were developed to span the range of cementitious binder mixtures anticipated for a saltstone grout. The mass fractions of cement, fly ash, ground granulated blast furnace slag (GGBFS), and silica fume for each of the eight mixtures are given in Table 3. The water:cementitious materials $(w / \mathrm{cm})$ mass ratio for all mixtures was 0.40 .

Table 3. Mixture mass fractions of the cementitious binders in each mixture.

\begin{tabular}{|l|l|l|l|l|}
\hline Mix \# & Cement & Fly Ash & GGBFS & Silica Fume \\
\hline 1 & 1.00 & & & \\
\hline 2 & 0.70 & 0.30 & & \\
\hline 3 & 0.70 & & 0.30 & \\
\hline 4 & 0.70 & 0.20 & & 0.10 \\
\hline 5 & 0.50 & 0.50 & & \\
\hline 6 & 0.50 & & 0.50 & \\
\hline 7 & 0.30 & 0.35 & 0.35 & \\
\hline 8 & 0.10 & 0.45 & 0.45 & \\
\hline
\end{tabular}

All the materials are commercial products. The ASTM Type I/II portland cement contained $3.5 \%$ limestone by mass and had a Blaine fineness of $372 \mathrm{~m}^{2} / \mathrm{kg}$. The fly ash is an ASTM Type C, and the GGBFS and the silica fume were commercial products. The oxide mass fractions were measured at a commercial laboratory using X-ray fluorescence, and the values are given in Table 4. The slag contained no crystalline phases, and the fly ash contained $7 \%$ quartz, $5 \%$ mullite, and $2 \%$ hematite by mass. Also given in the table are the cement calcite content and the slag sulfide content.

Table 4. Oxide mass fractions for the binders. The cement calcite content and the slag sulfide content are also given.

\begin{tabular}{|l|l|l|l|l|}
\hline Phase & Cement & Fly Ash & GGBFS & Silica Fume \\
\hline $\mathrm{CaO}$ & 0.605 & 0.246 & 0.371 & 0.005 \\
\hline $\mathrm{SiO}_{2}$ & 0.191 & 0.370 & 0.373 & 0.962 \\
\hline $\mathrm{Al}_{2} \mathrm{O}_{3}$ & 0.050 & 0.200 & 0.104 & 0.003 \\
\hline $\mathrm{Fe}_{2} \mathrm{O}_{3}$ & 0.033 & 0.053 & 0.005 & 0.000 \\
\hline $\mathrm{MgO}$ & 0.041 & 0.048 & 0.116 & 0.001 \\
\hline $\mathrm{SO}_{3}$ & 0.031 & 0.014 & 0.022 & 0.000 \\
\hline $\mathrm{Na}_{2} \mathrm{O}$ & 0.001 & 0.015 & 0.002 & 0.001 \\
\hline $\mathrm{K}_{2} \mathrm{O}$ & 0.007 & 0.006 & 0.003 & 0.005 \\
\hline $\mathrm{TiO}_{2}$ & 0.003 & 0.016 & 0.005 & 0.000 \\
\hline $\mathrm{CaCO}_{3}$ & 0.034 & & & \\
\hline Sulfide & & & 0.010 & \\
\hline
\end{tabular}


The paste specimens were made by combining the dry binder, adding distilled water, mixing in a blender, and then casting into $25 \mathrm{~mm}$ diameter, $25 \mathrm{~mm}$ tall cylinders. The cylinders were placed into re-sealable bags and kept in a walk-in environmental chamber maintained at $25^{\circ} \mathrm{C}$. The samples were demolded after 24 hours (48 hours for Mix 7 and Mix 8), and placed into a sealed jar that was stored in the walk-in environmental chamber. At (12 \pm 1$)$ weeks of hydration, individual samples approximately $1 \mathrm{~mm}$ thick were cut from the specimen on a diamond saw using ethanol as the cutting lubricant; the first $1 \mathrm{~mm}$ at the surface was discarded. After cutting each sample, the surface was cleaned with a soft plastic-bristled brush and rinsed with ethanol.

\subsection{Results}

Calorimetry data for each mixture is given below in Figure 12 below. Mixes 1-4 and Mix 6 had a primary exothermic peak occurring between $10 \mathrm{~h}$ and $15 \mathrm{~h}$, and each curve exhibited very slight peak separation. Mix 5, Mix 7, and Mix 8 exhibited distinct secondary sulfate peak separation. The response of Mix 8 was particularly unique because the primary heat peak occurred at $100 \mathrm{~h}$, and the secondary peak occurred near $500 \mathrm{~h}$.
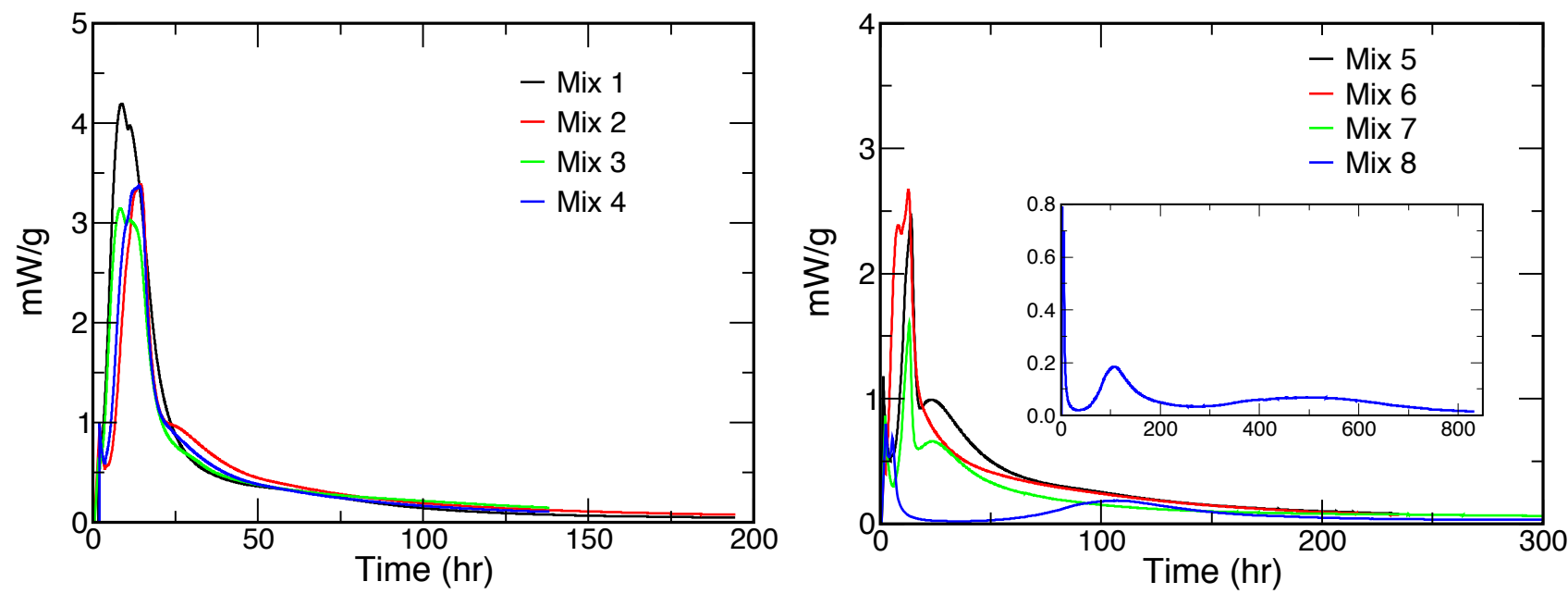

Figure 12. Calorimetry data for Mixes 1-4 (1) and for Mixes 5-8 (r). Inset shows data from Mix 8 until 800 hours of hydration.

The differential scaled mass loss $(-d \mu / d T)$ for each of the eight mixes after 12 weeks of hydration is given in Figure 13. The broad, overlapping peaks below approximately $150{ }^{\circ} \mathrm{C}$ are from water being liberated from multiple hydration products containing chemically bound water. Isolated, individual peaks begin to appear at temperatures above approximately $150{ }^{\circ} \mathrm{C}$. 

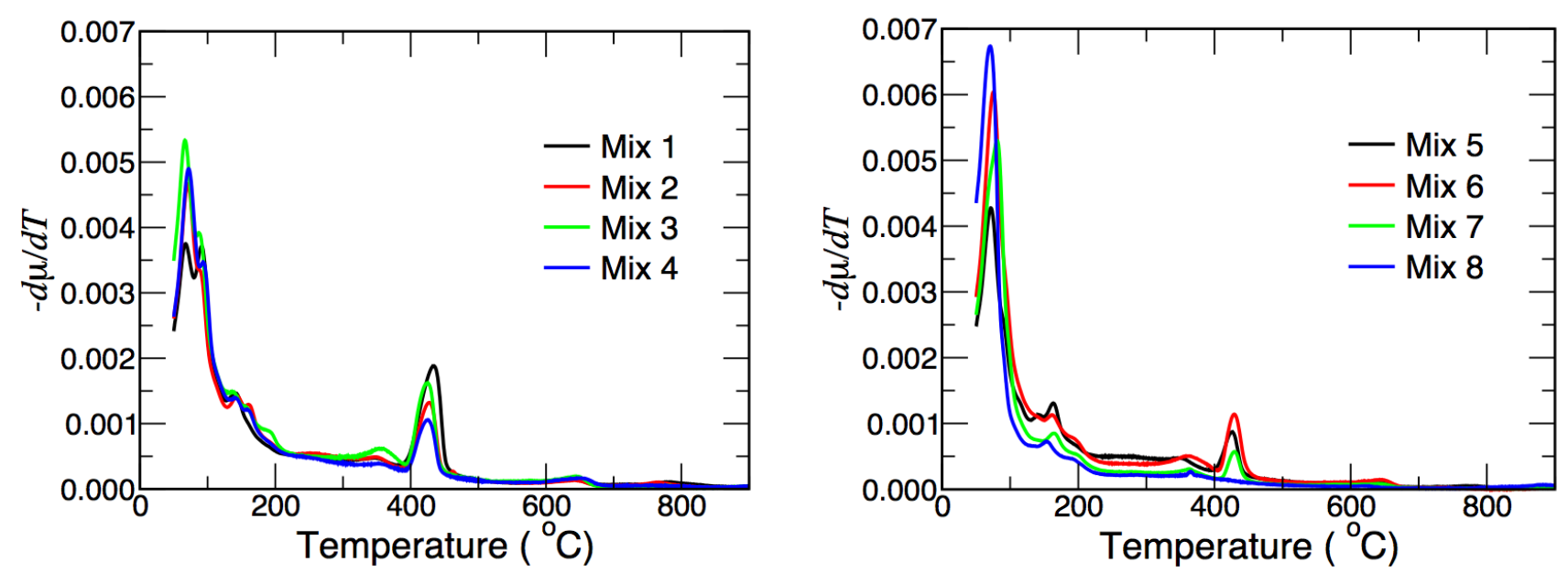

Figure 13: Thermogravimetric data for Mix 1-4 (1) and Mix 5-8 (r) after 12 weeks of hydration.

The peak at approximately $425^{\circ} \mathrm{C}$ is due to loss of water in the conversion of portlandite to lime. The portlandite peak prominence and separation is exploited to obtain an estimate for the portlandite content. This value is then used to establish the quantity of portlandite for the XRD Rietveld analysis. The portlandite mass fractions for the mixtures are reported in Table 5.

Table 5: Estimated portlandite mass fraction as calculated from TGA data. The parameter coefficient of variation reported by the regression software was typically less than $0.3 \%$, and other comparisons to XRD data were generally within $2 \%$.

\begin{tabular}{|l|l|}
\hline Mix & Portlandite Mass Fraction \\
\hline 1 & 0.119 \\
\hline 2 & 0.064 \\
\hline 3 & 0.063 \\
\hline 4 & 0.049 \\
\hline
\end{tabular}

\begin{tabular}{|l|l|}
\hline Mix & Portlandite Mass Fraction \\
\hline 5 & 0.031 \\
\hline 6 & 0.039 \\
\hline 7 & 0.019 \\
\hline 8 & - \\
\hline
\end{tabular}

No portlandite was detected in Mix 8 . Therefore, corundum ( $87 \%$ crystalline) was added as an internal standard. To stabilize the powder mass prior to adding the corundum, the sample was dried briefly in a $60{ }^{\circ} \mathrm{C}$ oven. Prior to adding the corundum, a small portion was taken and analyzed by TGA to estimate the adjusted water content so that the corundum mass fraction could be expressed as a mass fraction of the original sample.

The XRD data from all 8 mixes are shown in Figure 14 after hydration for 12 weeks. Sequential repetitions on a single sample showed no measurable difference in the XRD data, so only a single scan is shown. 

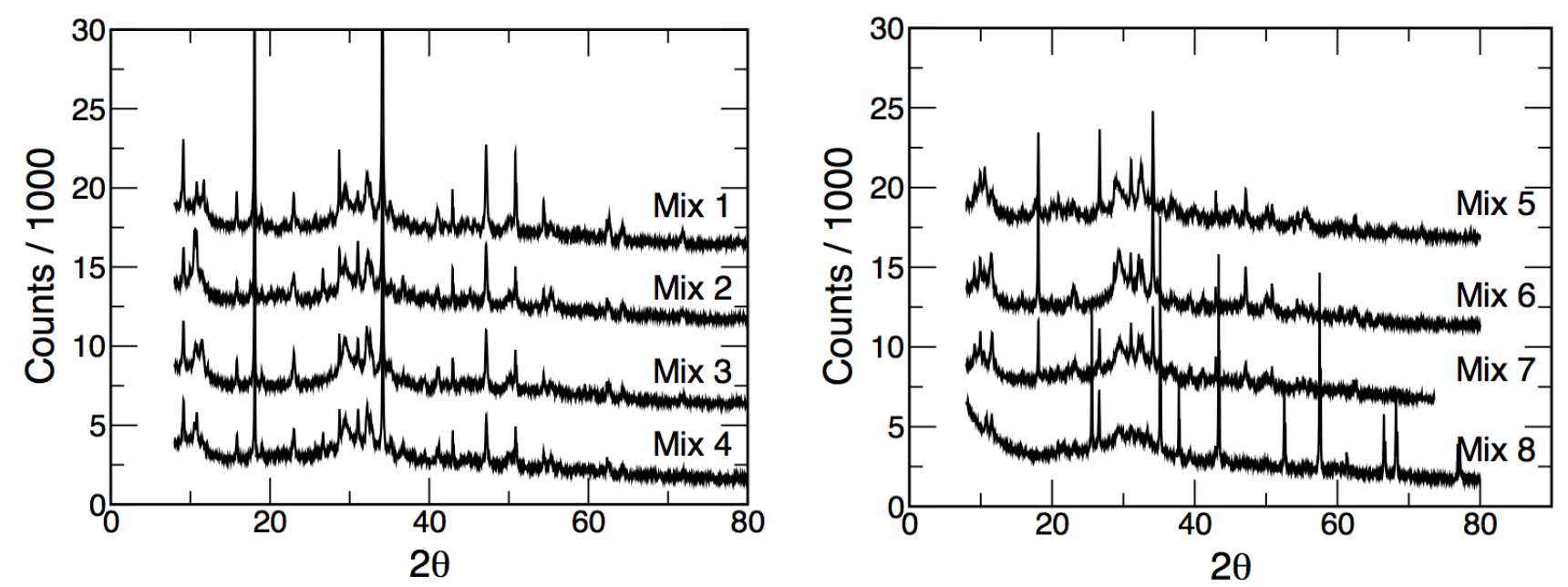

Figure 14: XRD scans for all 8 mixes. The consecutive upper curves are displaced from the immediately lower curve by a value of 5 .

Rietveld analysis was performed using the data from the range $8^{\circ} \leq 2 \theta \leq 80^{\circ}$. The structural model for each cement phase was taken from Stutzman and Leigh [18]. The available structural models for the hydrated phases were obtained from public web sites [19]. The structural model for hemicarbonate was created using structural information from Taylor [20]. The amorphous 'hump' in the range $0^{\circ} \leq 2 \theta \leq$ $40^{\circ}$ was approximated by amorphous silica using the approach of Le Bail [21]. Quartz was the only crystalline phase from the fly ash that remained after 12 weeks of hydration. The final results of the Rietveld analysis are given in Table 6, and the refinement estimated standard deviation for each crystalline phase was rarely greater than 0.002 .

Mix 8 required special consideration. The XRD data range was expanded to $6^{\circ} \leq 2 \theta \leq 80^{\circ}$ to quantify the strätlingite. To accommodate changes in Mix 8 that occurred while drying to prepare for the corundum addition, the amounts of $\mathrm{C}_{2} \mathrm{~S}$ and periclase were assumed to remain unchanged, allowing the Rietveld analysis results to be expressed as a mass fraction of the original material.

Furthermore, the nearly equal mass fractions of unhydrated $\mathrm{C}_{3} \mathrm{~S}$ in both Mix 1 and Mix 8 suggests that the uncertainty in the determination of low mass fraction phases may be greater than the $10 \%$ relative error reported by the Rietveld software. Therefore, phases with mass fractions below approximately $2 \%$ may be better categorized as 'trace'. 
Table 6: Hydrated phase mass fractions after 3 months hydration at $25^{\circ} \mathrm{C}$, as determined by Rietveld analysis. Mix 1 through Mix 7 use the portlandite content (see Table 5) as the internal standard. Mix 8 uses corundum as an internal standard.

\begin{tabular}{|l|l|l|l|l|l|l|l|l|}
\hline & Mix 1 & Mix 2 & Mix 3 & Mix 4 & Mix 5 & Mix 6 & Mix 7 & Mix 8 \\
\hline Amorphous & 0.600 & 0.691 & 0.674 & 0.749 & 0.730 & 0.785 & 0.751 & 0.816 \\
\hline $\mathrm{C}_{3} \mathrm{~S}$ & 0.013 & 0.014 & 0.041 & 0.023 & 0.033 & 0.021 & 0.017 & 0.014 \\
\hline$\beta_{-} \mathrm{C}_{2} \mathrm{~S}$ & 0.060 & 0.037 & 0.037 & 0.027 & 0.040 & 0.014 & 0.028 & 0.016 \\
\hline $\mathrm{C}_{3} \mathrm{~A}$ & 0.002 & 0.001 & & & 0.003 & & 0.001 & 0.008 \\
\hline $\mathrm{C}_{4} \mathrm{AF}$ & 0.027 & 0.017 & 0.019 & 0.011 & 0.009 & 0.006 & 0.013 & 0.013 \\
\hline Portlandite & 0.119 & 0.064 & 0.063 & 0.049 & 0.031 & 0.039 & 0.019 & \\
\hline Ettringite & 0.075 & 0.041 & 0.052 & 0.052 & 0.015 & 0.019 & 0.034 & 0.016 \\
\hline Calcite & 0.014 & 0.014 & 0.018 & 0.019 & 0.011 & 0.024 & 0.016 & 0.013 \\
\hline Monocarbonate & 0.058 & 0.042 & 0.040 & 0.028 & 0.051 & 0.030 & 0.038 & 0.028 \\
\hline Periclase & 0.012 & 0.009 & 0.008 & 0.007 & 0.006 & 0.003 & 0.006 & 0.006 \\
\hline Hemicarbonate & 0.015 & 0.032 & 0.015 & 0.016 & 0.016 & 0.008 & 0.006 & 0.007 \\
\hline Quartz & & 0.015 & 0.003 & 0.010 & 0.025 & 0.002 & 0.017 & 0.026 \\
\hline Monosulfate & 0.007 & 0.018 & 0.008 & 0.011 & 0.029 & 0.018 & 0.028 & 0.018 \\
\hline Hydrotalcite & & 0.004 & 0.024 & & & 0.032 & 0.026 & 0.019 \\
\hline Strätlingite & & & & & & & & 0.009 \\
\hline
\end{tabular}

\subsection{Thermodynamic Calculations}

The thermodynamic calculations require an assumption for the rate of hydration for the slag and the fly ash. To achieve this, the fraction of each supplemental material that was "consumed" was the value that resulted in the best agreement with the measured quantities of the hydration products. Results from the calculations are given in Table 7.

Table 7: Estimated phase mass fractions after 3 months hydration as calculated using the Lothenbach et al. [17] thermodynamic hydration model.

\begin{tabular}{|l|l|l|l|l|l|l|l|l|}
\hline & Mix 1 & Mix 2 & Mix 3 & Mix 4 & Mix 5 & Mix 6 & Mix 7 & Mix 8 \\
\hline Amorphous & 0.362 & 0.544 & 0.531 & 0.605 & 0.673 & 0.652 & 0.796 & 0.886 \\
\hline $\mathrm{C}_{3} \mathrm{~S}$ & 0.026 & 0.016 & 0.016 & 0.016 & 0.012 & 0.012 & 0.007 & 0.002 \\
\hline$\beta_{-} \mathrm{C}_{2} \mathrm{~S}$ & 0.069 & 0.049 & 0.049 & 0.049 & 0.035 & 0.035 & 0.021 & 0.007 \\
\hline $\mathrm{C}_{3} \mathrm{~A}$ & 0.002 & 0.001 & 0.001 & 0.001 & 0.001 & 0.001 & 0.001 & 0.000 \\
\hline $\mathrm{C}_{4} \mathrm{AF}$ & 0.017 & 0.011 & 0.011 & 0.011 & 0.008 & 0.008 & 0.005 & 0.002 \\
\hline Portlandite & 0.127 & 0.054 & 0.064 & 0.013 & 0.030 & 0.027 & 0.006 & \\
\hline Ettringite & 0.144 & 0.080 & 0.109 & 0.100 & 0.041 & 0.079 & 0.045 & 0.017 \\
\hline Calcite & 0.008 & & 0.003 & 0.002 & & & & \\
\hline Monocarbonate & 0.102 & 0.101 & 0.085 & 0.092 & 0.072 & 0.072 & 0.015 & 0.014 \\
\hline Periclase & & & & & & & & \\
\hline Hemicarbonate & & & & & & & 0.056 & \\
\hline Quartz & & & & & & & & \\
\hline Monosulfate & & 0.036 & & & 0.051 & 0.008 & & \\
\hline
\end{tabular}




\begin{tabular}{|l|l|l|l|l|l|l|l|l|}
\hline Hydrotalcite & & & & 0.020 & 0.009 & 0.039 & 0.006 & 0.002 \\
\hline Strätlingite & & & & & & & & 0.037 \\
\hline
\end{tabular}

There is general agreement between the observed and the predicted phases present. The thermodynamic model assumed a greater degree of reactivity for the periclase and the calcite than otherwise expected, and the quantity of quartz could have been approximated by assuming zero reactivity. Although the quantity of each phase differs between the measured and predicted values, this is due, in large part, to uncertainty in estimating the degree of reactivity for each of the supplementary materials. 


\subsection{Image Segmentation}

The approach of developing training sets using processed images and performing the segmentation using the original images was repeated for Mix 1 (OPC paste), Mix 2 (30\% fly ash), and Mix 3 (30\% slag). The BEI image, and the segmented image (using non-processed images for the training set) for all three mixtures are shown in Figure 15, Figure 16, and Figure 17. For all three mixtures, the segmentation process is able to identify the more finely distributed phases within the hardened cement paste.
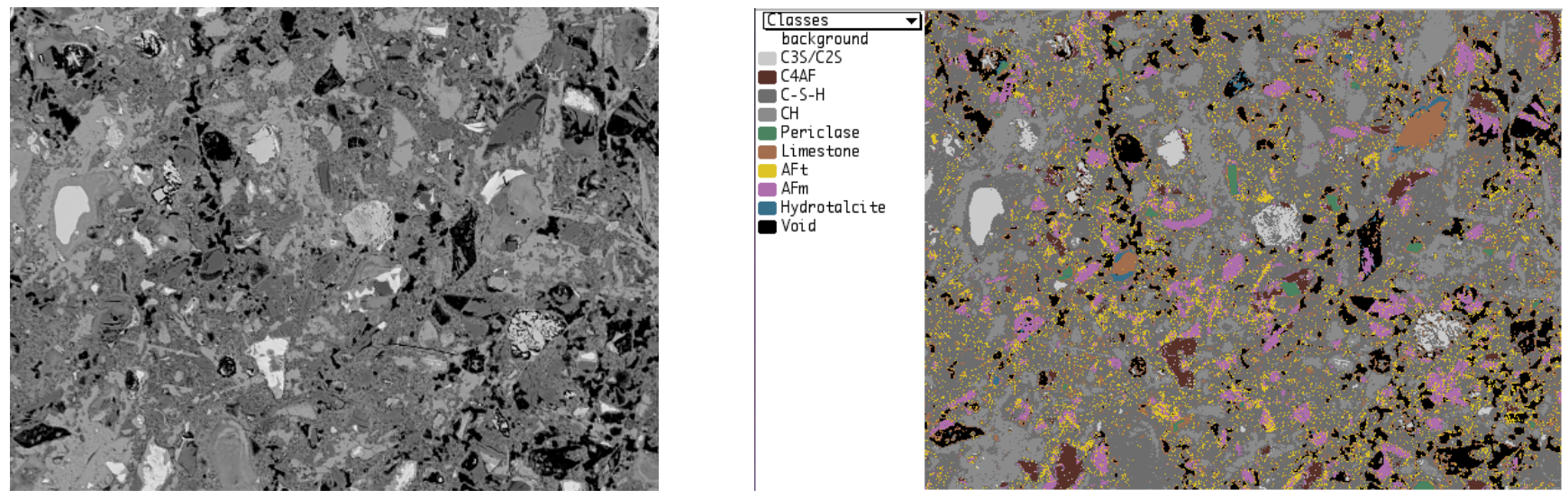

Figure 15. Backscattered electron image (BEI) and segmented image of the fly ash cement paste in Mix 1 after 3 months hydration.
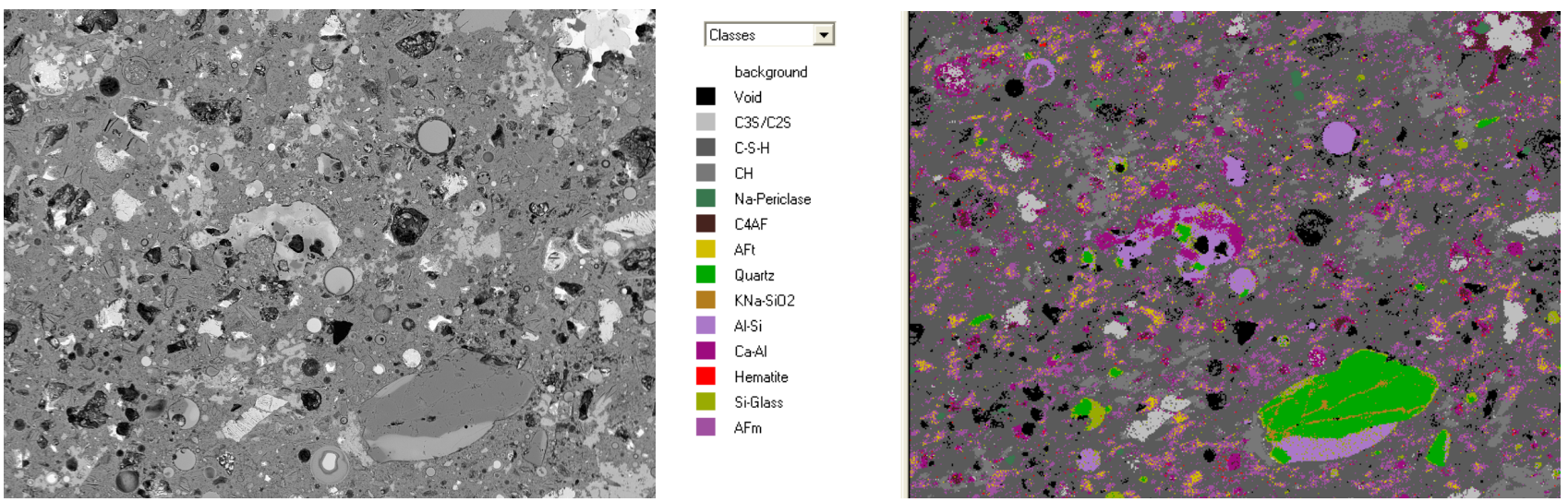

Figure 16. Backscattered electron image (BEI) and segmented image of the fly ash cement paste in Mix 2 after 3 months hydration. 

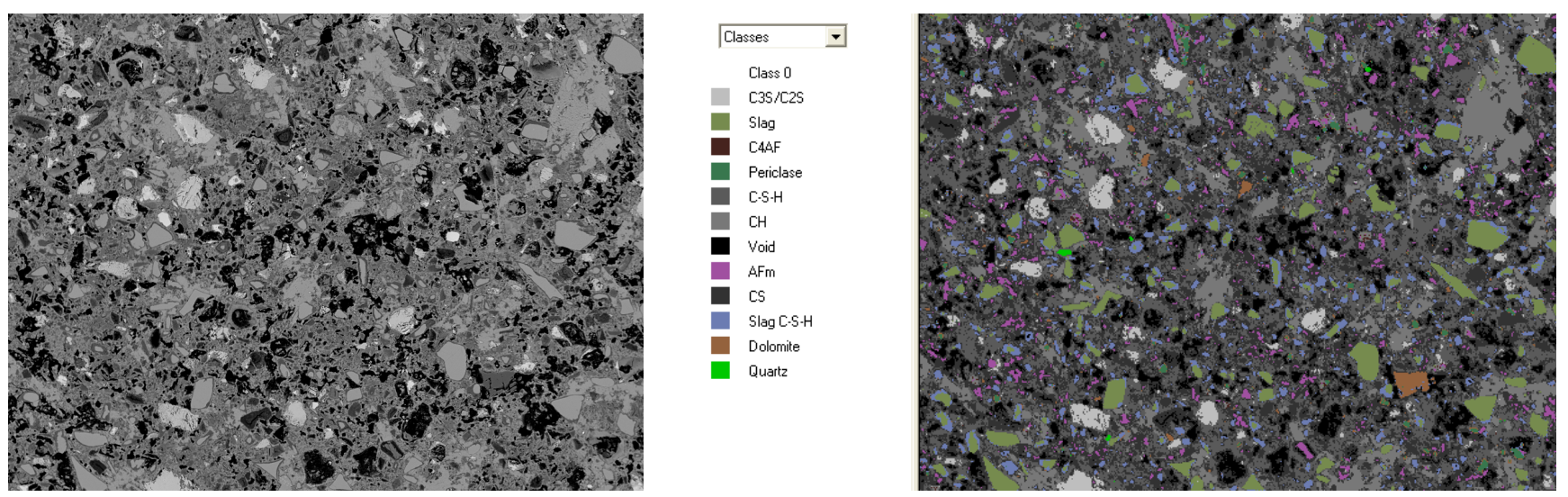

Figure 17. Backscattered electron image (BEI) and segmented image of the slag cement paste in Mix 3 after 3 months hydration.

A comparison of the result for the mass fraction as determined by XRD to the mass fraction estimated from image segmentation is given in Table 8. There is general agreement between the two methods. For the sulfate-bearing phases, however, the difference between the estimated values is nearly a factor of ten for Mix 1 and Mix 2. 
Table 8. Estimated mass fractions from quantitative XRD (QXRD) and imaging.

\section{QXRD \\ Mix $1 \quad \operatorname{Mix} 2 \quad \operatorname{Mix} 3$ \\ Imaging \\ Mix 1 Mix $2 \quad \operatorname{Mix} 3$}

\begin{tabular}{|l|l|l|l|l|l|l|l|}
\hline Amorphous & 0.600 & 0.691 & 0.674 & & 0.572 & 0.666 & 0.693 \\
\hline $\mathrm{C}_{3} \mathrm{~S} / \mathrm{C} 2 \mathrm{~S}$ & 0.073 & 0.051 & 0.078 & & 0.028 & 0.044 & 0.054 \\
\hline $\mathrm{C}_{4} \mathrm{AF}$ & 0.027 & 0.017 & 0.019 & & 0.033 & 0.006 & 0.020 \\
\hline Portlandite & 0.119 & 0.064 & 0.063 & & 0.133 & 0.069 & 0.099 \\
\hline Ettringite & 0.075 & 0.041 & 0.052 & & 0.052 & 0.022 & \\
\hline Periclase & 0.012 & 0.009 & 0.008 & & 0.005 & 0.026 & 0.004 \\
\hline Quartz & & 0.015 & 0.003 & & & 0.048 & \\
\hline Monosulfate & 0.007 & 0.018 & 0.008 & & 0.084 & 0.121 & 0.009 \\
\hline Hydrotalcite & & 0.004 & 0.024 & & & & \\
\hline
\end{tabular}

\subsection{Discussion}

The methods used here for characterizing hydrated phases will require further development and refinement. Using amorphous silica to approximate the amorphous phases is useful in representing the XRD data background, and the results generally agree with SEM image segmentation. Also, using TGA to estimate portlandite content will have limited applicability in the study of blended systems with very little portland cement because hydration processes in these mixes will eventually consume all the portlandite.

The advantage of the image segmentation procedure is the ability to classify a number of amorphous phases. By comparison, the XRD process estimates total amorphous content by subtraction of the crystalline phases. More specifically, XRD can only lump together all amorphous phases, where as image segmentation can classify cementing glassy phases (fly ash or slag) differently from the calcium silicate hydrate gel $(\mathrm{C}-\mathrm{S}-\mathrm{H})$. However, because the effort required for SEM image segmentation is very large in relation to the information obtained, this technique will not be used to characterize the saltstone mixtures.

\subsection{Summary}

Combining thermogravimetric data with X-ray diffraction data shows promise for characterizing the type and quantity of hydrated phases in blended cement systems. The phases identified are consistent with current thermodynamic models, but further research is needed to quantify the rate of reaction of fly ash and slag. Further experimentation is needed, however, to independently validate the quantity of phases observed through XRD and TGA. Image segmentation shows promise in being able to quantity the degree of fly ash and slag hydration, but independent chemical analysis is needed to validate the results. 


\section{SALTSTONE GROUT}

There exist a number of computer tools that can be used to assess the performance of a cementitious barrier. The most useful models are those like 4sight [22] that incorporate the relevant physics and chemistry of the interactions between the material and its environment. These processes include both transport (through a non-ideal aqueous pore solution) and reaction (with ion-exchange, surface complexation, etc.). For these types of models, the material composition (type and quantity of phases) constitutes the initial condition, and the environment (temperature, humidity, dissolved species in the groundwater, etc.) constitutes the (potentially time-dependent) boundary condition.

An important part of the predictive nature of these computer tools is the ability to predict the initial material composition due to hydration. The thermodynamic "hydration models" convert the mineral phase composition of the binding phases and, along with an additional model for the rate of hydration for each phase, predict the type and quantity of phases produced; this differs from a hydration model that can also predict the microstructure. There exist models for the rate that cement phases hydrate [23] and for the rate of slag hydration [17], but there are no reliable models for the rate of fly ash hydration. These models have been validated for mixtures composed mostly of portland cement.

Some engineered barrier applications, however, use cementitious blends composed of very little portland cement, and may use a treated salt solution as the "mix water". The concentrated salt supernate and crystallized saltcake are to be treated and then stabilized as a cementitious saltstone grout [1] formulated by the Savannah River National Laboratory (SRNL) for final disposal in vaults at the Saltstone Disposal Facility at the Savannah River Site (SRS). These grout mixtures may contain as little as $5 \%$ portland cement, with the remainder of the binder being equal portions of (ASTM Class F) fly ash and slag. Moreover, the supernate contains, among other salts, sodium hydroxide, sodium nitrate, and sodium nitrite [24]. Therefore, not only is this solution highly alkaline, it contains nitrates and nitrites, which are typically not found in thermodynamic databases for cementitious systems.

In anticipation of these challenges, the $\mathrm{NRC}$ has become a member of the Cementitious Barriers Partnership (CBP) [25]. The CBP works to improve the understanding, and develop tools for predicting the long-term structural, hydraulic, and chemical performance of cementitious materials and waste forms used primarily in nuclear waste disposal. The CBP objective is to develop a set of computational software tools that are expected to reduce the uncertainties of current methodologies for performance assessment. As part of the CBP program there are software tools for estimating the mineral phase composition of the starting material, but none of these tools have been validated on mixtures having such low portland cement contribution to the total binder.

In support of the CBP program, the National Institute of Standards and Technology (NIST) characterized the mineral composition of a set of pastes that mimic the type of saltstone grout being developed for SRS. These pastes contained the same cement, slag, and fly ash used at SRNL, and the "mix water" was an approximation to the SRNL surrogate waste for physical testing [24] that contains no radionuclides.

The raw materials and the hydrated pastes were characterized using quantitative X-ray powder diffraction (QXRD) and thermogravimetric analysis (TGA) to provide direct estimates of the bulk mineralogical composition and texture of the materials. The pore solution composition was characterized by elemental analysis using inductively-coupled plasma optical emission spectroscopy. The results represent a validation data set for the THAMES [26] microstructural development model that is used to compute realistic transport and mechanical properties for cement paste microstructures as a function of time. 


\subsection{Experimental Plan}

The portland cement, fly ash, and slag, were obtained from SRNL, and the composition of the surrogate waste solution was based on a SRNL report on the properties of the saltstone grouts [24]. These mixtures are different from typical portland cement concrete formulations in two important ways: very low cement content, and a "mix water" that is a concentrated solution. Anticipating the effects due to either of these differences is a formidable challenge to the computer models. To bridge the gap, paste mixtures were developed having two levels of cement content and two levels of "mix water" composition (water or SWS).

In addition, two series of pastes were made having different water:cementitious mass ratio $(w / \mathrm{cm})$. The grout formulated by SRNL [24] had a $w / \mathrm{cm}$ (neglecting the dissolved solids in the waste solution) of 0.60 . At this water content, there can be considerable sedimentation and bleed water. If sedimentation and bleeding do occur, there will be a gradient of properties through the paste, as the effective $w / \mathrm{cm}$ decreases with depth. Therefore, mixtures were also made with a $0.40 \mathrm{w} / \mathrm{cm}$ ratio so that comparisons could be made to systems for where there should have been relatively little bleeding. The binder compositions of all mixture designs considered are given in Table 9, and the composition of the SWS is described below.

Table 9. Binder proportions for mixtures at two water:cementitious material mass ratios $(w / \mathrm{cm})$, neglecting the dissolved salts in the surrogate waste solution. The quantity of cement, fly ash, and slag are designated by the corresponding mass fraction.

\begin{tabular}{|l|l|l|l|l|l|}
\hline $\boldsymbol{w} / \mathbf{c m}$ & Water / SWS & Cement & Fly Ash & Slag & $\begin{array}{l}\text { Sample } \\
\text { Name }\end{array}$ \\
\hline 0.40 & Water & 1.00 & & & $40-0-100$ \\
\hline & SWS & 1.00 & & & $40-1-100$ \\
\hline & SWS & 0.10 & 0.45 & 0.45 & $40-1-055$ \\
\hline & & & & & \\
\hline 0.60 & Water & 1.00 & & & $60-0-100$ \\
\hline & SWS & 1.00 & & & $60-1-100$ \\
\hline & SWS & 0.10 & 0.45 & 0.45 & $60-1-055$ \\
\hline
\end{tabular}

\subsection{Surrogate Waste Solution (SWS)}

The composition of the SWS was based on that used by Dixon et al. [24]. The salts used, and the corresponding concentrations, are given in Table 10. Using the reported solution specific gravity of 1.248 [24], the molar ( $\mathrm{mol} / \mathrm{L})$ concentrations were converted to molal $\left(\mathrm{mol} / \mathrm{kg}_{\mathrm{w}}\right)$ units to facilitate thermodynamic calculations.

Table 10. Composition of the surrogate waste solution; there are $0.8866 \mathrm{~kg}$ of water in each liter of solution.

\begin{tabular}{|l|l|l|}
\hline Salt & $\mathbf{m o l} / \mathbf{L}$ & $\mathbf{m o l} / \mathbf{k g}_{\mathbf{w}}$ \\
\hline $\mathrm{NaOH}$ & 2.866 & 3.233 \\
\hline $\mathrm{NaNO}_{3}$ & 1.973 & 2.225 \\
\hline $\mathrm{NaNO}_{2}$ & 0.485 & 0.547 \\
\hline
\end{tabular}




\begin{tabular}{|l|l|l|}
\hline $\mathrm{Na}_{2} \mathrm{CO}_{3}$ & 0.118 & 0.133 \\
\hline $\mathrm{Na}_{2} \mathrm{SO}_{4}$ & 0.055 & 0.062 \\
\hline $\mathrm{Al}\left(\mathrm{NO}_{3}\right)_{3} \bullet 9 \mathrm{H}_{2} \mathrm{O}$ & 0.114 & 0.129 \\
\hline $\mathrm{Na}_{2} \mathrm{H}_{(}\left(\mathrm{PO}_{4}\right) \bullet 12 \mathrm{H}_{2} \mathrm{O}$ & 0.007 & 0.008 \\
\hline
\end{tabular}

The component composition of the SWS is given in Table 11. The component concentrations are provided to facilitate thermodynamic modeling because the calculations are performed on a component basis.

Table 11. The component composition of the surrogate waste solution. The numbers between parentheses represent the oxidation state; this is the notation used in a number of thermodynamic databases.

\begin{tabular}{|l|l|l|}
\hline Component & Molarity $(\mathbf{m o l} / \mathbf{L})$ & Molality $\left(\mathbf{m o l} / \mathbf{k g}_{\mathbf{w}}\right)$ \\
\hline $\mathrm{Na}$ & 5.684 & 6.411 \\
\hline $\mathrm{N}(5)$ & 2.315 & 2.611 \\
\hline $\mathrm{N}(3)$ & 0.485 & 0.547 \\
\hline $\mathrm{C}$ & 0.118 & 0.133 \\
\hline $\mathrm{S}(6)$ & 0.055 & 0.062 \\
\hline $\mathrm{Al}$ & 0.114 & 0.129 \\
\hline $\mathrm{P}(5)$ & 0.007 & 0.008 \\
\hline $\mathrm{H}$ & 0.007 & 0.008 \\
\hline
\end{tabular}

\subsection{Cementing Materials}

The portland cement, the fly ash, and the slag obtained from SRNL included the certification report that the material producer supplies with the material. The materials were the same as those used to develop the saltstone mixture, and they have been characterized by SRNL [27].

The primary means of characterizing the cementing materials are the oxide contents and the crystalline mineral content. The oxide content can be determined from X-ray fluorescence measurement, and the crystalline phase identification and quantification can be determined from X-ray diffraction coupled with Rietveld analysis.

\subsubsection{Portland Cement}

The portland cement was an ASTM Type I/II containing $1.8 \%$ limestone $\left(93 \%\right.$ as $\left.\mathrm{CaCO}_{3}\right)$. The Blaine fineness was $393 \mathrm{~m}^{2} / \mathrm{kg}$, and the loss on ignition was $1.8 \%$. The chemical composition provided in the mill certificate is given in Table 12 below.

Table 12. Oxide composition of the ASTM Type I/II cement from the mill certificate report based on a single measurement.

\begin{tabular}{|l|l|}
\hline Oxide & Mass Fraction (\%), \\
\hline $\mathrm{CaO}$ & 64.3 \\
\hline $\mathrm{SiO}_{2}$ & 20.3 \\
\hline
\end{tabular}




\begin{tabular}{|l|l|}
\hline $\mathrm{Al}_{2} \mathrm{O}_{3}$ & 5.0 \\
\hline $\mathrm{Fe}_{2} \mathrm{O}_{3}$ & 3.8 \\
\hline $\mathrm{SO}_{3}$ & 3.0 \\
\hline $\mathrm{MgO}$ & 1.2 \\
\hline $\mathrm{CO}_{2}$ & 0.7 \\
\hline $\mathrm{Na}_{2} \mathrm{O}_{e}$ & 0.48 \\
\hline
\end{tabular}

The cement was analyzed to determine the mineral phases present. The analysis was conducted using Xray powder diffraction, according to the standardized procedure described in ASTM C1365 [4]. The results of the analysis are shown in Table 13 below. The detection of syngenite was confirmed by the thermogravimetric analysis (discussed below).

Table 13. Portland cement mineral phase composition as determined by X-ray diffraction with Rietveld analysis (ASTM C1365); uncertainty expresses one standard deviation.

\begin{tabular}{|l|r|}
\hline Phase (XRD) & Mass Fraction (\%) \\
\hline $\mathrm{C}_{3} \mathrm{~S}$ & $56.2 \pm 2.4$ \\
\hline $\mathrm{C}_{2} \mathrm{~S}$ & $15.1 \pm 1.6$ \\
\hline $\mathrm{C}_{3} \mathrm{~A}$ & $3.4 \pm 0.5$ \\
\hline $\mathrm{C}_{4} \mathrm{AF}$ & $13.1 \pm 0.6$ \\
\hline Gypsum & $1.9 \pm 0.3$ \\
\hline Bassanite & $1.0 \pm 0.5$ \\
\hline Calcite & $2.7 \pm 0.4$ \\
\hline Syngenite & $1.7 \pm 0.1$ \\
\hline Portlandite & $1.0 \pm 0.8$ \\
\hline Amorphous & $4.9 \pm 1.4$ \\
\hline
\end{tabular}

Additional analysis of the portland cement was conducted using the TGA data shown in Figure 18. In the figure, the distinguishable peaks for syngenite, portlandite, and limestone are denoted by arrows. For the analysis, the portlandite and limestone peaks are modeled using the symmetrical error function, and the syngenite peak is modeled using the asymmetrical logistic function. 


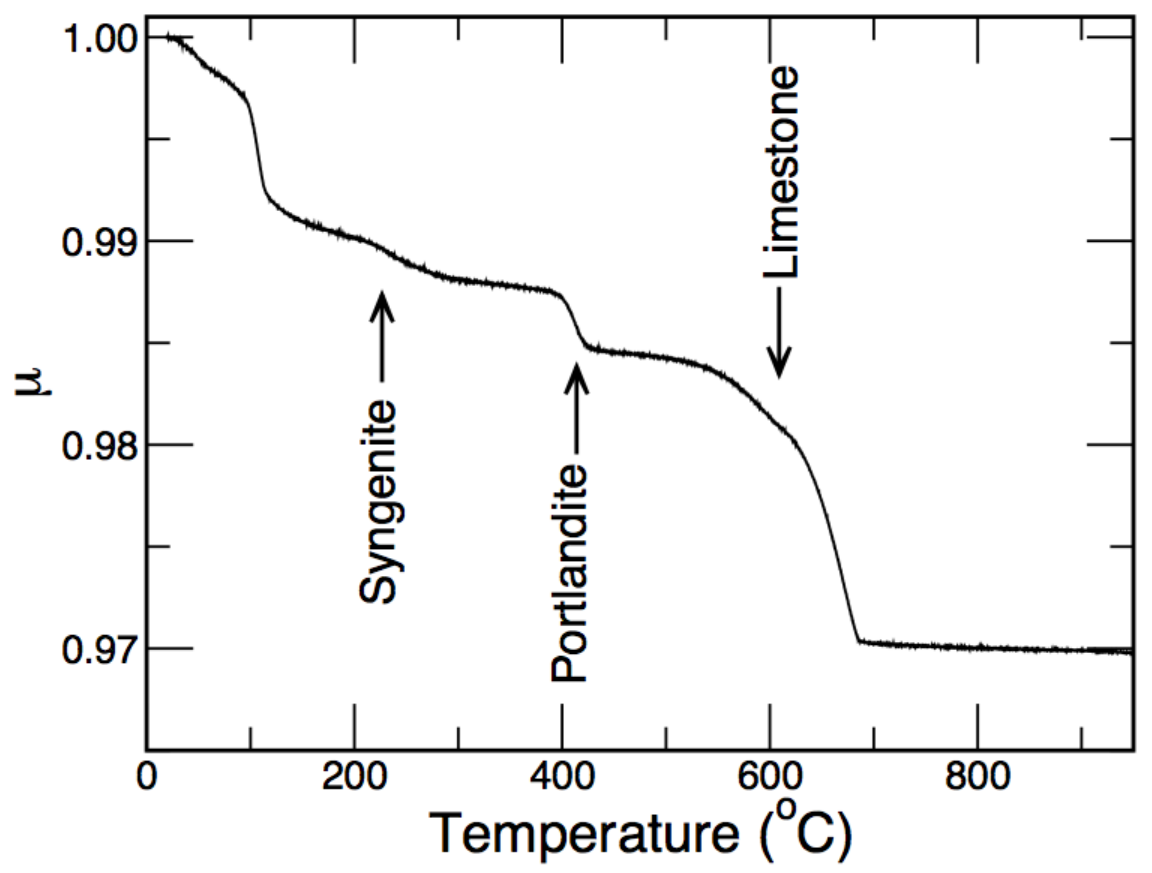

Figure 18. Relative remaining mass $\mu$ as a function of temperature for the portland cement. Individual peaks are labeled; the mass loss near $100^{\circ} \mathrm{C}$ is due to water loss from C-S-H and other hydrated phases.

The presence of syngenite $\left(\mathrm{K}_{2} \mathrm{Ca}\left(\mathrm{SO}_{4}\right)_{2} \cdot\left(\mathrm{H}_{2} \mathrm{O}\right)\right)$ and portlandite $\left(\mathrm{Ca}(\mathrm{OH})_{2}\right)$ suggest that the cement has been exposed to a humid environment for an extended period. The extent to which this has occurred, however, was characterized through a TGA regression analysis. The results of the regression analysis for each peak are shown below in Figure 19 through Figure 21 below.
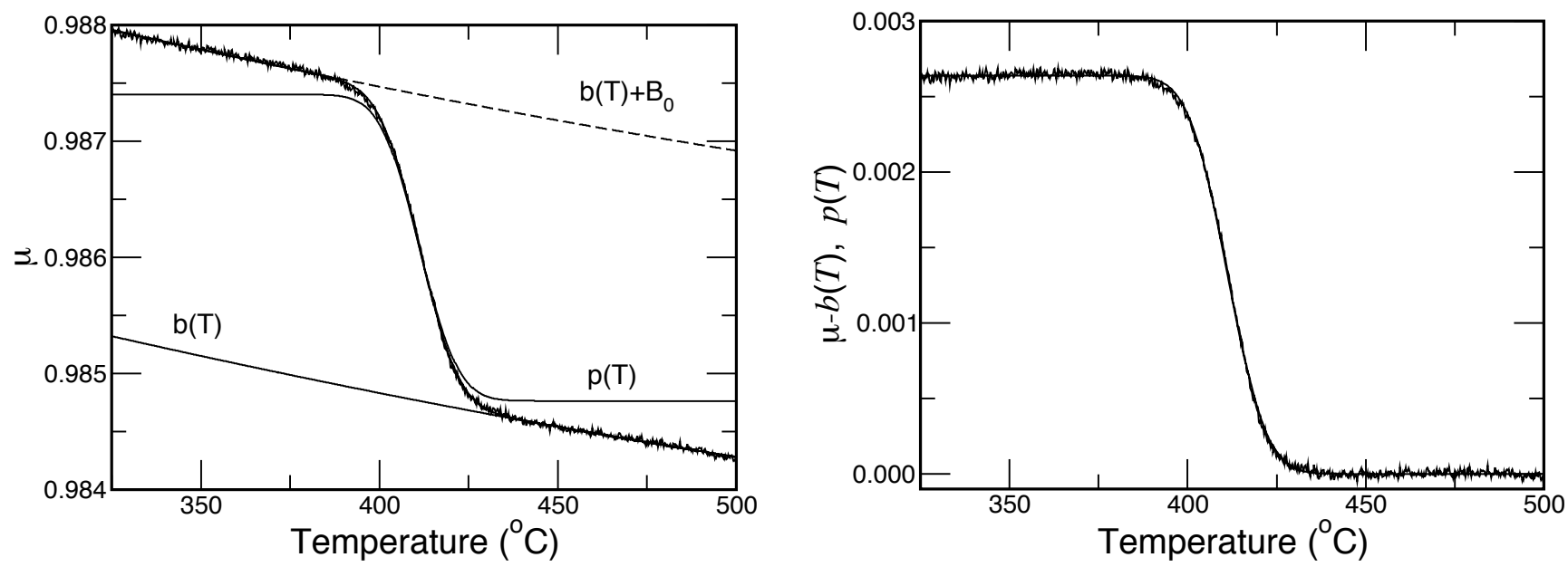

Figure 19. Analysis of the portlandite peak in the cement: (left) regression to the TGA data, showing the background function $b(T)$ and the peak function $p(T)$; (right) the measured data minus the background function, compared with the peak function (the two lie nearly on top of one another). 
The result of the regression of the portlandite peak is shown in Figure 19. The error function was chosen for the peak function because the data appear symmetrical. Upon determining the best fit to the data, the left figure in Figure 19 shows the measured data (fuzzy line), the background function (along the lower flat portion of the curve), the background function plus the parameter $B_{0}$ (dashed line), the peak function $p(T)$, and the overall function $f(T)$; the function $f(T)$ lies nearly on top of the measured data and is difficult to see. The right figure in Figure 19 shows the measured data minus the background function $b(T)$, and the peak function $p(T)$; the two lie nearly on top of one another. For portlandite (74.09268 $\mathrm{g} / \mathrm{mol})$, the mass loss is due to water $(18.01528 \mathrm{~g} / \mathrm{mol})$ evaporation. Therefore, the mass fraction of portlandite is equal to $B_{0}(74.09268 / 18.01528)$.

An advantage of using regression is that the regression software reports estimated parameters, along with the associated uncertainty. Based on the estimated value for $B_{0}$ and its uncertainty, the estimated mass fraction of portlandite was $(0.0107 \pm 0.0002)$, where the uncertainty represents one standard deviation, and the decomposition temperature $T_{0}$ was equal to approximately $411^{\circ} \mathrm{C}$. For comparison purposes, the estimated portlandite mass fraction determined by XRD (Table 13) was $(0.010 \pm 0.008)$.
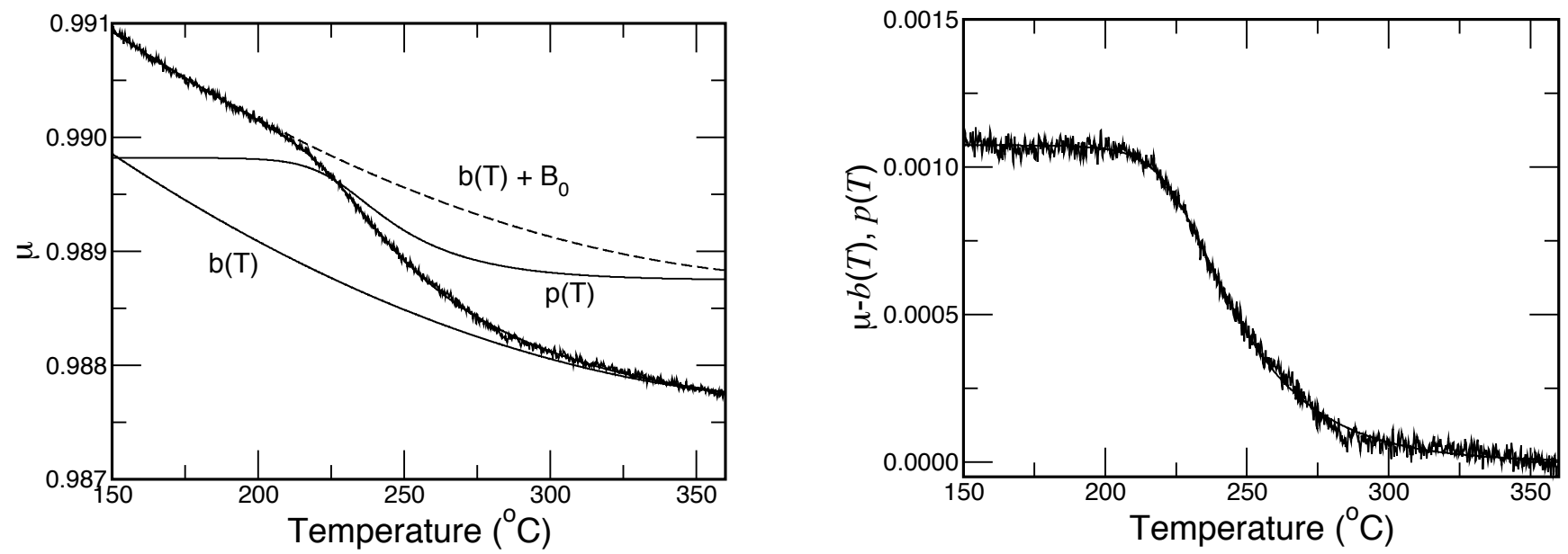

Figure 20. Analysis of the syngenite peak in the cement: (left) regression to the TGA data, showing the background function $b(T)$ and the peak function $p(T)$; (right) the measured data minus the background function, compared with the peak function (the two lie nearly on top of one another).

The result of the regression of the syngenite peak is shown in Figure 20. The curves in Figure 20 are the same as those shown in Figure 19. For these data, however, the peak was fit with the logistic function because the peak was not symmetric. Using the same regression analysis as for the portlandite peak, the estimated mass fraction of syngenite was $(0.0208 \pm 0.0003)$, and the parameter $T_{0}$ was equal to approximately $227^{\circ} \mathrm{C}$. For comparison purposes, the estimated syngenite mass fraction determined by XRD (Table 13) was $(0.017 \pm 0.001)$. 

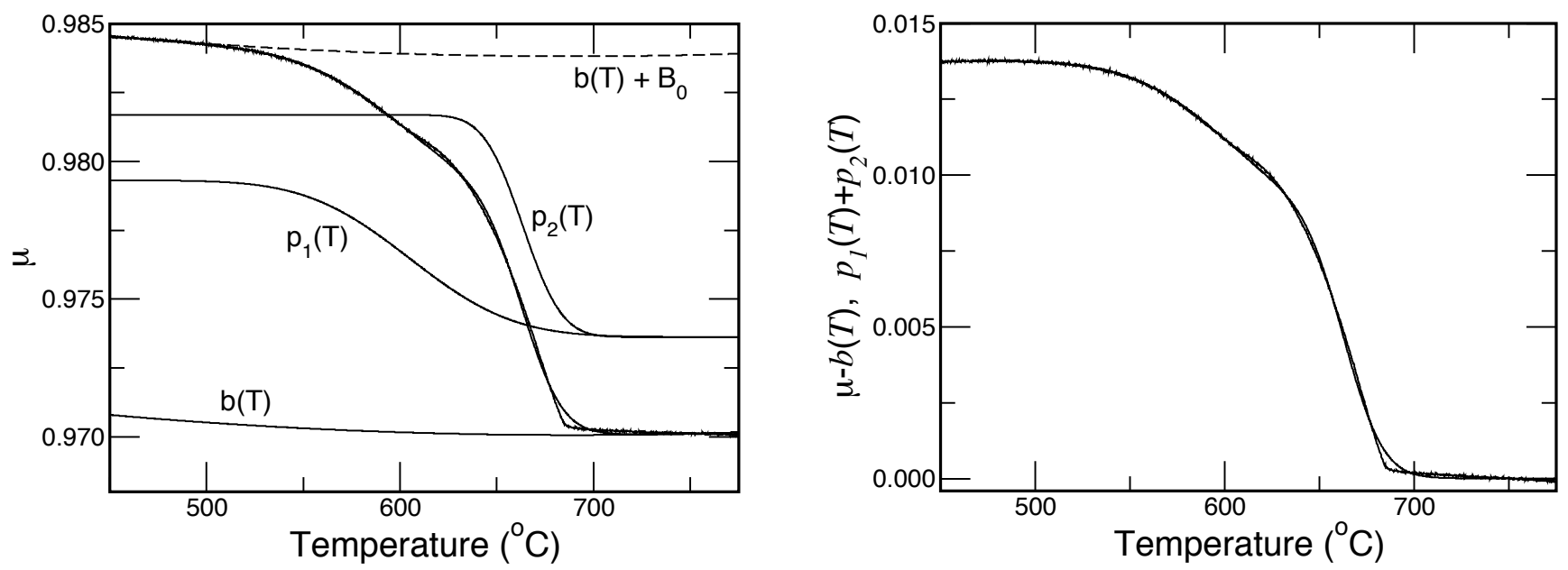

Figure 21. Analysis of the limestone peak in the cement: (left) regression to the TGA data, showing the background function $b(T)$ and the two peak functions $p_{1}(T)$ and $p_{2}(T)$; (right) the measured data minus the background function, compared with the sum of the two peak functions (the two lie nearly on top of one another).

The result of the regression of the limestone peak is shown in Figure 21. The mass loss due to the decomposition of the limestone was resolved into two distinct peak functions, both regressed against individual complementary error functions. This double-peak mass loss is attributed to the presence of a dolomitic limestone. The estimated mass fraction of limestone (as calcite) was $(0.0315 \pm 0.0005)$, and the peak location parameters were approximately $605^{\circ} \mathrm{C}$ and $663{ }^{\circ} \mathrm{C}$. For comparison purposes, the estimated calcite mass fraction determined by XRD (Table 13$)$ was $(0.027 \pm 0.004)$.

\subsubsection{Fly Ash}

The fly ash was an ASTM Class F with a specific gravity of 2.38 , and $17.8 \%$ (by mass) was retained on a \#325 (45 $\mu \mathrm{m})$ sieve. The chemical composition data provided by the material supplier are provided in Table 14 below. According to these values, more than $90 \%$ of the total mass is composed of silicon, aluminum, and iron oxides.

Table 14. Fly ash oxide composition reported in the mill certificate, based on a single measurement.

\begin{tabular}{|l|l|}
\hline Oxide & Mass Fraction (\%) \\
\hline $\mathrm{SiO}_{2}$ & 53.09 \\
\hline $\mathrm{Al}_{2} \mathrm{O}_{3}$ & 27.97 \\
\hline $\mathrm{Fe}_{2} \mathrm{O}_{3}$ & 10.12 \\
\hline $\mathrm{CaO}$ & 1.39 \\
\hline $\mathrm{MgO}$ & 1.63 \\
\hline $\mathrm{SO}$ & 0.10 \\
\hline $\mathrm{Na}_{2} \mathrm{O}_{\mathrm{e}}$ & 0.59 \\
\hline
\end{tabular}


The fly ash was also analyzed at NIST using X-ray powder diffraction to identify and quantify the crystalline mineral composition, and the results are shown in Table 15 below. The major crystalline minerals are mullite and quartz.

Table 15. Fly ash mineral phase composition as determined by X-ray powder diffraction and Rietveld analysis.

\begin{tabular}{|l|l|l|}
\hline Phase (XRD) & $\begin{array}{l}\text { Mass Fraction } \\
(\%)\end{array}$ & $\begin{array}{l}\text { Assumed Chemical } \\
\text { Composition }\end{array}$ \\
\hline Mullite & $18.3 \pm 0.4$ & $\left(\mathrm{~A}_{2} \mathrm{O}_{3}\right)_{2}\left(\mathrm{SiO}_{2}\right)$ \\
\hline Quartz & $7.3 \pm 0.4$ & $\mathrm{SiO}_{2}$ \\
\hline Hematite & $2.2 \pm 0.1$ & $\mathrm{Fe}_{2} \mathrm{O}_{3}$ \\
\hline Magnetite & $1.0 \pm 0.0$ & $\left(\mathrm{Fe}_{3} \mathrm{O}_{4}\right)$ \\
\hline Amorphous & $71.2 \pm 0.8$ & \\
\hline
\end{tabular}

\subsubsection{Slag}

The slag certification report did not include the oxide content, and a lack of any quantifiable peaks in the XRD data suggested that the material lacked crystalline phases.

\subsubsection{Previous Reports}

For comparison purposes, and to provide supplementary information about the slag, the oxide analysis of Harbour et al. [27] for all three materials is repeated in Table 16 below. The values for portland cement and fly ash are in agreement with the mill certificates.

Table 16. Oxide percentages reported by Harbour et al. [27 (Table 3-5)] for the portland cement, the fly ash, and the slag.

\begin{tabular}{|l|l|l|l|l|l|l|}
\hline \multirow{2}{*}{ Oxide } & \multicolumn{2}{|c|}{ Portland Cement } & \multicolumn{2}{c|}{ Fly Ash } & \multicolumn{2}{c|}{ Slag } \\
\cline { 2 - 7 } & Batch 1 & Batch 2 & Batch 1 & Batch 2 & Batch 1 & Batch 2 \\
\hline $\mathrm{Al}_{2} \mathrm{O}_{3}$ & 5.4 & 5.2 & 28.6 & 28.6 & 8.4 & 6.6 \\
\hline $\mathrm{CaO}$ & 64.9 & 63.0 & 0.7 & 0.6 & 38.5 & 35.0 \\
\hline $\mathrm{Fe}_{2} \mathrm{O}_{3}$ & 3.7 & 3.8 & 6.0 & 5.6 & 0.4 & 0.3 \\
\hline $\mathrm{K}_{2} \mathrm{O}$ & 0.5 & 0.7 & 2.6 & 2.5 & 0.3 & 0.5 \\
\hline $\mathrm{MgO}$ & 1.2 & 1.2 & 0.9 & 0.8 & 12.9 & 13.1 \\
\hline $\mathrm{Na}_{2} \mathrm{O}$ & 0.1 & 0.2 & 0.3 & 0.4 & 0.3 & 0.3 \\
\hline $\mathrm{SO}_{3}$ & 3.2 & 3.3 & 0.1 & 0.3 & 1.0 & 2.5 \\
\hline $\mathrm{SiO}_{2}$ & 20.5 & 20.3 & 54.2 & 56.8 & 37.9 & 40.4 \\
\hline $\mathrm{TiO}_{2}$ & 0.3 & 0.3 & 1.6 & 1.4 & 0.4 & 0.3 \\
\hline $\mathrm{Volatiles}$ & 0.0 & 0.0 & 2.5 & 1.4 & 0.0 & 0.0 \\
\hline Total & $\mathbf{9 9 . 8}$ & $\mathbf{9 8 . 0}$ & $\mathbf{9 7 . 5}$ & $\mathbf{9 8 . 4}$ & $\mathbf{1 0 0 . 1}$ & $\mathbf{9 9 . 0}$ \\
\hline
\end{tabular}




\subsection{Mixture Designs}

The saltstone grout to be used is a combination of cement, fly ash, slag, and an alkaline solution for which there is relatively little engineering experience in the concrete construction industry. As a result, hydrated phase models would have to make a dramatic leap between typical mixes used today and the proposed mixture. To help span this conceptual gap, a progressive series of mixture designs was chosen, starting from mixtures that existing models could use as a frame of reference.

The mixture designs were divided between two water:binder (mass basis) ratios. The reference mixtures were ordinary portland cement (OPC) and water. The three spanning mixtures were OPC and synthetic waste solution (SWS), a ternary blend and water, and a ternary blend and SWS. The mixture designs are shown in Table 17 and Table 18, and are proportioned to make approximately $500 \mathrm{~mL}$ of paste.

Table 17. Mixture designs for $w / \mathrm{cm}=0.40$ pastes.

\begin{tabular}{|c|l|l|l|l|}
\hline & \multicolumn{5}{|c|}{ Mass (g) } \\
\hline & $\mathbf{4 0 - 0 - 1 0 0}$ & $\mathbf{4 0 - 1 - 1 0 0}$ & $\mathbf{4 0 - 0 - 0 5 5}$ & $\mathbf{4 0 - 1 - 0 5 5}$ \\
\hline Water & 280.7 & 256.0 & 263.3 & 241.1 \\
\hline $\mathrm{NaOH}$ & 0.0 & 33.9 & 0.0 & 31.9 \\
\hline $\mathrm{NaNO}_{3}$ & 0.0 & 49.5 & 0.0 & 46.7 \\
\hline $\mathrm{NaNO}_{2}$ & 0.0 & 9.9 & 0.0 & 9.3 \\
\hline $\mathrm{Na}_{2} \mathrm{CO}_{3}$ & 0.0 & 3.7 & 0.0 & 3.5 \\
\hline $\mathrm{Na}_{2} \mathrm{SO}_{4}$ & 0.0 & 2.3 & 0.0 & 2.2 \\
\hline $\mathrm{Al}_{2}\left(\mathrm{NO}_{3}\right)_{3} \bullet 9 \mathrm{H}_{2} \mathrm{O}$ & 0.0 & 12.6 & 0.0 & 11.9 \\
\hline $\mathrm{Na}_{2} \mathrm{H}_{2}\left(\mathrm{PO}_{4}\right) \bullet 12 \mathrm{H}_{2} \mathrm{O}$ & 0.0 & 0.7 & 0.0 & 0.7 \\
\hline Cement & 701.8 & 654.7 & 65.8 & 61.7 \\
\hline Fly Ash & 0 & 0.0 & 296.2 & 277.6 \\
\hline Slag & 0 & 0.0 & 296.2 & 277.6 \\
\hline
\end{tabular}

Table 18. Mixture designs for $w / \mathrm{cm}=0.60$ pastes.

\begin{tabular}{|c|l|l|l|l|}
\hline & \multicolumn{5}{|c|}{ Mass (g) } \\
\hline & $\mathbf{6 0 - 0 - 1 0 0}$ & $\mathbf{6 0 - 1 - 1 0 0}$ & $\mathbf{6 0 - 0 - 0 5 5}$ & $\mathbf{6 0 - 1 - 0 5 5}$ \\
\hline Water & 328.8 & 296.4 & 312.7 & 283.0 \\
\hline $\mathrm{NaOH}$ & 0.0 & 39.2 & 0.0 & 37.4 \\
\hline $\mathrm{NaNO}_{3}$ & 0.0 & 57.4 & 0.0 & 54.8 \\
\hline $\mathrm{NaNO}_{2}$ & 0.0 & 11.4 & 0.0 & 10.9 \\
\hline $\mathrm{Na}_{2} \mathrm{CO}_{3}$ & 0.0 & 4.3 & 0.0 & 4.1 \\
\hline $\mathrm{Na}_{2} \mathrm{SO}_{4}$ & 0.0 & 2.7 & 0.0 & 2.6 \\
\hline $\mathrm{Al}_{(}\left(\mathrm{NO}_{3}\right)_{3} \bullet 9 \mathrm{H}_{2} \mathrm{O}$ & 0.0 & 14.6 & 0.0 & 14.0 \\
\hline $\mathrm{Na}_{2} \mathrm{H}_{(}\left(\mathrm{PO}_{4}\right) \bullet 12 \mathrm{H}_{2} \mathrm{O}$ & 0.0 & 0.9 & 0.0 & 0.8 \\
\hline Cement & 547.9 & 505.4 & 52.1 & 48.3 \\
\hline Fly Ash & 0.0 & 0.0 & 234.5 & 217.1 \\
\hline Slag & 0.0 & 0.0 & 234.5 & 217.1 \\
\hline
\end{tabular}


The fresh pastes hydrated under sealed curing conditions, to the extent possible. Each mixture was cast into $25 \mathrm{~mm}$ diameter, $25 \mathrm{~mm}$ tall, cylindrical plastic molds. The molds were sealed in plastic bags, and the samples were demolded after 24 hours, placed into airtight plastic jars, and stored at $25^{\circ} \mathrm{C}$ until the time of testing. The $w / \mathrm{cm}=0.60$ pastes were rotated (at approximately 1 rotation every 10 seconds) during the first 24 hours, and then demolded. The demolded samples were placed into sealed highdensity polyethylene (HDPE) jars and stored in a walk-in environmental chamber maintained at $25^{\circ} \mathrm{C}$.

\subsection{Results}

\subsubsection{Calorimetry}

The calorimetry results for these mixtures are shown in Figure 22 and are similar to the results from the previous study shown in Figure 12. The ordinary portland cement (OPC) systems (0-100) displayed the common overlapping peaks. The OPC pastes containing SWS (1-100) were accelerated by the alkalinity of the SWS, as one would expect. The saltstone mixtures (1-055) exhibited a heat peak at approximately the same time as the OPC peak, but the peak was much lower and much wider. The water and ternary blend is only included for the $0.40 \mathrm{w} / \mathrm{cm}$ mixture because the corresponding $0.60 \mathrm{w} / \mathrm{cm}$ mixture did not react appreciably during the same time frame (as might be expected). The $0.40 \mathrm{w} / \mathrm{cm}$ water and ternary blend paste exhibits a significantly delayed peak, suggesting that the material would remain in a liquid state for a very long time.
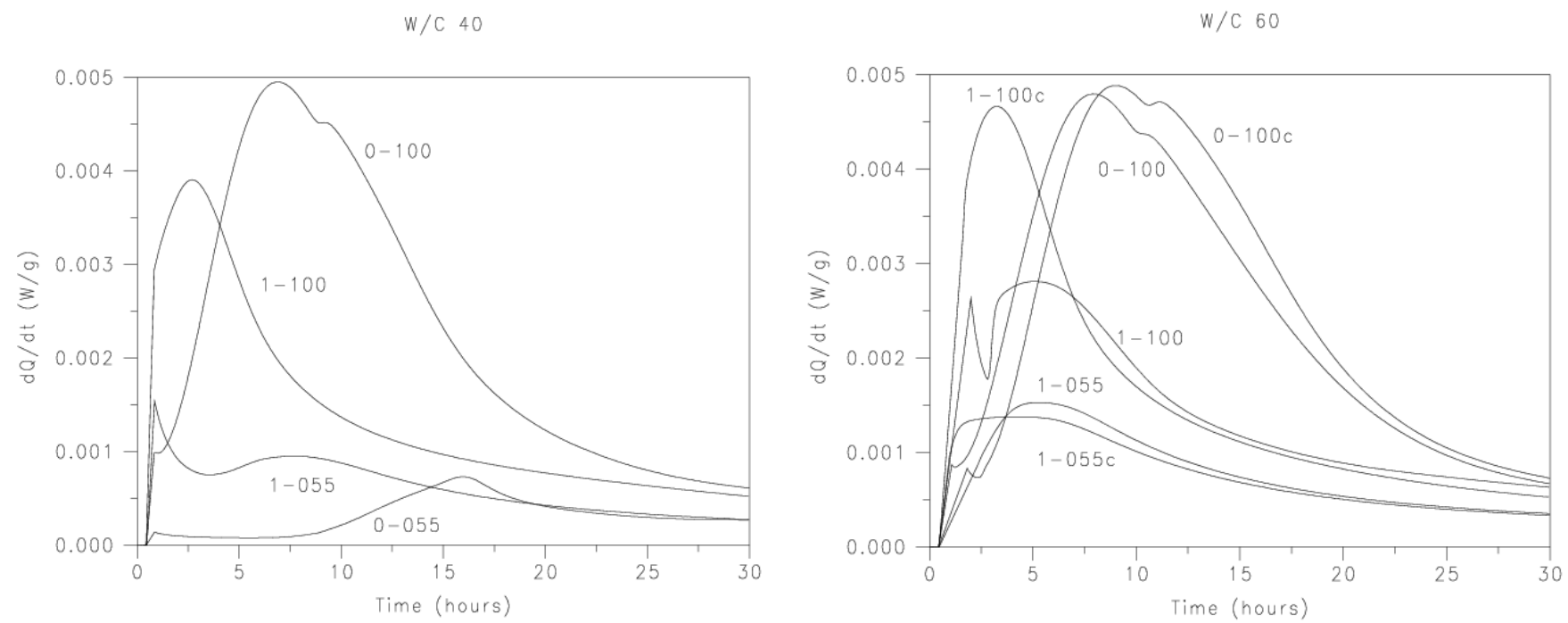

Figure 22. Heat generation rates (W/g) as a function of time (hours) for the $0.40 \mathrm{w} / \mathrm{cm}$ pastes (left) and the $0.60 \mathrm{w} / \mathrm{cm}$ pastes (right).

Because the blended systems made with water (0-055) were so significantly delayed in the hydration, data from these mixtures is omitted from the subsequent results. The very low portland cement content contributed to a very low alkalinity that delayed the hydration of the Class F fly ash and the slag. Therefore, there is very little to glean from any subsequent analysis of these systems. 


\subsubsection{Thermogravimetric Analysis}

The hydrated pastes were cut on a diamond saw, using ethanol as a lubricant, to create discs that were $1 \mathrm{~mm}$ to $2 \mathrm{~mm}$ thick. These discs were gently broken into pieces using a mortar and pestle. Two of these pieces were selected (total mass approximately $50 \mathrm{mg}$ ) and placed into the TGA sample holder.

The TGA data for the mixtures are shown in Figure 23 through Figure 25. Each figure shows a series of TGA curves for a particular mixture, with each curve representing a different age. The large peak below $250{ }^{\circ} \mathrm{C}$ is the loss of free water and the decomposition of most of the hydration products. The peak between $400{ }^{\circ} \mathrm{C}$ and $500{ }^{\circ} \mathrm{C}$ is due to portlandite $\left(\mathrm{Ca}(\mathrm{OH})_{2}\right)$ decomposition. The barely perceptible peak at $650{ }^{\circ} \mathrm{C}$ in Figure 23 is due to limestone calcination.
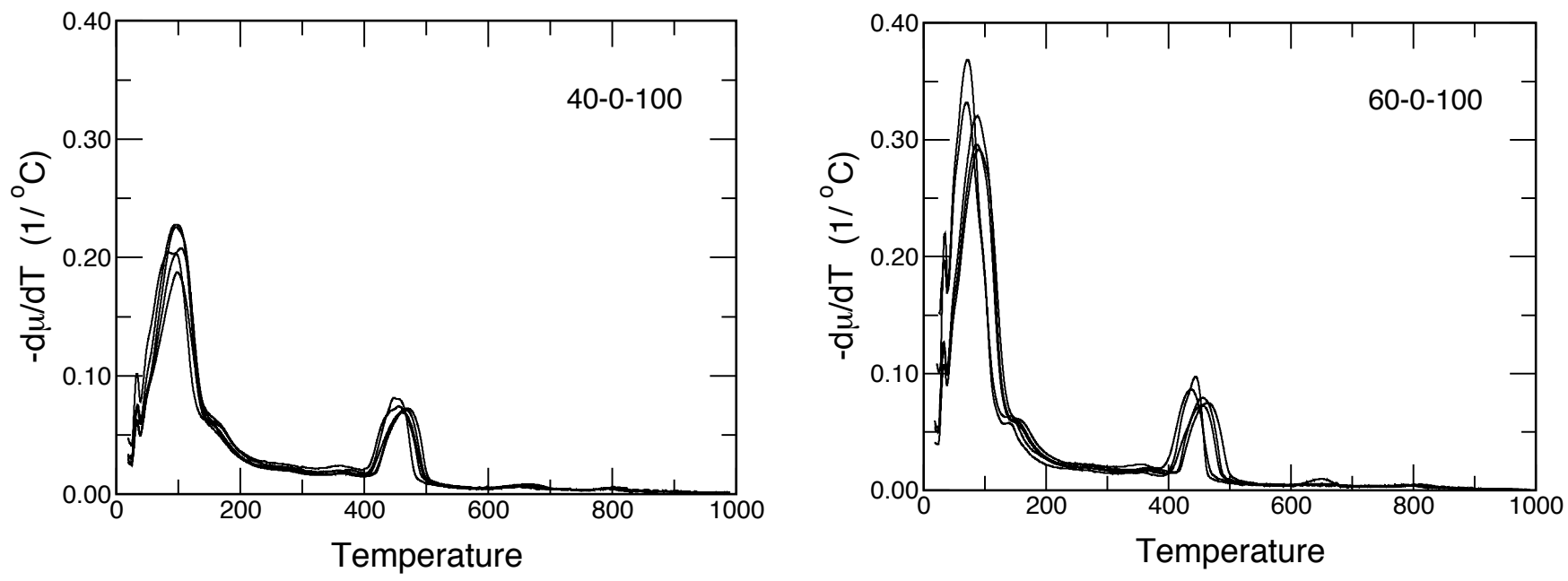

Figure 23. Differential relative mass loss $(\mathrm{d} \mu / \mathrm{d} T)$ as a function of temperature $\left({ }^{\circ} \mathrm{C}\right)$ for pastes made with portland cement and water: $w / \mathrm{cm}=0.4$ (left); $w / \mathrm{cm}=0.60$ (right). Each line corresponds to a different age: $7 \mathrm{~d}, 14 \mathrm{~d}, 28 \mathrm{~d}$, and $56 \mathrm{~d}$.
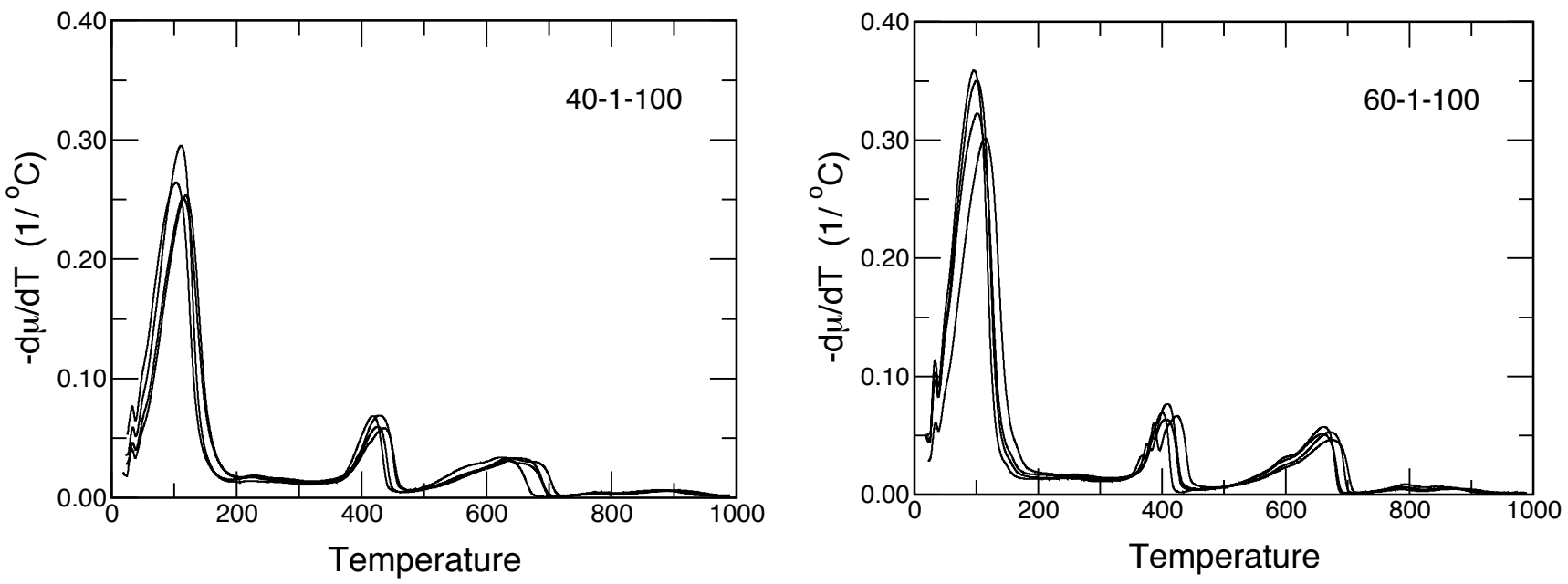

Figure 24. Differential relative mass loss $(\mathrm{d} \mu / \mathrm{d} T)$ as a function of temperature $\left({ }^{\circ} \mathrm{C}\right)$ for pastes made with portland cement and surrogate waste solution: $w / \mathrm{cm}=0.4$ (left); $w / \mathrm{cm}=0.60$ (right). Each line corresponds to a different age: $7 \mathrm{~d}, 14 \mathrm{~d}$, and $28 \mathrm{~d}$. 
The portlandite content of the OPC mixtures were estimated using the process described previously, and the results are given in Table 19. The regression process reports an uncertainty for the mass loss that is propagated to the estimated portlandite content. After 8 weeks of hydration at $25^{\circ} \mathrm{C}$, the mass fraction of portlandite is relatively constant.

Table 19. Portlandite mass fraction, as determined by TGA analysis, for the four portland cement mixtures. The uncertainty represents the measurement uncertainty having a coverage factor of one standard deviation.

\begin{tabular}{|l|l|l|l|l|} 
Age & $\mathbf{4 0 - 0 - 1 0 0}$ & $\mathbf{6 0 - 0 - 1 0 0}$ & $\mathbf{4 0 - 1 - 1 0 0}$ & $\mathbf{6 0 - 1 - 1 0 0}$ \\
\hline $7 \mathrm{~d}$ & $0.1321 \pm 0.0003$ & $0.1350 \pm 0.0004$ & $0.1050 \pm 0.0028$ & $0.1146 \pm 0.0000$ \\
\hline $14 \mathrm{~d}$ & $0.1375 \pm 0.0005$ & $0.1502 \pm 0.0007$ & $0.1081 \pm 0.0016$ & $0.1224 \pm 0.0006$ \\
\hline 28d & $0.1350 \pm 0.0003$ & $0.1568 \pm 0.0006$ & $0.1248 \pm 0.0013$ & $0.1416 \pm 0.0009$ \\
\hline $56 \mathrm{~d}$ & $0.1433 \pm 0.0004$ & $0.1502 \pm 0.0004$ & $0.1370 \pm 0.0009$ & $0.1458 \pm 0.0008$ \\
\hline
\end{tabular}

The TGA data for the mixtures that were composed of the ternary mixtures are shown in Figure 25. Because of the supplemental mineral admixtures present, there are no peaks corresponding to portlandite. Moreover, there would be far too little limestone present to use it as an internal standard.
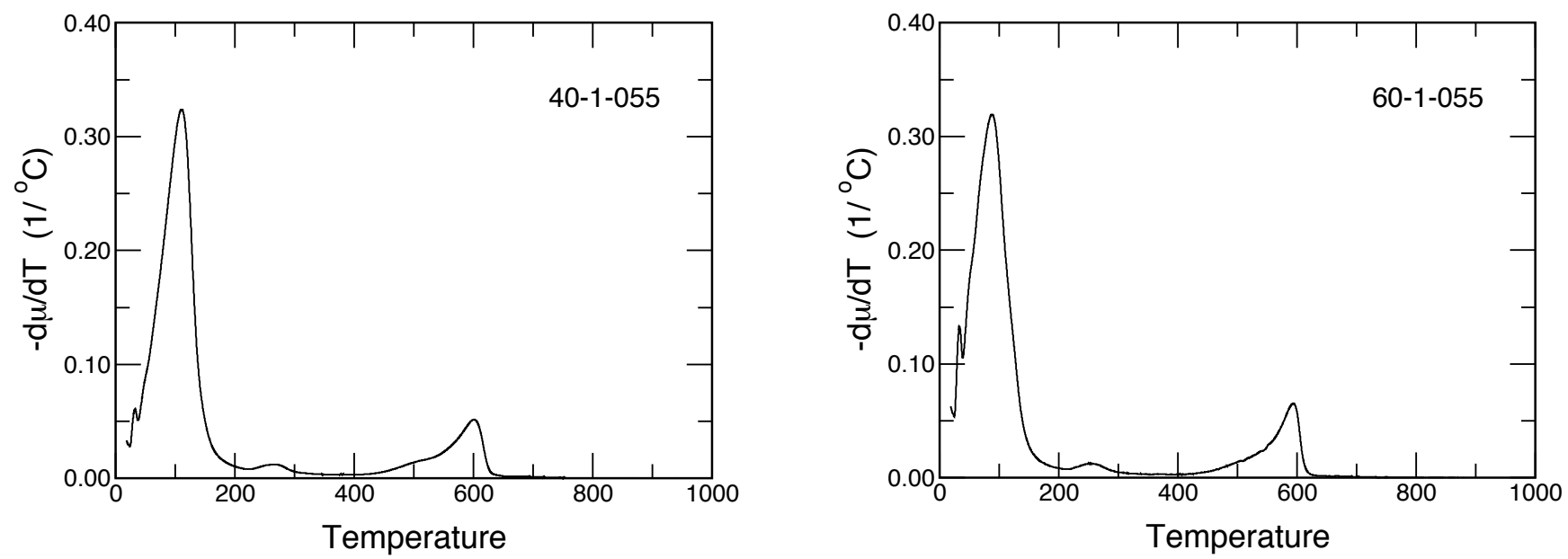

Figure 25. Differential relative mass loss $(-\mathrm{d} \mu / \mathrm{d} T)$ as a function of temperature $\left({ }^{\circ} \mathrm{C}\right)$ for pastes made with portland cement paste, fly ash, slag, and surrogate waste solution: $w / \mathrm{cm}=0.4$ (left); $w / \mathrm{cm}=0.60$ (right). Each line corresponds to a different age: $7 \mathrm{~d}, 14 \mathrm{~d}$, and $28 \mathrm{~d}$.

For the samples containing the SWS, there is a significant peak located near $600{ }^{\circ} \mathrm{C}$ that does not appear in samples without the SWS. Upon studying the corresponding X-ray diffraction data for these samples, it was determined that these peaks correspond to the decomposition of nitratine (sodium nitrate). The temperature at which this mass loss occurred was consistent with reported decomposition temperatures [28]. 


\subsubsection{X-ray Powder Diffraction}

The X-ray powder diffraction samples were cut from the smaller cylindrical samples using a diamond saw with ethanol as the lubricant. A circular disc approximately $2 \mathrm{~mm}$ thick was cut from the specimen, and the tested surface was gently polished with a 600 -grit abrasive paper using ethanol as the lubricant. The polished sample was mounted onto a sample holder, and the sample was rotated to maximize the sampling area. The X-ray diffraction data for the different mixtures, with the data from each age offset from one another, are shown in Figure 26 through Figure 28 below. 

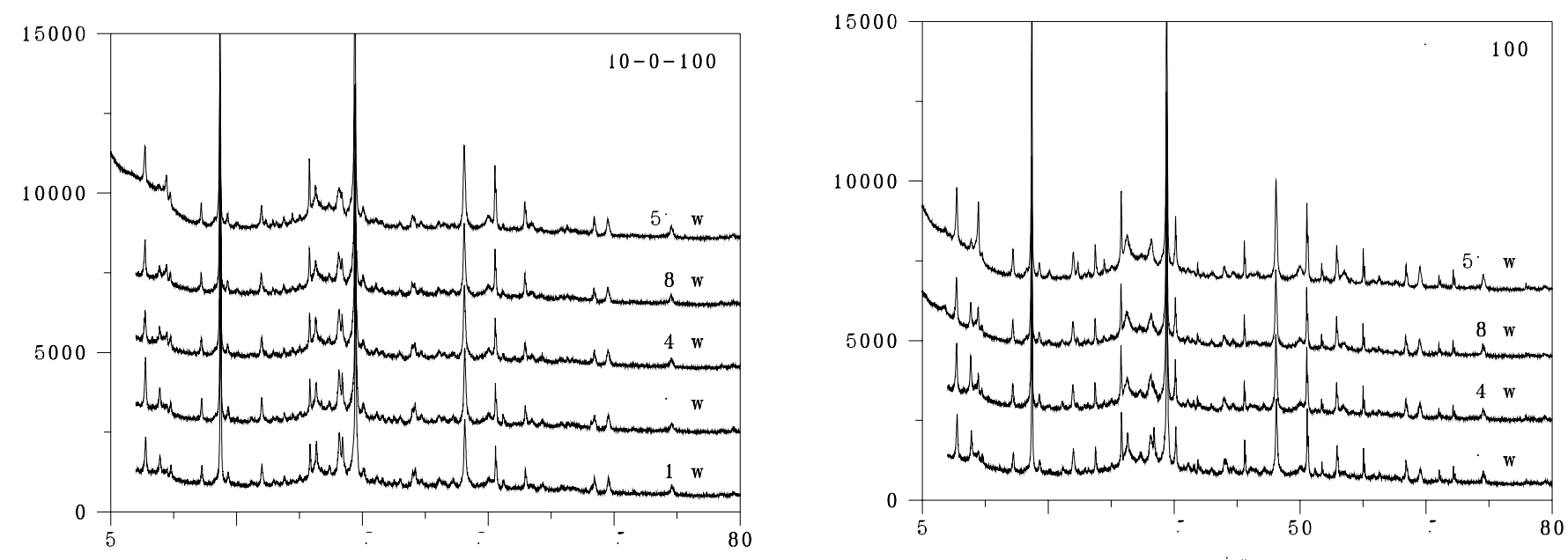

Figure 26. X-ray powder diffraction data showing counts as a function of angle $2 \theta$ for pastes made with portland cement and water: $w / \mathrm{cm}=0.4$ (left); $w / \mathrm{cm}=0.60$ (right). Data after $7 \mathrm{~d}$ are offset for comparison purposes.

A number of the peaks appearing in the ordinary portland cement pastes in Figure 26 also appear in the portland cement and SWS mixtures in Figure 27. The most prominent peaks are the portlandite peaks near $18^{\circ} 2 \theta$ and $35^{\circ} 2 \theta$. Also, although the monocarbonate peaks (below $12^{\circ} 2 \theta$ ) appear in both of these mixtures, the effect of the SWS is to suppress these peaks.

$40-1-100$

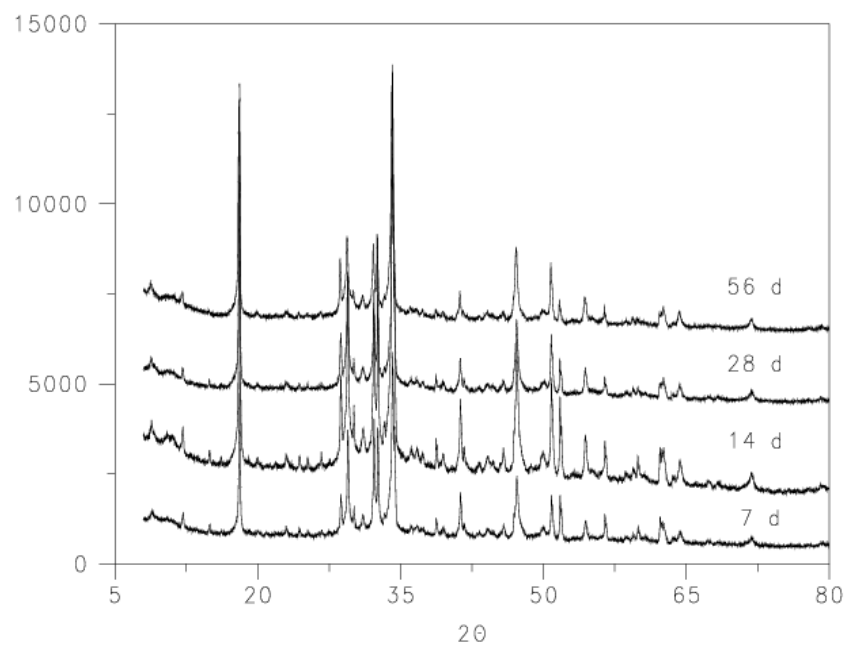

$60-1-100$

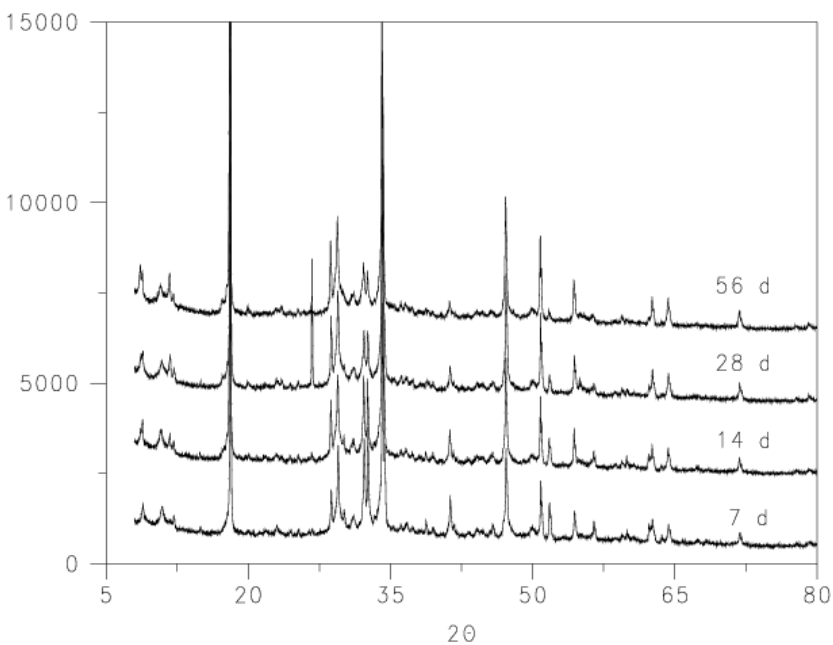

Figure 27. X-ray powder diffraction data showing counts as a function of angle $2 \theta$ for pastes made with portland cement and surrogate waste solution: $w / \mathrm{cm}=0.4$ (left); $w / \mathrm{cm}=0.60$ (right). Data after $7 \mathrm{~d}$ are offset for comparison purposes. 
$40-1-055$

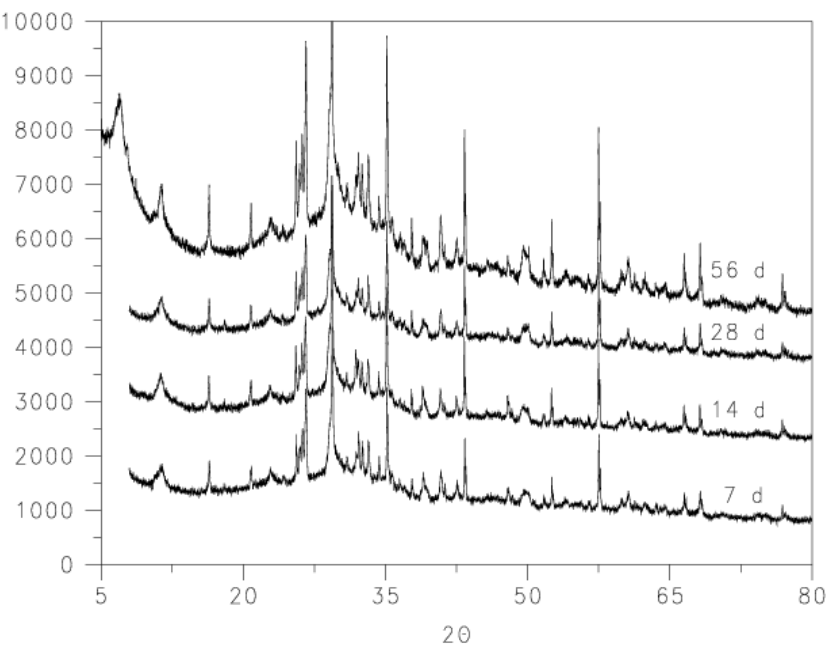

$60-1-055 c 2$

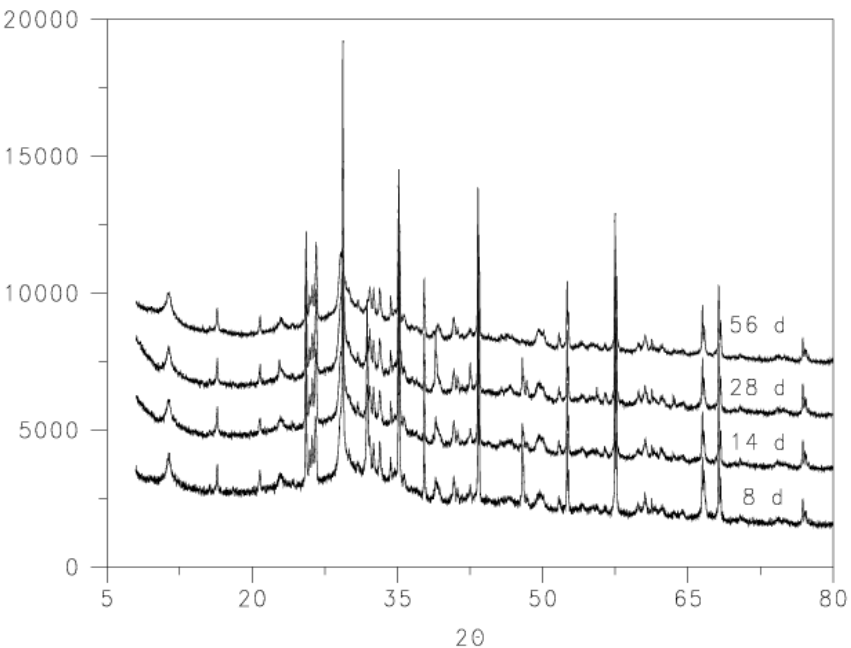

Figure 28. X-ray powder diffraction data showing counts as a function of angle $2 \theta$ for pastes made with portland cement, fly ash, slag, and surrogate waste solution: $w / \mathrm{cm}=0.4$ (left); $w / \mathrm{cm}=0.60$ (right). Data after $7 \mathrm{~d}$ are offset for comparison purposes.

The data in Figure 28 for specimens having both low portland cement content and SWS exhibit had certain unique features. The higher glass content of these specimens is evident by the more prominent "hump" between $20^{\circ} 2 \theta$ and $35^{\circ} 2 \theta$. Moreover, the structure of the peaks below $12^{\circ} 2 \theta$ has changed in character: the two peaks have become one peak, and an extension of the scan angle (uppermost scan on the left side of Figure 28) reveals yet another "peak". The peak near $12^{\circ} 2 \theta$ is in a location that is consistent with tobermorite, but the peak width is much broader than would be expected for tobermorite. The peak found near $6^{\circ} 2 \theta$ has not been identified, and further study is needed.

The excessive peaks near $30^{\circ} 2 \theta$ and $35^{\circ} 2 \theta$ correspond to nitratine [29]. These peaks were consistent with the appearance of the TGA peaks near $600{ }^{\circ} \mathrm{C}$. The existence of nitratine was consistent with chemical shrinkage (consumption of free water) during hydration that would increase the concentration of nitrate species, possibly bringing it near a concentration sufficient to precipitate nitratine because the initial sodium nitrate concentration within the SWS was already very large. A subsequent analysis of the hydrated system by successive rapid XRD scans is discussed below.

\subsubsection{Nitratine}

Further analysis was made of the peak near $29^{\circ} 2 \theta$. In hydrated systems made from only portland cement, the broader peak near this angle would be attributed to an "ordered" C-S-H, or to calcite (for a cement made with limestone). The "sharp" peak that extends above the broader peak is consistent with the presence of nitratine (sodium nitrate) [29]. A contribution from nitratine in the XRD data is consistent with the appearance of the TGA peaks near $600^{\circ} \mathrm{C}$. To determine whether the nitratine existed within the hardened paste prior to sample preparation, repeated rapid XRD scans were conducted on a freshly cut specimen (mixture 60-1-055 after 16 weeks of hydration), and the results are shown in Figure 28. The six successive scans shown in the figure are each 20 minutes apart, representing a total duration of approximately 100 minutes. The growing nitratine peaks are located near $29^{\circ} 2 \theta, 32^{\circ} 2 \theta$, and $39^{\circ} 2 \theta$; the precipitation of nitratine leads to preferred orientation due to its rhombohedral habit. Moreover, the estimated nitratine mass fraction, based on Rietveld analysis, was less than $3 \%$ for the scan with the 
most prominent nitratine peak, so the XRD method is sensitive to nitratine. Given that each of the scans in the previous XRD figures occurred over a span of 80 minutes, the height of the nitratine peak in those scans was a function of how long the specimen was exposed to the laboratory environment prior to being analyzed by XRD. Therefore, it was concluded that the appearance of nitratine peaks in both the TGA and the XRD data are artifacts of the sample drying during testing, and not due to the presence of nitratine within the paste prior to testing.

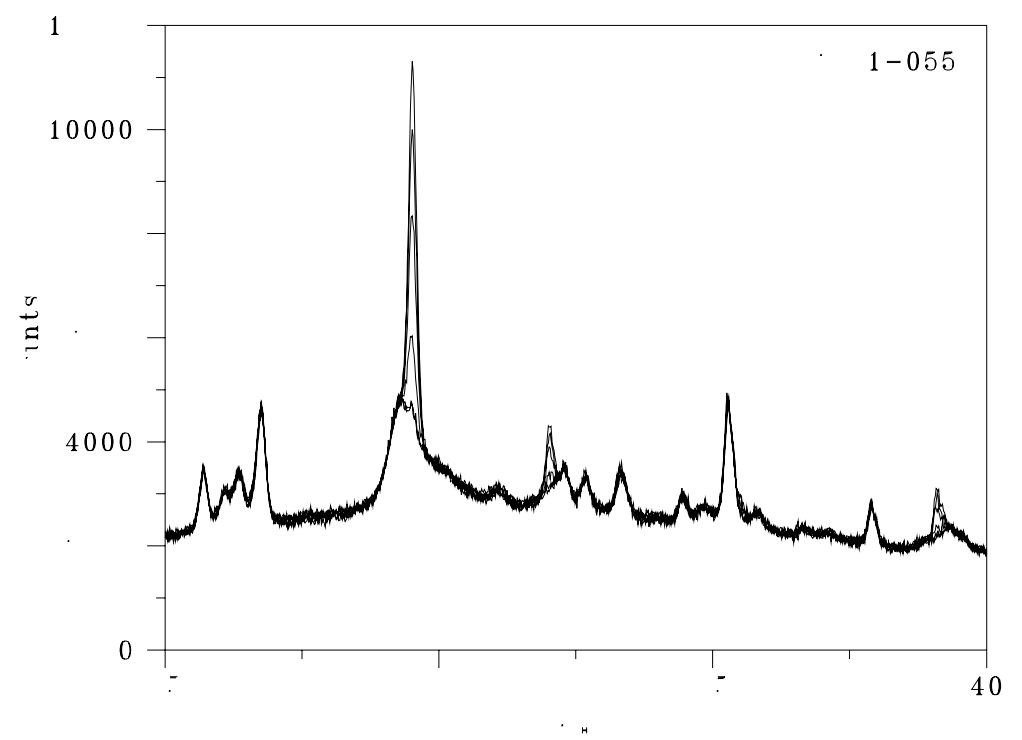

Figure 29. Six successive X-ray powder diffraction scans of the 60-1-055 mixture after 16 weeks of hydration. Successive scans are 20 minutes apart. The nitratine peaks are near $29^{\circ} 2 \theta, 32^{\circ} 2 \theta$, and $39^{\circ} 2 \theta$.

\subsubsection{Rietveld Analysis}

The results of the Rietveld analyses are shown in Table 20 below. One important observation is that the phases that were identified are commonly seen in different types of cementitious materials that have been studied in the past. Another important observation is the extent of sulfate hydration phases in the saltstone mixtures. Particularly, there are relatively normal quantities of ettringite and monocarbonate present, even though the SWS contained a significant quantity of sulfate. It is quite likely that the high $\mathrm{pH}$ (which suppresses the calcium and aluminum concentrations in the pore solution), coupled with the high ionic strength of pore solution, contributed to decreased ettringite and monocarbonate precipitation. 
Table 20. Results of Rietveld analysis for the six mixtures. The values reported are the mass fractions, and the numbers in parentheses represent the uncertainty (one standard deviation) in the last two digits.

\begin{tabular}{|c|c|c|c|c|c|c|c|c|c|c|}
\hline 40-0-100 & \multicolumn{2}{|c|}{$7 d$} & \multicolumn{2}{|c|}{ 14d } & \multicolumn{2}{|c|}{ 28d } & \multicolumn{2}{|c|}{ 56d } & \multicolumn{2}{|c|}{$12 w$} \\
\hline Alite & 0.0494 & (34) & 0.0499 & (32) & 0.0369 & (31) & 0.0291 & (29) & 0.0303 & $(28)$ \\
\hline Belite & 0.0886 & $(60)$ & 0.0588 & (48) & 0.0623 & (53) & 0.0443 & (46) & 0.0298 & (39) \\
\hline \multicolumn{11}{|l|}{ Aluminate } \\
\hline Ferrite & 0.0844 & (61) & 0.0835 & (65) & 0.0835 & (61) & 0.0826 & (59) & 0.0690 & $(54)$ \\
\hline Portlandite & 0.1321 & $(32)$ & 0.1375 & (43) & 0.1350 & $(40)$ & 0.1433 & (34) & 0.1390 & (33) \\
\hline Ettringite & 0.0679 & $(30)$ & 0.0812 & (36) & 0.0647 & (34) & 0.0719 & (32) & 0.0712 & (31) \\
\hline Hemicarbonate & 0.0148 & (12) & 0.0171 & (12) & 0.0160 & (14) & 0.0161 & (14) & 0.0107 & (13) \\
\hline Monocarbonate & 0.0384 & (59) & 0.0365 & (45) & 0.0458 & (47) & 0.0582 & (45) & 0.0502 & (41) \\
\hline Amorphous & 0.5244 & (118) & 0.5357 & (113) & 0.5559 & (112) & 0.5546 & (104) & 0.5998 & (96) \\
\hline
\end{tabular}

\begin{tabular}{|c|c|c|c|c|c|c|c|}
\hline 60-0-100c & $7 d$ & $14 d$ & \multicolumn{2}{|c|}{ 28d } & \multicolumn{2}{|c|}{ 56d } & $12 w$ \\
\hline Alite & & $0.0366 \quad(32)$ & 0.0354 & (46) & 0.0184 & $(48)$ & \\
\hline Belite & & 0.0740 & 0.0347 & (65) & 0.0411 & (78) & \\
\hline Aluminate & & $0.0028 \quad(12)$ & 0.0029 & (12) & 0.0024 & (11) & \\
\hline Ferrite & & $0.0764 \quad(57)$ & 0.0778 & $(62)$ & 0.0727 & (57) & \\
\hline Portlandite & & 0.1406 & 0.1441 & (40) & 0.1448 & (32) & \\
\hline Ettringite & & 0.0788 & 0.0839 & $(35)$ & 0.0909 & (34) & \\
\hline Hemicarbonate & & 0.0207 & 0.0237 & $(12)$ & 0.0176 & (11) & \\
\hline Monocarbonate & & 0.0521 & 0.0664 & (44) & 0.0705 & (39) & \\
\hline Corundum & & 0.0579 & 0.0520 & (21) & 0.0562 & $(20)$ & \\
\hline Amorphous & & 0.4600 & 0.4792 & $(125)$ & 0.4853 & $(126)$ & \\
\hline
\end{tabular}

\begin{tabular}{|l|ll|lll|ll|lll|ll|}
\hline $\mathbf{4 0 - 1 - 1 0 0}$ & $\mathbf{7 d}$ & & $\mathbf{1 4 d}$ & $\mathbf{2 8 d}$ & $\mathbf{5 6 d}$ & & $\mathbf{1 2 w}$ \\
\hline Alite & 0.1275 & $\mathbf{( 4 3 )}$ & 0.1206 & $(41)$ & 0.0896 & $(36)$ & 0.0735 & $(30)$ & 0.0576 & $(27)$ \\
\hline Belite & 0.0604 & $(65)$ & 0.0443 & $(55)$ & 0.0605 & $(51)$ & 0.0385 & $(41)$ & 0.0285 & $(32)$ \\
\hline Aluminate & 0.0029 & $(11)$ & 0.0039 & $(10)$ & 0.0046 & $(10)$ & 0.0039 & $(99)$ & & \\
\hline Ferrite & 0.0569 & $(59)$ & 0.0576 & $(57)$ & 0.0593 & $(55)$ & 0.0603 & $(54)$ & 0.0532 & $(49)$ \\
\hline Portlandite & 0.1050 & $(33)$ & 0.1081 & $(32)$ & 0.1248 & $(39)$ & 0.1370 & $(37)$ & 0.1222 & $(33)$ \\
\hline Ettringite & 0.0044 & $(26)$ & 0.0038 & $(20)$ & 0.0096 & $(35)$ & 0.0032 & $(28)$ & 0.0117 & $(36)$ \\
\hline Hemicarbonate & & & & & 0.0053 & $(12)$ & 0.0065 & $(13)$ & 0.0027 & $(13)$ \\
\hline Monocarbonate & & & & & 0.0199 & $(38)$ & 0.0189 & $(45)$ & 0.0109 & $(44)$ \\
\hline Amorphous & 0.6429 & $(107)$ & 0.6617 & $(97)$ & 0.6517 & $(107)$ & 0.6836 & $(140)$ & 0.7268 & $(93)$ \\
\hline
\end{tabular}

\begin{tabular}{|l|ll|ll|lll|ll|l|}
\hline $\mathbf{6 0 - 1 - 1 0 0 c}$ & $\mathbf{7 d}$ & & $\mathbf{1 4 d}$ & $\mathbf{2 8 d}$ & & $\mathbf{5 6 d}$ & & $\mathbf{1 6 w}$ \\
\hline Alite & 0.1010 & $(40)$ & 0.0639 & $(34)$ & 0.0499 & $(31)$ & 0.0375 & $(66)$ & \\
\hline Belite & 0.0551 & $(67)$ & 0.0556 & $(75)$ & 0.0427 & $(75)$ & 0.0060 & $(23)$ & \\
\hline Aluminate & & & & & & & & & \\
\hline Ferrite & 0.0687 & $(60)$ & 0.0449 & $(69)$ & 0.0441 & $(58)$ & 0.0435 & $(59)$ & \\
\hline Portlandite & 0.1085 & $(34)$ & 0.1122 & $(37)$ & 0.1184 & $(36)$ & 0.1258 & $(38)$ & \\
\hline Ettringite & 0.0043 & $(29)$ & 0.0108 & $(39)$ & 0.0023 & $(18)$ & 0.0043 & $(31)$ & \\
\hline
\end{tabular}




\begin{tabular}{|l|ll|ll|ll|ll|l|}
\hline Hemicarbonate & 0.0109 & $(15)$ & 0.0071 & $(14)$ & 0.0084 & $(14)$ & 0.0057 & $(13)$ & \\
\hline Monocarbonate & 0.0568 & $(44)$ & 0.0530 & $(49)$ & 0.0543 & $(47)$ & 0.0492 & $(41)$ & \\
\hline Corundum & 0.0513 & $(22)$ & 0.0431 & $(22)$ & 0.0407 & $(19)$ & 0.0421 & $(19)$ & \\
\hline Amorphous & 0.5364 & $(130)$ & 0.6084 & $(143)$ & 0.6324 & $(128)$ & 0.6942 & $(124)$ & \\
\hline
\end{tabular}

\begin{tabular}{|c|c|c|c|c|c|}
\hline $40-1-055 c$ & $7 d$ & 14d & 28d & 56d & $16 w$ \\
\hline Alite & 0.0216 & $0.0216 \quad(24)$ & $0.0209 \quad(26)$ & $0.0170 \quad(56)$ & \\
\hline Belite & $0.0069 \quad(24)$ & $0.0041 \quad(25)$ & $0.0026 \quad(27)$ & $0.0059 \quad(36)$ & \\
\hline \multicolumn{6}{|l|}{ Aluminate } \\
\hline Ferrite & 0.0174 & 0.0103 & 0.0105 & $0.0136 \quad$ (32) & \\
\hline \multicolumn{6}{|l|}{ Portlandite } \\
\hline \multicolumn{6}{|l|}{ Ettringite } \\
\hline Hemicarbonate & 0.0077 & 0.0094 & $0.0091 \quad$ (14) & $0.0092 \quad(16)$ & \\
\hline Monocarbonate & 0.0208 & $0.0164 \quad(36)$ & $0.0203 \quad(38)$ & $0.0165 \quad$ (35) & \\
\hline Corundum & 0.0449 & 0.0449 & 0.0449 & $0.0449 \quad(61)$ & \\
\hline Quartz & 0.0289 & 0.0216 & 0.0234 & 0.0232 & \\
\hline Mullite 2:1 & 0.0638 & 0.0509 & 0.0543 & 0.0541 & \\
\hline Amorphous & 0.8250 & 0.8594 & 0.8522 & 0.8539 & \\
\hline
\end{tabular}

\begin{tabular}{|l|ll|lll|ll|lll|l|}
\hline $\mathbf{6 0 - 1 - 0 5 5 c}$ & $\mathbf{7 d}$ & $\mathbf{1 4 d}$ & $\mathbf{2 8 d}$ & $\mathbf{5 6 d}$ & $\mathbf{1 6 w}$ \\
\hline Alite & 0.0261 & $(30)$ & 0.0200 & $(34)$ & 0.0259 & $(30)$ & 0.0192 & $(18)$ & \\
\hline Belite & 0.0090 & $(99)$ & 0.0072 & $(99)$ & 0.0072 & & 0.0052 & $(99)$ & \\
\hline Aluminate & & & & & & & & & \\
\hline Ferrite & 0.0056 & $(30)$ & 0.0060 & $(26)$ & 0.0067 & $(24)$ & 0.0048 & $(31)$ & \\
\hline Portlandite & & & & & & & & & & & \\
\hline Ettringite & & & & & & & & & \\
\hline Hemicarbonate & 0.0081 & $(14)$ & 0.0086 & $(17)$ & 0.0079 & $(13)$ & 0.0141 & $(18)$ & \\
\hline Monocarbonate & 0.0143 & $(41)$ & 0.0108 & $(35)$ & 0.0148 & $(38)$ & 0.0134 & $(45)$ & \\
\hline Corundum & 0.0890 & $(46)$ & 0.0890 & $(14)$ & 0.0890 & $(34)$ & 0.0890 & $(44)$ & \\
\hline Quartz & 0.0164 & $(13)$ & 0.0173 & $(28)$ & 0.0173 & $(15)$ & 0.0178 & $(12)$ & \\
\hline Mullite 2:1 & 0.0378 & $(27)$ & 0.0423 & $(67)$ & 0.0385 & $(35)$ & 0.0413 & $(27)$ & \\
\hline Amorphous & 0.8238 & $(128)$ & 0.6685 & $(136)$ & 0.5447 & $(118)$ & 0.8255 & $(127)$ & \\
\hline
\end{tabular}

\subsubsection{Pores Solution Analysis}

The results from the pore solution analyses of the OPC pastes appear in Table 21 and Table 22. The limited number of observations from the $0.40 \mathrm{w} / \mathrm{cm}$ OPC paste is due, in part, to the limited ability to extract useable samples from these relatively low $w / \mathrm{cm}$ systems. By comparison, the $0.60 \mathrm{w} / \mathrm{cm}$ OPC pastes yielded useable samples after 113 days of hydration. 
Table 21. Pore solution composition of the $0.40 \mathrm{w} / \mathrm{cm}$ paste made with only portland cement; numbers in parentheses indicate one standard deviation of uncertainty.

\begin{tabular}{|l|l|l|}
\hline \multirow{2}{*}{} & \multicolumn{2}{|c|}{$\begin{array}{c}\mathbf{4 0 - 0 - 1 0 0} \\
(\mathbf{m m o l} / \mathbf{k g w})\end{array}$} \\
\hline Element & 7 days & $\mathbf{1 6}$ days \\
\hline $\mathrm{K}$ & $463.3(2.8)$ & $407.2(1.7)$ \\
\hline $\mathrm{Na}$ & $141.6(1.3)$ & $167.35(0.86)$ \\
\hline $\mathrm{S}$ & $12.48(0.42)$ & $14.41(0.04)$ \\
\hline $\mathrm{Ca}$ & $3.63(0.11)$ & $1.924(0.023)$ \\
\hline $\mathrm{Al}$ & $0.079(0.005)$ & $0.0910(0.0015)$ \\
\hline
\end{tabular}

Table 22. Pore solution composition of the $0.60 \mathrm{w} / \mathrm{cm}$ paste made with only portland cement; numbers in parentheses indicate one standard deviation of uncertainty.

\begin{tabular}{|l|l|l|l|l|l|}
\hline \multirow{2}{*}{} & \multicolumn{5}{|c|}{$\begin{array}{c}\text { 60-0-100 } \\
\text { (mmol/kgw) }\end{array}$} \\
\hline Element & 8 days & 16 days & 28 days & 113 days & 360 days \\
\hline $\mathrm{K}$ & $262.1(3.0)$ & $230.1(1.8)$ & $250.6(1.5)$ & $281.1(1.2)$ & \\
\hline $\mathrm{Na}$ & $73.74(0.47)$ & $98.05(0.92)$ & $169.32(0.99)$ & $101.77(0.14)$ & \\
\hline $\mathrm{S}$ & $3.24(0.11)$ & $4.327(0.078)$ & $8.11(0.21)$ & $4.194(0.057)$ & \\
\hline $\mathrm{Ca}$ & $3.112(0.026)$ & $2.396(0.026)$ & $2.761(0.027)$ & $2.765(0.041)$ & \\
\hline $\mathrm{Al}$ & $0.069(0.002)$ & $0.0637(0.0003)$ & $0.0141(0.0019)$ & $0.0752(0.0018)$ & \\
\hline $\mathrm{Mg}$ & & & $0.0085(.0001)$ & & \\
\hline
\end{tabular}

The results from the pore solution analyses of the saltstone waste forms appear in Table 23 and Table 24. For saltstone waste form samples, the challenge in collecting usable samples was the converse of the OPC pastes. The solid microstructure developed sufficiently slowly that useable samples could not be obtained until there was sufficient mechanical strength to resist the entire sample from flowing through the outlet tube on the die. For the $0.40 \mathrm{w} / \mathrm{cm}$ waste forms, usable samples were not attainable until after $14 \mathrm{~d}$ hydration, and the $0.60 \mathrm{w} / \mathrm{cm}$ waste forms did not yield usable samples until after $90 \mathrm{~d}$ hydration. The advantage of this slower microstructural development was that samples could be obtained at later ages than for the OPC pastes. In the case of the $0.6 \mathrm{w} / \mathrm{cm}$ waste form, samples were obtained out past one year of hydration.

Table 23. Pore solution composition of the $0.40 \mathrm{w} / \mathrm{cm}$ paste made with fly ash, slag, and surrogate waste solution; numbers in parentheses indicate one standard deviation of uncertainty.

\begin{tabular}{|l|l|l|l|l|}
\hline & \multicolumn{4}{|c|}{$\begin{array}{c}\text { 40-1-055 } \\
\text { (mmol/kgw) }\end{array}$} \\
\hline Element & 14 days & $\begin{array}{l}\text { 34 days } \\
\text { (HNO3) }\end{array}$ & $\begin{array}{l}\text { 34 days (DI } \\
\text { Water) }\end{array}$ & 86 days \\
\hline $\mathrm{K}$ & $186.1(2.5)$ & $211.4(3.8)$ & $198.5(1.9)$ & $238.9(4.9)$ \\
\hline $\mathrm{Na}$ & $2482 .(46)$. & $3380 .(48)$. & $3478 .(63)$. & $3284 .(16)$. \\
\hline $\mathrm{S}$ & $167.7(1.3)$ & $181.0(2.0)$ & $186.5(3.9)$ & $197.4(6.4)$ \\
\hline $\mathrm{Ca}$ & $0.335(0.006)$ & $0.151(.002)$ & $0.179(.005)$ & $0.205(0.002)$ \\
\hline $\mathrm{Al}$ & - & & & - \\
\hline $\mathrm{Si}$ & & $88.7(1.5)$ & $90.78(0.37)$ & \\
\hline
\end{tabular}


Table 24. Pore solution composition of the $0.60 \mathrm{w} / \mathrm{cm}$ paste made with fly ash, slag, and surrogate waste solution; numbers in parentheses indicate one standard deviation of uncertainty.

\begin{tabular}{|l|l|l|l|l|l|}
\hline \multicolumn{5}{|l|}{} & \multicolumn{5}{|c|}{$\begin{array}{l}\text { 60-1-055 } \\
\text { (mmol/kgw) }\end{array}$} \\
\hline Element & 91 days & $\begin{array}{l}\text { 126 days } \\
\text { (HNO3) }\end{array}$ & $\begin{array}{l}\text { Water) } \\
\text { 391 (DI }\end{array}$ & $\begin{array}{l}\text { 391 days } \\
\text { (HNO3) }\end{array}$ & $\begin{array}{l}\text { 391 days (DI } \\
\text { Water) }\end{array}$ \\
\hline $\mathrm{K}$ & $152.4(6.3)$ & $199.4(1.7)$ & $198.13(.82)$ & $235.88(.81)$ & $237.66(.58)$ \\
\hline $\mathrm{Na}$ & $3267 .(30)$. & $3260 .(40)$. & $3311 .(44)$. & $3287 .(45)$. & $3381 .(79)$. \\
\hline $\mathrm{S}$ & $172.0(7.0)$ & $186.2(1.4)$ & $201.8(1.3)$ & $226.6(2.1)$ & $245.4(1.6)$ \\
\hline $\mathrm{Ca}$ & $1.154(0.009)$ & $0.546(0)$ & $0.262(.003)$ & $1.67(.11)$ & $0.195(.003)$ \\
\hline $\mathrm{Al}$ & - & & & & \\
\hline $\mathrm{Si}$ & & $128.90(.35)$ & $139.11(.22)$ & $78.73(.29)$ & $85.31(.23)$ \\
\hline
\end{tabular}

There were two notable observations from the elemental concentration data. The sodium concentration in pore solution of all the mixtures made with SWS was considerably lower than the more than $5 \mathrm{~mol} / \mathrm{kg}_{\mathrm{w}}$ sodium concentration in the SWS solution. There are a number of plausible explanations for this. The very high concentration is a challenging measurement challenge; one must reproduce the background accurately. The lower than expected concentration may also be due to a greater than expected amount of sodium binding in the calcium silicate hydrate $(\mathrm{C}-\mathrm{S}-\mathrm{H})$. This is plausible because the alkali binding increases with increasing cement replacement (resulting in lower $\mathrm{Ca} / \mathrm{Si}$ molar ratios in the $\mathrm{C}-\mathrm{S}-\mathrm{H}$ ) [30], and there are few data on binding at these sodium concentrations. By contrast, the silicon concentration was consistent with thermodynamic modeling prediction of a relatively significant silicon concentration in the pore solution.

\subsubsection{Total Sulfur}

Determining the total sulfur content of the pore solution may be complicated by the two different forms in which it may be present. Sulfates are commonly available in portland cement; it is often added as gypsum during grinding. It has been known for some time that blast furnace slag contributes sulfides to the pore solution of cementitious systems. In principle, the ICP-OES method will detect both forms of sulfur. In practice, however, diluting the pore solution with nitric acid could convert some or all the sulfide to hydrogen sulfide (HS), which could be released as a gas. If this were to occur, the total quantity of sulfur detected by ICP would be less than the true value due to some of the sulfur being lost as a gas before the ICP measurement took place.

On a few of the samples taken from mixtures made using surrogate waste solution, two different dilution protocols were used. The collected pore solution was filtered and divided into two sub-samples. The first sample was diluted with nitric acid, as described above. The second sample was diluted using only water, following the practice described by Lothenbach et al. [31]. These results have been included in the data in Table 23 and Table 24 with the dilution solution shown in parentheses. From the data given in Table 23 and Table 24, there is no evidence that acid dilution removed much, if any, sulfur from the sample. 
One possible explanation for observing the same sulfur, regardless of dilution type, is that the sulfide had already oxidized prior to the pore expression, resulting in all the sulfur being present as a sulfate. This explanation, however, would be inconsistent with the samples being stored in air-tight plastic jars, the observation of a dark green interior of the paste sample (the color saturation diminished upon exposure to air), and is inconsistent with detecting hydrogen sulfide gas ("rotten eggs") when cleaning a mortar and pestle with acid after the mortar and pestle had been used to crush small saltstone waste form samples.

\subsection{Discussion}

As expected, the blended binder systems (40-1-055 and 60-1-055) contained no measureable portlandite. This is to be expected because, in the absence of a source of additional calcium, the alumina and silica in the fly ash and slag will consume the calcium in the portlandite (created by the portland cement hydration) to create additional C-S-H.

There are two important points of comparison between the ordinary portland cement paste mixtures and the blended binders with SWS. In the $0.40 \mathrm{w} / \mathrm{cm}$ ordinary portland cement paste $(40-0-100)$, the combined mass fraction of the hemicarbonate, monocarbonate, and ettringite phases is approximately $12.5 \%$ after 12 weeks of hydration. In the $0.40 \mathrm{w} / \mathrm{cm}$ pastes containing both blended binders and SWS (40-1-055), the same total was less then $2.5 \%$, and there was no ettringite detected. In the $0.60 \mathrm{w} / \mathrm{cm}$ ordinary portland paste $(60-0-100)$, the same sum was more than $17 \%$, while in the $0.60 \mathrm{w} / \mathrm{cm}$ paste containing both blended binders and SWS (60-1-055) the sum was below $2 \%$, and there was no ettringite detected. Therefore, although the SWS was contributing considerable sulfate to the mixture, the overall chemistry was suppressing the formation of sulfate-bearing phases, compared to the amount generated during the hydration of OPC pastes made with water.

The pore solution analysis bears this out. The sulfur content of the pore solution of the ordinary portland cement 40-0-100 specimen was approximately $15 \mathrm{mmol} / \mathrm{kg}_{\mathrm{w}}$, and the sulfur content of the blended binder and SWS 40-1-055 specimen pore solution was nearly $200 \mathrm{mmol} / \mathrm{kg}_{\mathrm{w}}$. This increase is consistent with having additional sulfur in the SWS and the simultaneous absence of sulfur-bearing minerals being formed during hydration. For the $0.60 \mathrm{w} / \mathrm{cm}$ specimens, the corresponding difference was more dramatic. The sulfur content of the pore solution of the ordinary portland cement 60-0-100 specimen was less than $10 \mathrm{mmol} / \mathrm{kg}_{\mathrm{w}}$, and the sulfur content of the blended binder and SWS 60-1-055 specimen pore solution reached nearly $250 \mathrm{mmol} / \mathrm{kg}_{\mathrm{w}}$. This greater difference between the ordinary portland cement system and the blended system is due largely to the greater "mix water" fraction of the $0.60 \mathrm{w} / \mathrm{cm}$ mixture designs.

After three months of hydration, the type and quantity of mineral phases appear to be stable. No unexpected phases are forming, and the quantity of existing minerals is changing gradually. Moreover, the types of mineral phases observed are also commonly found in typical blended cement systems using in construction.

\subsection{Summary}

In general, the hydrated phases and pores solution composition of saltstone grouts is similar to what one might expect for these systems. Despite the uniqueness of the binder proportions and the concentrated solution used as the mix water, the observed phases, and their proportions, were not significantly different from what is observed in an analysis of an ordinary portland cement paste made with water. 
The most notable difference between the ordinary portland cement pastes and the synthetic saltstone was the absence of ettringite, and the decreased production of hemicarbonate and monocarbonate, even after one year of hydration. The pore solution chemistry of the saltstone, which is dominated by the contribution of the SWS, appears to suppress the formation of sulfate-bearing mineral phases, despite the contribution of additional sulfate in the SWS. Moreover, although solid sodium nitrate (nitratine) was detected in both the XRD and the TGA measurements, it was determined that these observations were the result of an experimental artifact.

The sodium concentration in the pore solution was less than expected, most probably because the degree of sodium binding (into the hydration phases) has never been quantified at these very high concentrations, and for the type of C-S-H formed by these blended systems. Moreover, after one year of hydration, the mineral phases that were detected are found in blended cement concretes and these mineral phases appear to be relatively stable. 


\section{CONCLUSION}

Methods have been developed for characterizing the hydration phases and the pore solution composition of cementitious systems containing very little portland cement, large quantities of fly ash and slag, and a concentrated salt solution. The material was characterized using isothermal calorimetry, thermogravimetric analysis (TGA), quantitative X-ray powder diffraction (QXRD), image segmentation of elemental maps created by electron probe microanalysis performed on a scanning electron microscope (SEM), and aqueous phase analysis by inductively coupled plasma - optical emission spectroscopy (ICPOES). In nearly all cases, existing methodologies had to be modified or improved to work with these materials.

The hydrated phase analysis by QXRD was facilitated, to a degree, by TGA. For the mixtures having little or no fly ash or slag, TGA analysis of the portlandite content was a useful means of establishing an internal standard for the QXRD analysis. For the anticipated saltstone formulation, however, all of the portlandite is consumed by the fly ash and slag hydration, so an internal crystalline standard (corundum) is required.

A method using image segmentation was developed and shown to be a useful method of hydrated phase identification and quantification. The image segmentation process may have its greatest strength in classifying the glassy phases of these blended systems because the relevant glassy phases (fly ash, slag, and C-S-H) appear differently. By comparison, quantitative X-ray diffraction can only determine total mass fraction of glassy phases by using an internal standard and subtracting out the mass fraction of the crystalline phases. Before image segmentation can be used reliably, however, independent chemical analysis experiments are needed to validate the method.

The hydrated samples were squeezed in a press to extract the pore solution, which was then analyzed using ICP-OES to estimate the concentration of the atomic elements present. The observed sodium concentration in the pore solution was approximately one-half the sodium concentration in the salt solution, which was attributed, in part, to absorption of the sodium by the C-S-H. The total sulfur concentration in the saltstone was approximately twenty times greater than the sulfur concentration in the portland cement pastes mixed with water, and two different dilution methods were used to confirm that reduced sulfur (sulfide) was not being lost as hydrogen sulfide gas during sample preparation. The higher alkalinity in the saltstone pore solution resulted in a factor of ten lower calcium concentration in the saltstone waste. This fact was associated with a decrease in the quantity of sulfate phases being formed in the saltstone. From this, it was concluded that, as long as the saltstone pore solution remains alkaline, there is a low expectation of finding the types of sulfate phases that one associates with expansive sulfate attack.

Ultimately, these data and techniques will support the development of new tools for performance assessments of cementitious materials used in the nuclear infrastructure. These tools will need to accurately predict the mineralogy and pore solution composition for a wide range of cementitious systems, including saltstone waste forms. Because these mixtures, with their very low portland cement content and concentrated wastes solutions, are not common practice within the concrete construction industry, these data will help to develop a basis of understanding for these systems. Specifically, they will support models to accurately predict the type and quantity of hydrated phases, and the equilibrium pore solution, of blended cement systems. This information, coupled with detailed information about the environment, can then be used to predict the long-term performance of these materials. 


\section{REFERENCES}

1. Bradford, A., Esh, D., Ridge, A, Thaggard, M., Whited, R., Treby, S., Flanders, S. and Camper, L.W., "U.S. Nuclear Regulatory Commission Technical Evaluation Report for the U.S. Department of Energy Savannah River Site Draft Section 3116 Waste Determination for Salt Waste Disposal," Technical Report (U.S. Nuclear Regulatory Commission, Washington, D.C., 2005).

2 ASTM C 1679 "Standard Practice for Measuring Hydration Kinetics of Hydraulic Cementitious Mixtures Using Isothermal Calorimetry," Annual Book of ASTM Standards, Vol. 04.02, ASTM International, West Conshohocken, PA (2010).

3. M. Abramowitz and I.A. Stegun, Handbook of Mathematical Functions, Dover Publications, Inc., New York (1972).

4. ASTM C 1365 "Standard Test Method for Determination of the Proportion of Phases in Portland Cement and Portland Cement Clinker Using X-Ray Powder Diffraction Analysis," Annual Book of ASTM Standards, Vol. 04.01, ASTM International, West Conshohocken, PA (2010).

5. H.P. Klug and L.E. Alexander, X-Ray Diffraction Procedures, Wiley-Interscience, New York, 966 pp. (1974)

6. Certificate of Analysis, Standard Reference Material® 674b, X-Ray Powder Diffraction Intensity Set for Quantitative Analysis by X-Ray Powder Diffraction, National Institute of Standards and Technology (2007).

7. Certificate of Analysis, Standard Reference Material ${ }^{\circledR ~ 676, ~ A l u m i n a ~ I n t e r n a l ~ S t a n d a r d ~ f o r ~}$ Quantitative Analysis by X-Ray Powder Diffraction, National Institute of Standards and Technology (2005).

8. P. Stutzman, "Multispectral Imaging of Cementitious Materials", in Proceedings of the $29^{\text {th }}$ International Cement Microscopy Association Conference, pp. 20-24, Quebec City, Canada (2007).

9. P. Stutzman, “Scanning Electron Microscopy Imaging of Hydraulic Cement Microstructure." Cement and Concrete Composites, 26 (8), 957-966 (2004)

10. D.P. Bentz and P.E. Stutzman, "SEM Analysis and Computer Modeling of Hydration of Portland Cement Particles," in Dehayes, S.M., Stark D., Eds., Petrography of Cementitious Materials, ASTM STP 1215, pp. 60-73, ASTM International, West Conshohocken, PA (1994).

11. J.I. Goldstein, D.E. Newbury, P. Echlin, A.D. Romig, Jr., C.E. Lyman, C. Fiori, and E. Lifshin, Scanning Electron Microscopy and X-Ray Microanalysis, second edition, Plenum Press, New York (1981).

12. http://rsbweb.nih.gov/ij/

13. https://engineering.purdue.edu/ biehl/MultiSpec

14 R.S. Barneyback Jr. and S. Diamond, "Expression and analysis of pore fluid from hardened cement paste and mortars," Cement and Concrete Research, 11, 279-285 (1981).

15 B. Lothenbach and F. Winnefeld, "Thermodynamic modelling of the hydration of portland cement," Cement and Concrete Research, 36(2), 209-226 (2006).

16. T. Wagner, D.A. Kulik, F.F. Hingerl, S.V. Dmytriev, “GEM-Selektor geochemical modeling package: TSolMod library and data interface for multicomponent phase models," Canadian Mineralogist, 50(5), 1173-1195 (2012). 
17. B. Lothenbach, B, G. Le Saout, E. Gallucci, and K. Scrivener, "Influence of limestone on the hydration of Portland cements," Cement and Concrete Research, 38, 848-860 (2008).

18 Stutzman, P. and Leigh, S., "Phase Composition Analysis of the NIST Reference Clinkers by Optical Microscopy and X-ray Powder Diffraction," NIST Technical Note 1441, National Institute of Standards and Technology, Gaithersburg, MD (2002).

19. http://rruff.geo.arizona.edu/AMS/amcsd.php \& http://database.iem.ac.ru/mincryst/

20. H.F.W. Taylor, Cement Chemistry, Academic Press, New York (1990).

21. A. Le Bail, 'Modelling the silica glass structure by the Rietveld method,' J. Non-Cryst. Solids $\mathbf{1 8 3 ,}$ 39-42 (1995).

22. http://ciks.cbt.nist.gov/4sight

23. L.J. Parrott and D.C. Killoh, "Prediction of cement hydration," Br. Ceram. Proc., 35, 41-53,(1984).

24. K. Dixon, J. Harbour, and M. Phifer, "Hydraulic and Physical Properties of Saltstone Grouts and Vault Concretes," SRNL-STI-2008-00421, Savannah River National Laboratory (November 2008).

25. http://www.cementbarriers.org

26. J.W. Bullard, P.E. Stutzman, K.A. Snyder, E.J. Garboczi, "Task 7: THAMES Demonstration (NIST)" CBP-TR-2010-00007-C2, Rev. 00, DOE, Savannah River National Laboratory, Aiken, SC (2010).

27. J.R. Harbour, E.K. Hansen, T.B. Edwards, V.J. Williams, R.E. Eibling, D.R. Best, and D.M. Missimer, "Characterization of Slag, Fly Ash and Portland Cement for Saltstone," WSRC-TR-200600067, Savannah River National Laboratory, Aiken, SC (February 2006).

28. B.D. Bond and P.W.M. Jacobs, J. Chem. Soc. A, 1265-1268 (1966).

29. G.L. Paul and A.W. Pryor, Acta Cryst. Section B, 28, 2700-2702 (1972).

30. S.-Y. Hong and F.P. Glasser, "Alkali binding in cement pastes: Part I. The C-S-H phase," Cement and Concrete Research, 29, 1893-1903 (1999).

31. B. Lothenbach, G. LeSaout, M. Ben Haha, R. Figi, and E. Wieland, "Hydration of low-alkali CEM III/B-SiO2 cement (LAC)," Cement and Concrete Research, 42 (2), 410-423 (2012). 